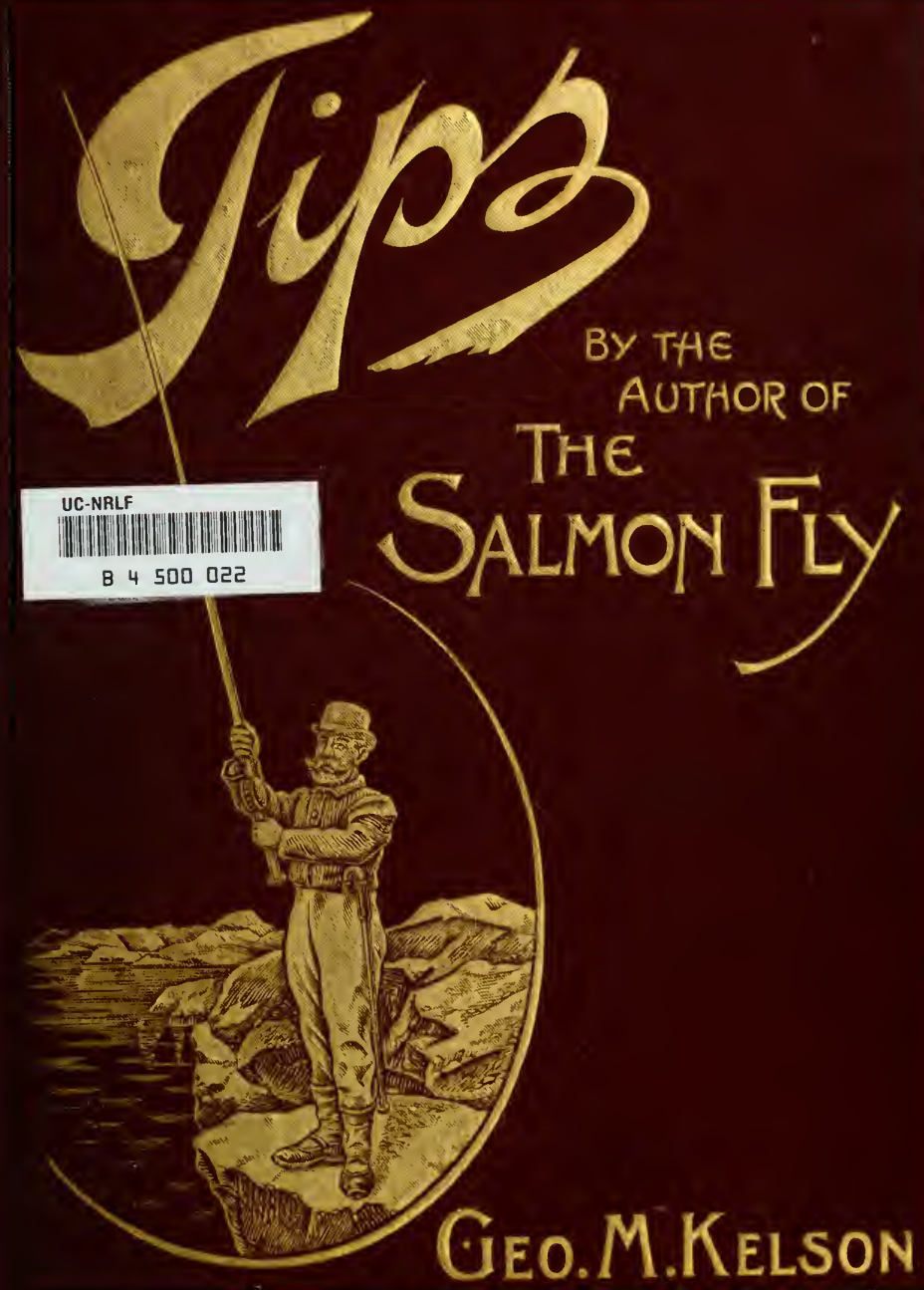




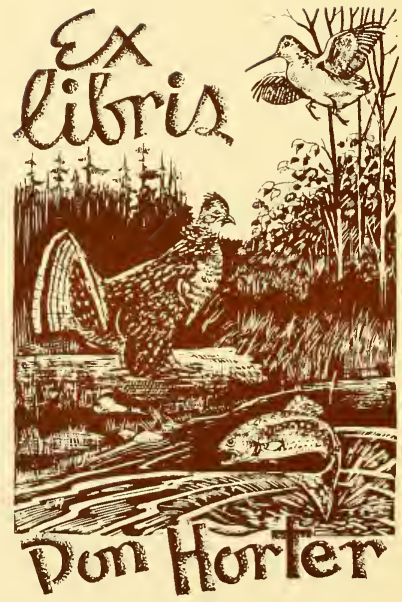




TIPS. 



\section{T I P S}

BY THE AUTHOR OF

"THE SALMON FLY,"

Geo. M. Kelson.

Ôcritas Emincalt (5loriam.

I.ONDON

PUblishen by tHe Author,

25. Victoria Street, Westminstfr,

ANd c/o The Dangerfieln Printing Company. I imited,

23. Henfokd Streft, Strand, w C

All $\frac{\overline{R \text { ghts Recrued. }}}{\text { Iyot }}$ 
THE

Dangfreteid Printino Co, Lto.

Printers,

293, BEDFord Strent, Strand,

L.ONDON. 


\section{Contents.}

CHAPTER

1. TIIE ROD TO SELECT - - 1

II. TIIE FLY TO USI: - - _ II

II. MFTIOOS OF CASIING: - -

IV. RIVERSIDE: IIINTS - $\quad$ - $\quad 79$

V. WADING

VI. KNOTS - $\quad$ - $\quad$ - $\quad 126$

VII. MOMERN IMPROVEMEXTS - -

WHAT THE PAIERS SAY ABOUT

"TIHE SAI,MON FII:" 162 



\section{Index.}

A Hint to Gillies

PAC:

81

Angling, why the unenlightened succeed 12

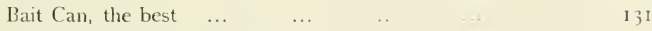

Casting a long line, advantages of ... 8

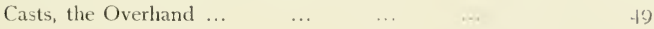

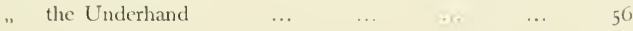

$\begin{array}{llllllll} & \text { " the Spey } & \ldots & \ldots & \ldots & \ldots & \ldots & \end{array}$

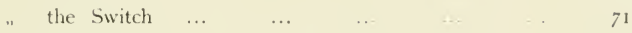

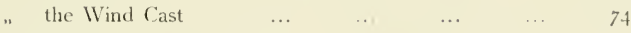

Cause and Effect, the Study of $\quad \ldots \quad \ldots . \quad \ldots \quad 30$

Comparison between two methods in the Overhand 50

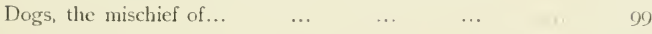

Downward Curve in the top of a rod ... .. 6 I

$\begin{array}{llllll}\text { Etiquette at the riverside } & \ldots & \ldots & \ldots & . . & 8\end{array}$

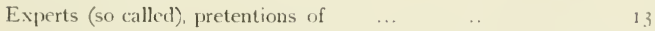

External objects, effect on the fish $\quad \ldots \quad \ldots . \quad \ldots \quad$ in

Extra standard flies described ... ... . . . 10 
INDEX.

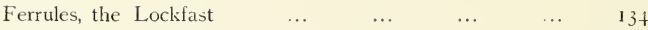

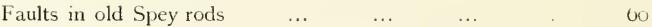

Flies, checking and hastening their transit $\quad . . . \quad S_{4}$

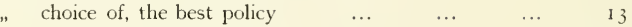

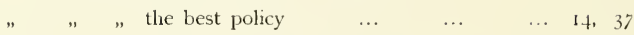

$\begin{array}{llllll} & \text { " } \quad \text { effect of natural surroundings } & \ldots & \ldots & 27\end{array}$

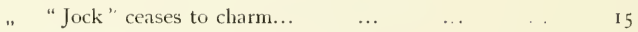

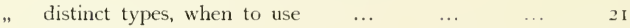

" the gut loop of $\quad \ldots \quad$...

$\begin{array}{llllll}\text { ". example of special patterns } & \ldots & \ldots & \ldots & 95\end{array}$

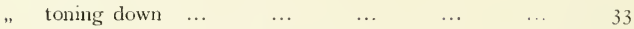

" selection and principles to pursue... $\quad . . \quad 34,37,38$

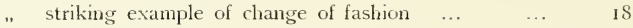

" natural, advantage of, imitation ... $\quad \ldots \quad 35,43,41$

$\begin{array}{llllllll}\text { " } & \text { working a slack } & \ldots & \ldots & \ldots & \ldots & 95\end{array}$

$\begin{array}{llllllll} & \text { Redpath's } & \ldots & \ldots & \ldots & \ldots & \ldots & 155\end{array}$

$\begin{array}{lllllll}\text { Fly box, aluminium } \ldots & \ldots & \ldots & \ldots & \ldots & \ldots & \text { ItH }\end{array}$

$\begin{array}{llllllll}\text { Garments } & \ldots & \ldots & \ldots & \ldots & \ldots & \ldots & 152\end{array}$

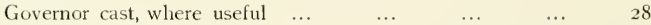

$\begin{array}{lllllll}\text { Gut casts, the best } & \ldots & \ldots & \ldots & \ldots & \ldots & 149\end{array}$

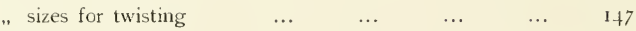

Harling, method of $\begin{array}{lllllll} & \ldots & \ldots & \ldots & \ldots & \ldots & 2\end{array}$

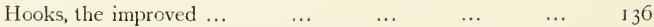

How to succeed in waler over-thrashed $\ldots \quad \ldots \quad \ldots \quad \ldots \quad \ldots 87,88$

How to manage fish hooked in the back or body 101, 102, 104, 105

India-rubber boots, how to dry $\quad \ldots \quad \ldots \quad \ldots \quad \ldots 113$

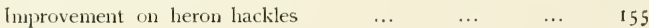


INDEX.

"Kelson" rods and lines

Knotting eyed hooks

Knotting gut

Leaping hsh, management of ...

Lines for different sized rods...

" the best dressing

Logan-stones, definition of

Mending a cast

Miss R _ 's practice on the Dee ... 16

Moonshine, effect of ...

New Century, first day

Observation, advantages of $\quad \ldots \quad \ldots . \quad \ldots 5$

Origin of "Spey" Improved Rod $\quad$... $\quad$... $\quad 59$

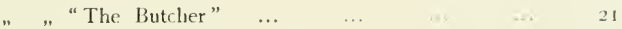

Picture of fine pool and how to proceed ... $\quad 8$ I

Reasons for underhand casting $\quad \ldots \quad \ldots y$

Result of Author's system of angling compared with those $\begin{array}{llllll}\text { of other anglers } & \ldots & \ldots & \ldots & \end{array}$

$\begin{array}{lllllllll}\text { Rods, cane } & \ldots & \ldots & \ldots & \ldots & \ldots & \ldots & 133\end{array}$

" composite, why wrong ... ... .. 5

" old style, and why given up $\quad \ldots \quad \ldots \quad \ldots \quad 1,4$

" manipulation of, in briglit weather and where _. $\quad \$ 6$

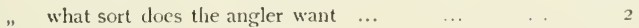

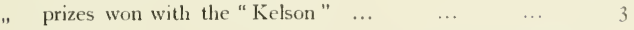

$\begin{array}{llllllll}\text { " length of } & \ldots & \ldots & \ldots & \ldots & \ldots & \end{array}$

" selection $\begin{array}{llllllll} & \text {, } & \ldots & \ldots & \ldots & \ldots & \ldots & 5\end{array}$

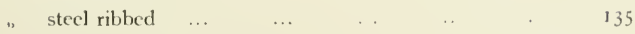


Salmon, when they invariably rise

$\begin{array}{llllllll} & \text { education of } & \text {. } & \ldots & \ldots & \ldots & \ldots & 36\end{array}$

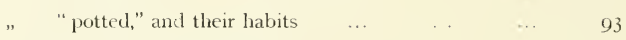

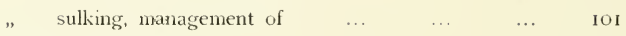

$\begin{array}{lllllll}\text { Splicing tape, perfected } & \ldots & \ldots & \ldots & \ldots & 157\end{array}$

$\begin{array}{lllllll}\text { Standard lines and traces } & \ldots & \ldots & \ldots & \ldots & 148\end{array}$

$\begin{array}{llllllll}\text { Stopping a runaway fish } & \ldots & \ldots & \ldots & \ldots & 98\end{array}$

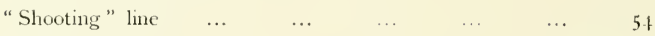

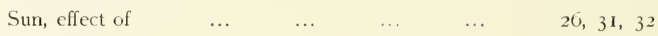

System of fishing, what happens in conversation ... $\quad \ldots \quad 20$

The highest privilege of the professed exponent of the art... So

$\begin{array}{llllllll}\text { Thermometer, rise and fall } & \ldots & \ldots & \ldots & \ldots & 38\end{array}$

$\begin{array}{lllllll}\text { Tinsels, untarnishable } & \ldots & \ldots & \ldots & \ldots & 156\end{array}$

$\begin{array}{llllll}\text { Tying up fish, new method } & \ldots & \ldots & \ldots & \ldots & 154\end{array}$

$\begin{array}{lllllll}\text { Two ways of Spey casting } & \ldots & \ldots & \ldots & \ldots & 66\end{array}$

$\begin{array}{llllll}\text { Unknown lay-byes, how to detect } & \ldots & \ldots & \ldots & 8_{\text {I }}\end{array}$

$\begin{array}{lllllll}\text { Usk, basket } & \ldots & \ldots & \ldots & \ldots & \ldots & 153\end{array}$

$\begin{array}{lllllll}\text { " river, new patterns for } & \ldots & \ldots & \ldots & \ldots & 17\end{array}$

$\begin{array}{llllllll}\text { Varnish for fly heads } & \ldots & \ldots & \ldots & \ldots & 156\end{array}$

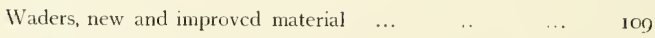

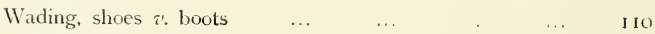

$\begin{array}{lllllll}\text { White wax, for silk hodies } & \ldots & \ldots & \ldots & \ldots & \text { I } 39\end{array}$

$\begin{array}{lllllllll}\text { Winches } & \ldots & \ldots & \ldots & \ldots & \ldots & \ldots & 130\end{array}$ 


\section{Illustrations.}

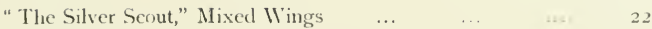

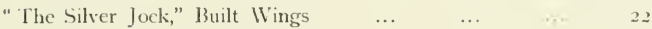

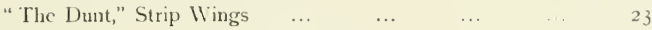

"Variegated Sun Fly," Topping Wings... … ... 23

"Black Ranger," Whole Feather Wings _.. $\quad$... 2 t

$\begin{array}{llllllll}\text { The Overhand Cast } & \ldots & \ldots & \ldots & \ldots & \ldots & \ldots & 53\end{array}$

$\begin{array}{llllllll}\text { "Shooting" Line } & \ldots & \ldots & \ldots & \ldots & \ldots & 55\end{array}$

$\begin{array}{lllllll}\text { The Underhand Cast } & \ldots & \ldots & \ldots & \ldots & 57\end{array}$

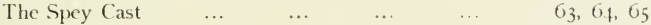

$\begin{array}{llllllll}\text { The Switch Cast } & \ldots & \ldots & \ldots & \ldots & \ldots & 72,73\end{array}$

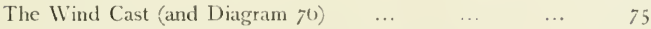

Costumes adapted to Wlading and Bank J ishing ... ... $11+$

The Double Cylinder Air Pump $\quad \ldots \quad \ldots \quad \ldots \quad \ldots \quad$ II

$\begin{array}{lllllll}\text { Knotting Gut Casts } \ldots & \ldots & \ldots & \ldots & \ldots & 127\end{array}$

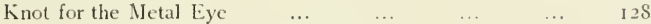

Knot for the Gut Loop (Diagrams I and 2) $\quad \ldots \quad \ldots \quad \ldots \quad 129$

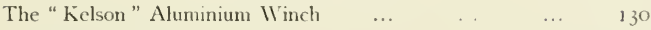

Field's Aerating Bait Can $\quad \ldots \quad$...

$\begin{array}{llllll}\text { The "Kelson" Hools } & \ldots & \ldots & \ldots & \ldots & 137\end{array}$

$\begin{array}{llllll}\text { Farlow's Aluminium Fly } \mathrm{B} \cap \mathrm{x} & \ldots & \ldots & \ldots & \ldots & \mathrm{I}+5\end{array}$

$\begin{array}{lllllll}\text { Usk Basket } & \ldots & \ldots & \ldots & \ldots & \ldots & 153\end{array}$

$\begin{array}{lllllll}\text { Fish Ticd for Carrying } & \ldots & \ldots & \ldots & \ldots & 15+\end{array}$ 



\section{PREFACE.}

THE object of this book is to present the writer's system of Salmon Fishing to those interested in the sport, at such a price as will bring it within the reach of all.

In order to secure this object it has been found necessary to compile the book in its present form.

As the Press, including "The Encyclopxdia of Spert," has done me the honour to accredit my former book, "The Salmon Fly," with being the stanclard work on the subject, I should be wanting in my simplest duty had not care been taken to bring the information in this volume thoroughly up-to-date. Perhaps few, if any, fishermen, have had larger opportunities than have fallen to my lot for studying everything connected with the numerous problems that bear reference to the art of catching the king of fish with a fly. Under these circumstances it is not likely that I should have relinquished my cfforts to know all that is worth publishing and publish all that is worth knowing of the latest schemes and devices incidental to this branch of the sport. I yield to an irresistible mpression inspired by former confidence reposed in me, that this work would be incomplete and not sufficiently instructive had I withheld a number of improvements and inventions, accompanicd with names and addresses, which I persuade myself will be most acceptable to the angling reader.

$$
\text { G. M. K. }
$$




\section{BURBERRYS,}

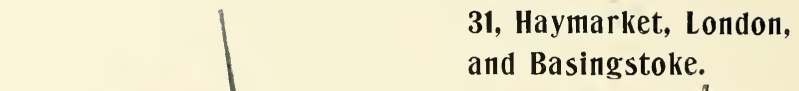




\section{CIIAPTER I.}

\section{THE ROD TO SELECT.}

" $\Lambda$ good deal depends on good 'play."

"Does it! My partner with nine trumps last night taught me, that 'good play' depends on a 'good deal.' "

"Ol, bother! We are discussing salmon rods, not whist."

At this moment the Gillie, in his usmal picturesque Highland garb, entered the room for orders. Following up the subject, we addressed the old Caledonian of many years' service: "Just take that rod there, put it together and tell us what you think of it."

We had already given our opinion - not a particularly favourable one either, for judging by the huge appearance of the butt and the lean, whippy top, it might have been a replica of a rod used by onc of our be-wigged and powdered ancestors, who, from the exalted position of their gilded frames in our hall, gaze down so gravely upon us. 
In due course the worthy Scot returned looking more than usually serious, and observed: “It's a' vera weel, but it fechles me just a wee bittic. If ye'r wull be wanting to reech 'em, an' hook 'em, an' get 'em aboot here mon, ye'r maun ha' a deil off the hinder end an' be pooting it fornenst."

This little Highland incident is recorded to illustrate that not only were old-fashioned rods over-burdened with wood in the wrong place, but also that, if properly remodelled, they are more reliable than those turned out at the present time. Nor is this difficult to realise when we remember that rods are now made of wood taken from the interior of more or less dense forests, whereas they used to be made from trees growing on the outskirts, the trunks of which had been exposed for years to the fine seasoning properties of air and sun.

Considered from the standpoint of economy, and this is an appropriate platform from which to ventilate our views on purchasing a rod, the angler must decide for himself whether he wants a rod for some particular mode of casting, or for salmon fishing generally. If, for instance, he wants it solely for the Spey, he is referred to our remarks on the Ifighland cast in Chapter III. ; for the Dee method of casting, he goes to Garden of Aberdeen, or Blacklaws of Kincardine O'Neil; and if he is bent on visiting the Tay, where preference is given to the poor business of harling, the inference must be that he should select a rod with plenty of "play" in the butt, so that, provided the top joint is not too slight, he is enabled to hasten matters in bringing a fish to the gaff.

In this connection it is desirable to mention that an ordinary Spey rod is fit for little more than Spey casting. Also, that in liarling the line is not cast but paid out from a boat rowed by two men; the 
rod is not even hekd, but rests in a groove at the stern, while the angler simply sits and watches and wishes and waits for a fish to seize the fly crossing the river as it works to and fro up stream. For this so-ealled engaging business, perhaps no rod equals a Castlecourill, which is specially constructed to hold fish from those awkward rocks that abound in the Shannon waters.

But for high-class fishing the rod really must be built on different lines. Sonetimes, for instance, we are called upon to adopt the Overhand cast, sonetimes the Wind or the Spey; at other times the Switch, and so on. Of the superiority of the rod fit for this work, there ran be no doubt ; for not only can the practised hand command with case all known Catches, but intervening spots, which he sees at a glance may hold a fish, are never leit " maiden," provided there is room to work the rod.

In further reference to this style of rod, some years ago, at one of the angilng tournaments, the present writer happened to win the first prize for the longest cast in six different competitions; but what is the more important to purchasers, he succeeded in carrying off the Cup offered by Mr. Nicholay "for the best cast of over forty yards made with the wind and then against it."

The "Kelson Rod"-for it is known only by that name-has been beautifully made in greenheart, by Farlow, for over thirty years. Go where one may, one constantly sees it in use, and hears it applauded to the echo. Hardy, as usual, makes the pattern in built cane and delights numerous customers.

An episode relating to my tackle in its complete form, though woven with extravagant fancies, is perhaps worthy of note.

A "typical creany English girl," engaged on a difficult fishery 
belonging to a grand old sportsman named Gould, modestly requested to try the tackle, and the chief point is, that with it this lady quickly achieved a brilliant success. But if the whole truth is to be told, when fish after fish had been placed in a hut prettily situated, the following doggerel concerning the proprietor, scrawled inside, met the eye :

"So you see, my dear Sir, though eighty years old,

A girl of nineteen falls in love with old Gould."

While some passing sceptic aired his views in this way:

"A girl of nineteen may love Gould, it is true,

But believe me, dear Sir, it is Gold without U."

Permission is given to add, that the fair devotee of our art is, perhaps, the only feminine expert living who can demonstrate nearly all the methods of casting a salmon fly.

Now, why is it we never come across our old-time acquaintance, the "trouty" salmon rod? It is for two very simple reasons. The first, because it will not carry the line we should now use ; the second, because distant fish cannot be covered unless the comparatively light line suited to it is taken out by the wind in the right direction.

These rods were generally made of hickory, most of them measured 20-ft. in length-some even more. But latter-day experience decides that $a \mathrm{I} 7-f t$. properly balanced rod of greenheart, or cane if not deprived of its action by the addition of any foreign substance, is sufficient for all practical purposes.

The marked and gladdening reduction made of late in the length is entirely due to vast improvements in lines and dressings.

It might here be mentioned that notwithstanding the advantages of cane over greenheart, wherein the economy of physical energy 
predominates in overhand casting, purchasers of a greenheart can use it at once, whereas a cane rod ought to remain several months in a nice even temperature before a single cast is made with it. By this treatment the cemented joints get hard and fit for every sort of emergency. Without it the particular strain of some individual cast causes weakness, making itself visible by a contortion of the upper joint.

A No. 3 line is best suited to either rod. But in summer, or at any time when the water runs low, it is advisable to use lighter tackle altogether. $\Lambda_{16-\mathrm{ft}}$, rod and a No. 4 line, or in fair weather even a No. 5 , is sufficient for almost every case, the exception being at times when the fish run large, and snow water, which is very lieavy and often prohibitive of deep wading, continues to flow.

In choosing a rod there is one point which seems to be of very considerable importance. Shall we select a composite rod that is, one constructed of different materials; or a homogeneous rod that is, one constructed of the same material throughout?

Upon this point my opinion is distinctly in favour of the latter. The first reason to be assigned for this preference, is one beyond which fishermen in general will not seek to go: viz., that as a matter of constant experiment under various conditions of weather, the composite rod has never been found to answer anything like as well as the other. In casting a short line overhead, the average angler finds but little difference between the two styles; but when it comes to covering distant fish, so certainly does the rod begin to labour and become inanimate, that any doubt lurking in the mind of the older hand is instantly dispelled.

To examine the matter from a theoretical point of vicw, let us 
consider the arguments for and against the composite rod.

One form of it is constructed of two different kinds of wood. For instance, a rod made partly of ash and partly of lance is still used on the Spey. Surely it may be taken as an axiom that no two kinds of wood are similar in grain, or would behave in the same way as far as pliability or weather-resisting qualities are concerned. The closer the grain, the less chance of injury from wet weather. Ash is an open grained wood; lance, on the contrary, is close grained. The rod that approaches perfection for general fishing is such a delicately balanced whole, and does its work so evenly and regularly, that to have one part working with a spring initially different, or liable to sudden changes differing from those which take place in other parts, cannot be advantageous.

As to this class of Spey rod it appears that, even for Spey casting, any possible advantage gained by the top of lance wood is utterly lost in the thrash-down, because of the inflexibility of the ash butt, which too slowly responds to the action of the more lively lance. The fact is that unless the wave of force set up by the quicker action of the top joint is maintained down to the winch fittings, the line in ordinary hands refuses to go beyond a limited distance.

Another, and curiously enough, a fashionable form of composite rod, is that composed of cane with a steel centre. Now, the steel centre is hardly thicker than a good-sized pin, and in one style of cane rod continues all the way down the three separate joints. When one tried to realise the purpose of this steel core at the dinner table the other day, he said it called to mind the irate father shouting in Les Fourberies de Scapin, "Qne diable allait-il faire dans cette galère."

"Oh! Oh!" (exclaimed another). 
"Well, if you object, slightly paraphrase it and say, "What the devil it's doing here '-Goodness only knows."

$\Lambda t$ all events, it cannot be doing the impossible.

In a gymnasium one can casily understand the bar (on which the gymnast circles) being furnished, as it often is, with a steel core, possibly one-third of an inch in diameter, but there is no comparison in this. The bar has to stand infinitcly rougher work; it has to sustain great weight and very severe strain, and hardly bends either way more than an inch or so out of its normal position. Strength, then, is the object sought for and undoubtedly attained by this mode of arrangement.

But is this the end sought for in a rod? How can its supporters maintain such a contention? They assert that the flexibility or liveliness, as well as the strength of the rod, is thereby increased. We should like to ask them to explain in what way the bending of the outer case is affected by the infinitely greater flexibility of the inner corc. In casting, of course, the strain affects the bend of the cane ; but the strain is primarily upon the outer surface, and subsegucntly upon the inner particles only so far as they are part and parcel of the whole. By no manner of means can a man make the stect-centrcd rod bend sufficiently for the wire to lend the least possible aid.

The core in the gymnastic bar resists the bend, but increases the spring, and this is eminently satisfactory for the purpose to which the bar is put.

But how can one imagine that this thin piece of wire, six fect in length, ran assist in the action of the cane? Supposing it were fixed at each end of a joint, the action of the cane would be considerably curtailed; and if not fixed, it would have free play inside the rane, in 
TIPS.

which case all comment would be superfluous, nay ridiculous.

Whether the injurious influence of the steel core in a small rod can be detected while making a moderate cast, is a question upon which expert opinion is uncertain. The subject is, however, of such far-reaching importance, that all those who want to realise the mischievous effect of a steel centre should consider this : Bend a cane rod and it will fly back, while a length of this wire would unquestionably fall the other way. Should not this fact of itself go far to help all who are in doubt? In short, no better proof of the deadening qualities of this core could be given than the fact that a much longer line can be cast with the full-sized rods in the absence of it.

No body of responsible manufacturers, whose services are of any value, will be likely to contest these statements. And yet in spite of their discriminating judgment, they are compelled to supply customers upon demand with this undesirable and messy mixture.

With reference to the remark on making a long cast, whatever arguments may be held for and against the practice, there is but one solution. A man who can cast forty yards can fish thirty-six. Therefore, another getting out only thirty yards loses ten yards of water-and his sovercign, if he backs himself to kill as many salmon as his companion.

No, there are places, many places, where a long line is most essential; and no greater mistake is made than to fancy that the fly under control thirty-five yards away misses more fish than the one roving within twenty yards of the rod. What we lave a low opinion of is the practice of using more line than is really required. The angler should not attempt to use a longer line or a longer rod than he can master, since it is prejudicial to the interests of others as well 
as to his own.

There is a certain section of anglers who openly contend that, not only is one rod as good as another, but that one man is no better than another in using it. Were this so, nothing but the element of luck lies at the root of that superior success frequently manifested at times when the fish are in a sulky mood and rest in a lifeless manner. How thoroughly mistaken are these innocent people! How absolutely useless the keen competition for supremacy in the trade to turn out the sort of rod wanted for this or that cast, in order that every Catch under the sun may not be passed over by us!

However, it is to be hoped that the few hints thrown out may bc of service to intending purchasers, who for their own sake sloould bear in mind, that all the known methods of propelling the line can be accomplished with the so-called "Kelson" rod, which, though sufficiently powerful to catch the heaviest salmon, is not unduly hard upon the tender mouth of a grilse. 


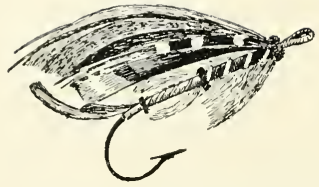

\section{BURBERRYS, \\ 31, Haymarket, London, and Basingstoke.}

WEATHERPROOFS FOR SPORTSMEN.

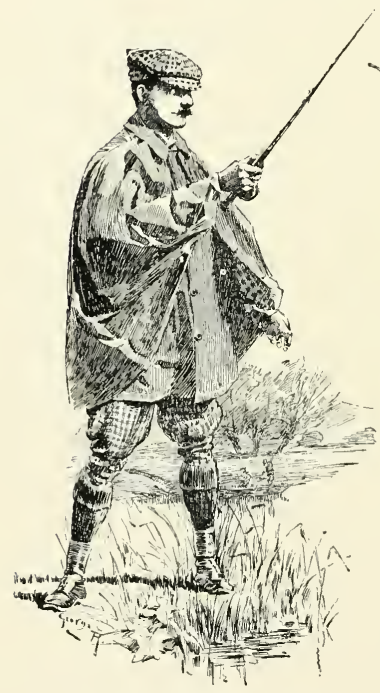

THE BURBERRY CAPE

1s fitted with a double front, providing warmtl when the wings are thrown back to allow freedom of arm for fishing. The wings can be formed (by buttoning at the wrist) into sleeves.

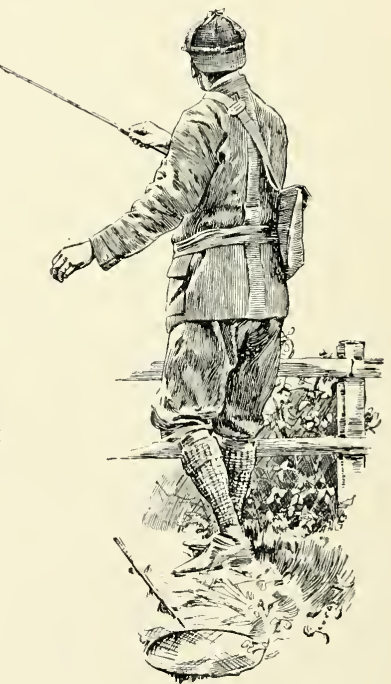

THE BURBERRY SUIT.

See page 152.

PROOF without HE.IT, it turns rain in a marvellous way, while the ventilation is natural.

WARM without $I I E I G H I$, and in textures suitable for all temperatures. 
CHAPTER HI.

\section{THE FLY TO USE.}

It is an impressive aphorism that, "to err is human"; but while the fly problem, that once scemed inserutable, is being satusfactorily solved by the light of modern experience, should we accept these words of warning with lamb-like serenity and indifference, or endeavour to minimise by constant effort the necessary amount of human error? . . . Another proposition to be laid down is suggested by a letter from a source which generally provides an object lesson to beginners. In descanting upon the gencral practice of fishing, an accomplished writer asks: "Are there not many upon whom the belief has been forced, that if one thing more than anther is responsible for the constant errors we commit of our own free will and accord, it is the ensnaring meshes of tradition?"

If called in to express an opinion, the fishcrman who writes these pages would not hesitate to announce, that tradition is a 
veritable prodigy of vital force well nigh impossible to evade : that it is the power of powers, and has irresistible charms for us : that we all bow down to it; and what is much more significant to the purpose, that we are all made fools by it.

It will be seen directly how far this view can be supported. Ingenious explanations have been advanced. Somebody suggests that fishermen are conservative by nature, but is this solution very satisfactory? In certain instances, perhaps, we are notoriously indisposed to raise our art above subservience to ancestral custom. If, for example, we take the haphazard policy of picking the first fly that comes- a policy that has been pursued by too many from generation to generation--we encounter one of the most formidable obstacles that lie in wait for all. This wretched practice, without a vestige of doubt, has formed a fearful barrier to all progress, and made it impossible for one to attempt much more than can be achieved by a novice with the crudest ideas.

In recent conversation with friends and acquaintances touching on the question of flies, an old "Rod"-than whom one could scarcely ask for a better authority-having previously scanned a few notes set aside for this chapter, quaintly described salmon fishermen as "a patient and over-credulous race, singularly disposed to fall into such errors as tradition entails upon its votaries."

"Let us have a clear understanding about that," exclaimed a listener; "give us one or two examples, will you?"

"With pleasure, for the statement can easily be verified. A man succeeds in catching salmon, not in pursuit of some scientific method, but because he happens to light by accident upon the sort of fly that suits the conditions which prevail at the time he uses it. . . " 
"Is that so?"

"Yes. Next day a score of men rush at the pattern which he favoured, regardless of the fact that conditions are altogether changed. Again, a man takes one fly in preference to another, solely on account of its superiority in point of beauty. The fly attracts the notice of, and becomes a 'pet' with, a large class of men who laud it to the slies and speak of it with delirions delight. The result is, that the unintelligent student regards the little pet, decorated in her Sunday hest, as a kind of fetish which he may bring out at all times when other flies fail. ... What do you think now of the tyramny of tradition?"

"We are much indebted to you, but ean you think of a worse. ...?"

"I anticipate your question. The worst policy to pursuc, at least I think so, is that which-on the analogy of IVordsworth's undiscerning clown, to whom ' a primrose on the river's brim a yellow primrose was to him and nothing more' lightly assumes that a fly is a fly, and that one pattern is as gocol as another on all occasions. Are you aware that the majority of angling students pretend to know all there is to know of the business in a week? We have evidence of this every day, if only by their unsolicited attentions. IVith an air of the most rasping pedantry they will criticise the fly but stop, we must not clwell on the dismal side of the picture suffice it to say that, after getting a fish or two, the youth of this country listens with eagerness to all he's told at the riverside, and thenthough the fact is hardly worth the dignity of argument thinks himself qualified to lay down the law in some inferior company as well as in the Press." 
"But where should we be without the Press?"

"In a worse plight still. . . . The 'Field' published a capital article a few weeks ago. The contributor remarked that 'in districts thrashed continuously by a large number of rods, the fish got absolutely sick of the same old flies played over them from morning till night. ... The pattern of fly to attract salmon when they have settled down in the recognised Catches, especially when the omnium gatherum are taking their turn at them, must be one with some original freshness in it. .... For you to say, 'the fish take kindly to the old designs on reaching the upper waters ' is all very well and very true. But if we direct our attention to the facts presented to us, we shall first see that the flies used at the top of rivers are only half the size, and mind you, size is a very important factor. Then again, are not the fish invigorated by the rise and freshness of the water which encouraged them to go ahead? "

These recollections must suffer from unavoidable abbreviations. However, just at that moment, while excitement seemed growing to a high pitch, we were pleasantly interrupted by the ladies, of whom one specially interested in the conversation made her presence felt.

After awhile the old "Rod," possessing a well-stored memory, cited a remark made no less than two thousand years ago. "A great orator (said he, cheeringly) declares that 'time obliterates the fictions of opinions and confirms the decisions of nature,' and yet (looking round with a smile) the sentiment of John Keats, in his immortal line, 'a thing of beauty is a joy for ever' is, when applied to the choice of a fly for its beauty alone, about to be repudiated by a large section of the angling fraternity. Change, not permanence, is what we require."

"The only change I want (it was the lady now speaking), is a 

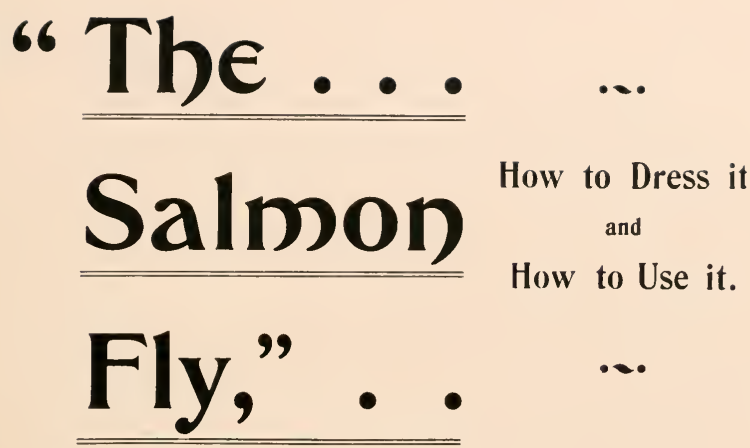

BY

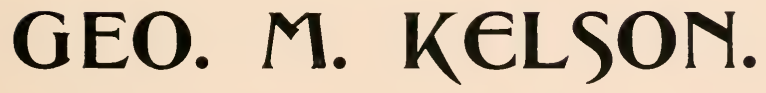

(See Press Opinions, p. 162).

To be had at . .

Farlow's, 191, Strand, and direct from the Author, 25, Victoria Street, Westminster.

ONLY A FEW COPIES LEFT. 
change of instruction. I want a gillie with a better power of imparting knowledge than mine, one who can make me do the Spey cast. (The old 'Rod' began to eat his moustache). It's so horrid to try, try, try, in presence of a lot of. . . ."

"Ten thousand pardons (interposed the old gentleman), but it would be so sweet of you to let us thresh out the present subject first. Do you mind? I'm sorry you dropped in so late, or you might have got a wrinkle or two; I _ 1 mean a hint or two on using flies dressed absolutely up to date."

"What! I give up dear old 'Jock'? Oh! Inconceivable! Think of the sacrifice. Remember it has taken eleven fish out of my fifteen; and didn't you say that 'Jock's' particular combination of colours made clear the fact that originality of design and independence of thought were the inventor's end in view? But still, I won't interrupt you for all the world. Pray continue. Tra, la, la; it sha'n't occur again."

(Fifteen fish, it might have been fifty, or even more.)

"That's all very nice, but since then we have made wonderful discoveries. We have discovered, for instance, that the methods of the fly-fisher are no longer irrational, and amongst other things, that the life of a fashionable fly is now of limited duration. Fashions change in every walk of life, and those of our kindred who refuse to make an effort to keep pace with the changes, are sure to taste the full bitterness of defeat. Delays are dangerous. And why should you, of all others, associate yourself with men who are sure to find it too late to-morrow because they regard to-day as ton soon !"

"Tell me why 'Jock Scott' has ceased to charm the fish?"

"Because it has exhausted their 'patience' by constantly 
being brought into operation. Like yourself, people tinctured with enthusiasm won't use anything else. Thousands sustain the frenzy of such enthusiasm - a trenzy that animated their fathers and mothers -but that only shows the influence exerted by all who acknowledge the authority of tradition. . . . ."

"Then I pity the man who vows that 'enthusiasm' is the genius of sincerity, and truth accomplishes no victories without it.' You are, nevertheless, a capital teacher, interesting because always interested. .... I wish you would tell me where the change you speak of is most needed?"

"Where? Everywhere, especially on hard fished waters. . . . Take the case of Miss R_, consider that. I knew her; took her out; taught her fishing. Last year, you remember, in May and June, she fished the Dee. Do you think for a moment that 'Lizzies' and 'Logies' occupied an atom of space in her book-pooh! rather not; they are absolutely out of it now ; she took a set of modern summer patterns, and caught twenty-seven fish. In my opinion that is twenty more than would have fallen to her lot without instructions. 'What was the most sucressful fly?' Well, you had better put the name down. It was the 'Silk Bodied Benchill,' a first-class pattern, and killed sixteen all told. . . . ."

"Oh, that satisfies me; I've made a note of it, and. . . ."

"Stop a minute, stop a minute; the summer this year may be very different. Still, if the conditions of water, weather, and stock of salmon are at all similar, there would be a very slight difference in the number caught."

"Well, I've tried the Dee; how about the 'Blue Charm' up there, eh?" 
“The 'Blue Charm' is by far the best of the old lot in summer, but isn't in it with the best of the new, I mean of that particular type. In fact, it's gone home to roost this three or four years, and passed into the limbo of worn out flies only to be forked out by the unenlightened."

"Tell us the names of the others?"

And then, while a single individual hailing from the Usk wanted a "tip" for his river, which he got later on, the veteran continued:

"The other three that complete the set, are known as 'Louise,' the 'Silver Grey,' and 'Little Inky-boy.' I will tell you when they all come into favour. Although we are talking of the months of May and June, none of these lies - all varying in size from one inch (dress) down to half an-inch-see daylight till the waters fall to summer height. In sunny weather, when we first want them, the largest silver-bodied specimen is 'real jam' from ten in the morning till three in the afternoon; but mind you, it is very useful late in the evenings of intense heat in Junc. 'Louise' is reserved for cloudy days; the 'Little Inky-boy' for daily use in the lowest water-when, by the bye, plenty of fine gut is absolutely neccssary."

"Are these flies good for the Usk?"

"When small ones come in, certainly. But to my mind the 'Penpergw'm Pet,' considerably reduced in body and wing, is a better fly there for general use."

"'Gencral use,' what's really meant by that?"

"It is an expression adopted in making reference to flies which we know turn out well on those days of quiet prosperity - days when the lion lies down with the lamb, and even the 'unco' guid' are as lucky as most other people. Those interesting 'goody-goodies' 
always take for gospel the fairy fishing tales flying about in the daily round of life, and seem to derive quite enough pleasure from a tug just now, and a solitary fish just then. Mind, they have no relations to blush for them, and so far as appearances are concerned have not the slightest intention of departing from the old beaten track."

"Well, people can't be happy unless they are good."

"That may be, but good people miss all the fun. The fun commences when their reverses begin, when the red-letter days are over. It is then a veritable transformation scene for all those who act in the 'stage play' at the riverside-a scene effecting a change from old-fashioned flies to clever 'variations' and then to our latest special patterns. However, soon after the 'Penpergwm Pet' came upon the scene at Usk, it accounted for no fewer than eleven salmon in one day, all taken in the vicinity of Penpergwm bridge. But note this, the body composed then of close coils of seals' fur carried as much wing material as a man could safely put on. So there you are ; you see how fashion changes! We really must go with the times, and not with the spirit of the age. And the sooner the folly of our lcyalty and devotion to tradition is conclusively demonstrated, and a system to reap the full fruits of victory is introduced into use, the sooner will salmon fishing attain to a higher level, and the greater hold it will exercise over one and all alike."

"Ladies included?"

"Yes, certainly; even including the prawn and minnow denomination whom we politely call Fishermen, because that's not their name."

"Oh, fancy the mistakes we all make!"

"Well, it is not so very surprising after all, for you know "error 
is an abyss of passion into which each successive generation plunges, without the slightest regard to the fatal effects which such conduct has produced upon their predecessors.' You should take courage, for the old saw, like every other rule, has its limitations."

"Well, I suppose I must think more about altering. . . . ."

"I have given you my advice about altering your tactics. If you reflect a little, you must realise that the mighty pendulum of change swings with impassive and impersonal regularity, apart from all controversies, from all imaginings-swings subject to the cosmic laws of gravitation, by which, at all events, the thoughts of scientific fishermen of to-day are carried on to ends and purposes of which our grandfathers did not dream."

"The idea is enough to. ....."

"The idea may be a little difficult for us to grasp at first, especially as we live in the midst of its evolution, part and parcel ourselves of the changing order. Take my word for it, Science is searching out the weak points and can override all opposition. Slie can wholly sweep away all barriers, and bring down to her own universal line of equalisation the most stubborn impediments. . . . . But my time is now up, though I have yet something to say which you may all like to hear. You may congratulate yourselves upon the following facts, namely, that certain methods established from age to age, on no evidence whatever, have already seen their day; that the pretensions of our so-called experts, who know nothing of the conditions which control our destinies, and have made tradition one of life's little worries, are gradually exploding; that the happy-golucky period of freedom in the chuck-and-chance-it school has passed and gone for ever, for the master key to the fly problem has been 
discovered at last. . . ." As he left the room he observed: "Here is something else that precludes all argument. The gentle influence of time has proved that the knowledge of what fly to use is no longer the distant goal of a vague idea, but an actual, achieved reality, brought home by that force which comes, not from the mist of sentiment, but from downright reason and understanding. There! The system will be explained presently, and this is what will happen : At first you'll regard it with unconcern, presently with allowance, then with approval, at last with participation. Goodbye." And the door closed.

The subject then turned upon a side issue respecting the determination of some to dispute all systematic methods of fishing, and culninated in a sharp attack upon current literature. "Of all national sports (continued the speaker), salmon fishing is the least fit to be judged by an outsider. Only last Saturday a newspaper contained a pointed criticism of one of the revelations in "The Salmon Fly,"* and. . . .."

"Oh! that is unimportant; go on please," remarked the author.

"Well, it stands to reason that newer ideas have gained hold upon those who have studied fishing as closely as our friend over there. According to the critic's own remarks, even the average angler will not grasp certain points of detail, the proper appreciation of which throws an entirely different light on the art, and raises it to a much higher level. The fact is that our angling literature is so full of inaccurate observations, hasty generalisations, and crude hypotheses, as to entail a great waste of time on the student of authentic books of reference."

$$
\text { * N.B. See "Side Issues" (page 39). }
$$


But let us turn, or rather return to more "Tips."

Some time ago the compiler of these pages wrote for a publication that ceased to cxist at very shrt notice, a review of our flies from those far-off days of boyhood when one John Jewhurst, of Tunbridgc, created a sensation by the introduction of a fly destined to be re-christened "The Butcher." So superior in outline, in constituent materials, in style and character was this happy creation, that thenceforward bis built wings made a regular commotion in the angling world, besides a reputation for themselves which can never die out. The fly was soon admired by all, including most of the trade. We saw it in all windows, dressed in all sizes. Customers had it universally recommended, and what is more, the discovery was the means of bringing in other men, who, in due course, thought out and devised a number of fresh patterns, which to this day occupy a prominent place in the list of Standards. Wright, of Sprouston, "Jock" Scott, also of Tweed notoriety- a celebrated gillie whose name will endure for ever by reason of that paragon of his, called after him-Bernard of London, and, besides the author of "The Salmon Fly " himself, one or two others may all lay claim to the credit of designing specimens, which in themselves are more or less remarkable for superior excellence and freshness of conception.

These observations bring to mind the assignment of the different types of flies to waters for which they are suited; and as the subject was not renewed after the old "Rod" had retired from the meeting. this part of the work of classification is here introduced.

Of the distinct types, five presented themselves for localisation. 
I. Mixed Wings, of single fibres-example "Silver Scout."

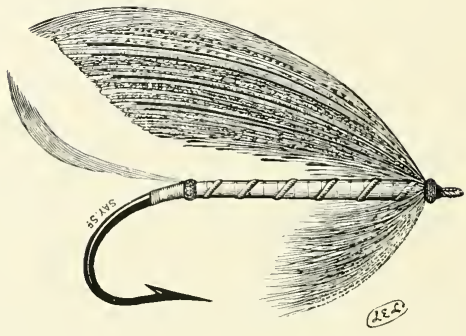

Note: These wings are often substituted for those of any fly.

2. Built Wings, of married strips-" The Silver Jock."

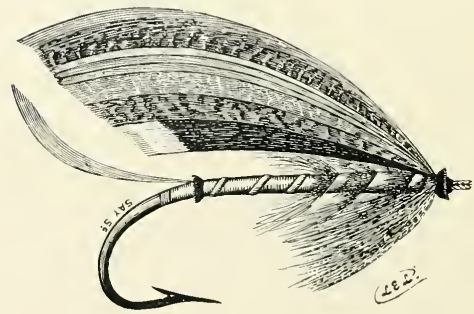


3. Strip Wings, of two single strips - "The Dunt."

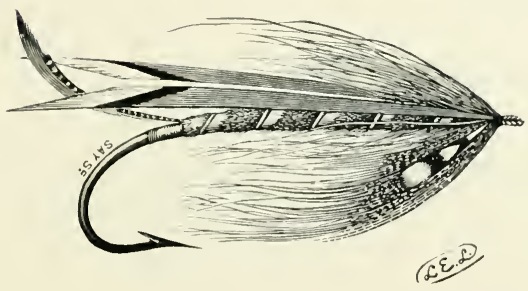

4. Topping Wings, of golden pheasant toppings-" Variegated Sun Fly."

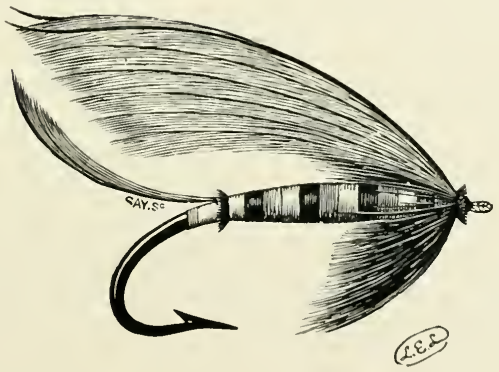


5. Whole Feather Wings, of feathers, not pieces of them"Black Ranger."

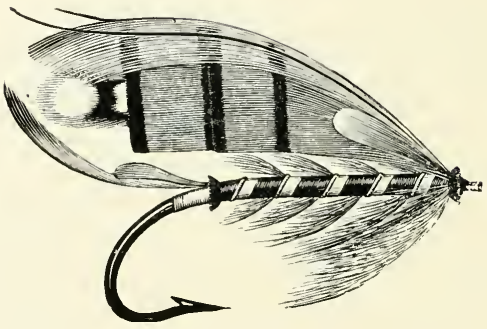

"Dr. Donaldson," amongst other patterns, whose under wings are likewise composed of the feathers of macaw, and even the "Butcher," when the water is not too rough, are generally included in the Ranger set.

Mixed wings (No. 1) - the most mobile of the set-were booked for calm, unruffled catches, and so on in comparative rotation up to whole feather wings (No. 5), which, being constructed to battle with waters dashing along in violent commotion, were naturally assigned to falls and rapids.

It may be necessary to note that nothing has occurred to lessen in the slightest degree the favourable impressions created by this manner of arrangement. But let us proceed with the still more interesting question of choice. 
To a very simple circumstance, that must have been noticed thousands of times, we owe the discovery of our system generally of deciding the sort of fly to use when fishing is practicable.

As all know, the bright sun brings out the brightest butterfly, and from this constant act of Nature the system has partly been evolved.

As a matter of course, observation is the basis of all scientific knowledge. From what other agency could inspiration be drawn? Observation seems to be the keynote of every solution in every field of enquiry; and in fishing, to disregard such things as, for instance, the effect of light and shade, leads to reverses the most unexpected. Hardly any of us form the slightest idea of the extent to which the faculty of observation can be utilised. Take, as an example, a brief illustration of this.

The writer was out on a river in Aberdeenshire, and had hardly put up his rod when a gillie, from the fishery below, handed in a letter to the following effect:

"We have a match on to-day-you to coach a friend of mine. Will you come?"

Je was referred to one of the places where he received the rudiments of his early education! He knew the pools of old, and the various methods of attack were all equally familiar. However, it soon became clear that his companion felt himself quite unable to grapple with the problem before him, since he had not heard of mounting a bright fly when the sun shines, or of one, after the living insect itself, which, from time to time, is deemed expedient. But later in the day, when it came to the corresponding principle of using a dull, sombre pattern, because the sky had become cloudy, he 
submitted in tame silence, and sank into an implicit confidence.

We were now making for the Catches which had been previously allotted, our "opponents" having moved in another direction.

Keen to a degree, the young fisherman, who had been at it long enough to catch the usual spirit of enthusiasm, seemed bent on trying one particular spot, and hurrying along, enquired about the fly to put on first.

The reply was, "first let me understand the exact spot you mean, for should it be at the hut in front of us, your only chance of success would be by shooting a net."

To paraphrase the proverb about true words spoken in jest, the idea of shooting a net, though spoken lightly, proved later on to be true.

"No, we must go round the turn. The sun shines straight down the water here and that's fatal. Higher up the river you will find it shining across the water, in which case it won't do the least harm."

Taking a short cut through the wood close by, a peep at the pool from the glade on the hill was obtained, and a spacious wet patch of gravel beside the bottom part of it came into view. This led to very close investigation on arrival. The grass-blades were freshly trodden down, the sharp edges of the footprints still well defined. And there, true enough, in amongst the stones at the water's edge, lay numerous scales of salmon, which to all appearance had recently been dragged ashore by the net of the poacher.

"Disappointment No. 2; one might just as well cast on the grass as try there. The only chance, for at least an hour, will be at the bend."

Thus we have only one instance of the numerous advantages 
easily obtained from persistent observation. The unmistakable truth is this: All objects which can be seen by the eye should be carefully considered and their meaning reasoned out.

However, though the following description of the waters at the bend is slightly and purposcly misrepresented, it affords a capital opportunity of giving one or two striking examples of the enlightened method of selecting flies.

Here we are, then, say in the month of February, beside a deep stretch of water one thousand yards in length, all of which holds fish on the far side, though thirty yards away from our wading track. Except at the tail end, which is fully exposed, the water is sheltered from the sun's rays by a steep bank studded with high Scotch firs almost from the edge of the river. The one peculiarity, which affords an element of fresh interest, occurs at a place half way down the reach. The little attractive ruffles there, plainly visible in the distance, are caused by a certain number of peaks which derive their origin from a mass of rock embedded in the bowels of the earth. But we will proceed from the beginning and deal with these deceptive little curls in their turn.

What we have first to decide is the size of our fly.

In considering this, it should be borne in mind that the river Dee. on which the picture is drawn, carries the largest of all Spring flies up to the middle of March, and even up to the end of the month if the water is high and the weather unusually cold.

(As the fact has been discredited in print, it may not be out of place here to mention that the writer had the best sport at Carlogic when casting a fly exactly six inclies from the hend of the look to the head. It may also be said that the most minute flies are wanted 
there in summer, and that no part of the river is more enjoyable, though it calls for far more intelligence and skill from practice than all the other districts have occasion for.)

However, the fish, be it remembered, are sheltered from the rays of the sun, which nevertheless brightens up the situation. This being the case, instead of the fly being full size, it should measure no more than four inches in length. Next must be decided the sort, the colour, and the character of the fly.

A black and yellow body toned down with long, dark hackles, is the best combination for shady places in the North. Consequently our "pupil" was given the fly almost universally known as the "Akroyd." Unfortunately he had never tried anything so large. Cast it, he could not. But still no blame attaches to him for failing to achieve the impossible.

Now, in such a dilemma, what is the only alternative? The answer is, to fall back upon the Governor Cast, if practicable, by which means a fly of any size can be propelled a distance of fifty yards and more in ten minutes' practice.

It is not necessary to dilate upon this method; suffice it to say, that the cast is made by hooking the fly on to an elastic band fixed to a staple at the top of a five foot prop, which is to be inserted into the ground at the rear of the fisherman. (The apparatus can be had at Farlow's.) Having thus looped his fly into position - the look does not penetrate the elastic itself-the angler walks towards the spot he wishes to cast from, lets out line as he goes, and then has only to make the ordinary thrash-down in the direction required.

Visible to the eye of observation, these ancient peaks, spoken of, stand fast, like sentinels, guarding their own self-made lay-byes. 
$\Lambda$ pparently rising from the tranquil regions below, they are made semi-columnar, to adopt a botanical expression, by the action of the torrent, which in course of time will reduce and spoil them for sheltcring the weary travellers that now seek their protection. Like ghosts, these so-called "hedgehogs" must be spoken to a little before they will explain themselves; for it is just here that the weakness of the convention-ridden is manifest, and the art of the scientist supreme.

In whatever else we differ, we are all united in this: that close behind these peaks will salmon lie. The inference is plain.

We lave to depart from the ordinary principle of presentation: we have to put our fly, not four or five yards in front of, but actually over the spot which holds the fish, or it will not be seen at all. In ordinary catches, salmon invariably refuse a fly thus presented. What on earth, then, would produce an effect, and satisfy their taste in the twinkling of an eye at such complicated places as these! An ordinary fly of any size, of any colour or combination of colours, an uncommon method of playing it over them, in fact, dodges and schemes of all sorts had but the one effect, viz., that produced by the appearance of the full moon in the sky. The fish invariably "go down " when the moon is up.

In the original belief that there remained an opening at these catches for not unreasonable hope, it was instinctively found on actual inspection that the key to the mystery lay hidden in the pursuit of some spccial feature in fly work as yet untried. This finding proved to be correct, for in due course a onc-inch variety of "Louise" came boastingly to the rescuc.

"I.ouise" herself belongs to the tribe "Impennates," i.e., small 
TIPS.

patterns with short wings. For these occasions, however, we made her ship-shape, but-and here is the point-with "sides" and "cheeks" of jungle and chatterer, extremely showy, and altogether out of proportion larger than little flies carry, in fact, the largest to be had.

The success attained with this unique object, though not very regular, bore eloquent testimony to the propriety of our neat discrimination. Once on the right track, imagination led to further practice. We knew what the fish wanted, and what they disliked. One did not walk therefore like a dazed man in a twilight of nebulous resolves, but continually practised in sombre patience. At last it was discovered that "Elsie" produced the effect desired, and knocked "Louise" into smithereens.

With this championess - the fact had better be mentioned-the greatest success resulted in 1886 , at one particular spot half a mile or so above the bridge at Crieff. "Elsie" has maintained her reputation on the Earn and elsewhere on subsequent occasions, and came off with flying colours at the ruffles, for she won the match for my protégé.

Let us reflect for a few moments on these accomplishments generally. Is our method clear? What does it all mean? It means simply this: Instead of going to a river and putting on the fly that first comes to hand, the study given to Cause and Effect enables us to progress by a system that works wonders, because it is founded on a perfectly natural, and therefore impregnable, basis. It is very simple. All other methods pale into insignificance. What ve do is to concentrate attention at the riverside, and deduce inferences from matters of fact. There is nothing very violent in the practice; it is 
quite consistent; all forms of philosophy must begin from some standpoint. And when we began to increase our takes by repeated additions-when, in other words, we noticed the regularity of successes brought about by adapting certain flies to meet certain cases, dependent, say, upon the variations of light, shade, temperature, and what not we said good-bye to the "tripper" element haunting subscription waters, and left all others hopelessly behind in the angling records of the year.

One move led to another. We tackled those contingencies, for instance, that formerly induced every onc of us to strike work right away. Picture the universal custom that prevailed. Fancy a whole army of the best of sportsmen in the very thick of excitement, reeling up and beating an ignominious retreat, simply on the supposition that some effect of the sun upon the fish compelled them to do so! Well, that happened. Now what was the result?

When the truth dawned upon my feeble understanding that "the lord of light," unless shining full in the face of the fish, did not really impede our daily march along the river's side, the change over the situation came with the most astounding surprise. Things are now totally different. No longer are we driven from the waters in despair; no longer are we disturbed or discouraged; no longer is Strength made the temporary slave of Wealness by the pardonab!c inability to interpret and deal with the sun's particular influence. Quite the contrary. For whether ficrcely blazing or slecping in undisturbed repose, the "monarch of the climes" alone is the very centre and soul of our system - a system which holds equally good even when he casts his last smile o'er hill and dale, and hastens " to seek the couch of timid twight." 
The desire to deal forthwith with these two different situations is imperative, and therefore it had better be gratified.

The writer can never forget the set expression of a friend when gazing at a number of trays, replete with furs and feathers, and speculating wildly on the proposed variation of Aywork, in order to meet the possible changes of the great luminary of the day. Times out of number, prior to this occasion, he had stood and watched the surroundings with strained eyes to get them to divulge their secret, and he worked just as often for the purpose of discovering the fly of incidental need.

It was, however, from the Spey, that were brought away the most agreeable memories of victory. The pattern ultimately devised and christened then and there "The Variegated Sun Fly," simply enraptured his friend by his own immediate experience with it. His success, followed by still further fortune at a second pool, brought the conviction that a new era had unmistakably been opened up. Personally, the writer has seen enough, and done enough-eleven fish taken with this fly at the stream opposite Aberlour on the Spey in four consecutive July days - to destroy effectively and permanently the last shred of contention that, to fish successfully under the brightest suns of Midsumner is a fallacy.

With regard to size and method of presentation, a very brief explanation will suffice.

The Sun Fly is always made comparatively small, a No. $11 / 2$ hook is the largest ever required. In streams, deep and rough - the best of all places for it - the wing carries as many as half a dozen golden toppings. The quicker the fly is played- that is, conformably to reason - the better one's chance of success; but in most of these 
Catches it is necessary to mend the cast, in the absence of which manceure the fish are more inclined to follow the fly than to jump at it.

Four toppings over a "dress" of not more than six-eighths of an inch seem to do most damage in average places. But in low water-even then the fly is played quickly across it - the smallest hooks are used.

To approach the second situation, namely, when the sun's magnetic beam is seen no more, it would seem ahmost superfluous, after what has already been said of our system, to urge the necessity of mounting quiet looking patterns-that is to say, those not decorated with bright, showy feathers.

On the Dee, for instance, we constantly hear it said, "the Gordon" time is coming," and this implies that the day is drawing to a close. But we must not overlook the fact that, in the evening, when the waters cease to sparkle, first there comes a flood of rosy light. Accordingly, the Gordon, disfigured by the substitution of a dark blue hackle at the throat for the light one, which the Dce fish so dearly love, is reserved for duty later in the evening. And is there any fly that kills in those waters so well at night time as the dark blue Gordon? In my expcricnce, none.

The principle of this toning down holds good on most rivers, in fact on all where the bright fly system is generally practised on bright days.

Referring again to the deep stretch shaded by Scotch firs, it must not be taken for granted that a four-inch fly would be $d^{\prime}$ rigueur elsewhere, far from it. The example is merely given to illustrate the practice under such circumstances and conditions. On other 
rivers, therefore, judgment must be exercised. Supposing a two-inch fly is the full size used, we should mount one of about an inch and a half in length.

When the angler's ingenuity, however, is so over-taxed in his efforts to cover distant fish with large flies, that by splashing the water he alarms the aquatic camp, the onerous duty of changing front becomes imperative. To begin with, an interval of ten minutes before the renewal of hostilities is a sine qua $n o m$; he has then to make up his mind to get nearer the fish; of course he will fare worse if he gets farther away from them. For this reason his fly must differ both in size and character. The size is reduced, because the fly will inevitably travel across the water at less speed. And, to carry the mind back a few pages, the fish, having seen a dusky pattern partly composed of feathers impervious to the light, should now be offered a gaudy specimen, even as radiant as "Beaconsfield" itself.

Thus we have a common illustration of what we are pleased to call " contrast."

Our subject now takes a more definite turn.

We have done with the sun, we have done with the shade, and partly with geological formation, and will now ronsider the principles to pursue at the riverside generally.

As the varicty poet says, "it takes a bit of doing," in the absence of local advice, to decide off-hand the size of fly to put on; but still, the behaviour of the fish will soon give one the cue.

If, for instance, a salmon only follows a fly, one smaller and brighter must be used. Should, however, a swirl be seen, and no tug or rise follows, the fish should be rested for about eight minutes.

If a salmon comes sharply in rough water and misses the fly, three 
minutes should be allowed, and a smaller specimen of the pattern in use put on ; but always remember that a fresh fish will take a lurger fly than a kelt.

If in smooth water the rise is not of a determined nature, allow ten minutes' interval and mount a very small, showy fly.

If a stranger to the neighbourhood is able to learn the size others are fishing with, he should use a fly a trifle smaller; but in the very early season, when the weather is very cold and the water high, he will increase his measure of success by putting on the largest pattern the river carrics.

Fishermen, as some know, acquire knowledge of these matters, and many others too, in the dear school of extensive experience. lior experience teaches us what fly to selert for the time being, and what method to adopt to command this or that pool, which formerly we passed by in utter ignorance and left undisturbed. Do we not often find in cramped situations-places in which the Overhand cast is impracticable- that we have to resort to one of the more modern methods to command them? And is not this the very time to discover that if we haven't got the tackle we love, we are either compelled to love what we have or calm ourselves by watching the progress of others more wisely appointed? The well-known fact remains that we are always wanting something, no matter what we possess, and few can say with the late Mr. Brotherton, "my riches consist, not in the extent of my possessions, but in the fewness of my wants."

To return to our subject. Let it be distinctly understood that when the natural fly is "up," we have a stereotyped routine that almost invariably accommodates itself to the prevailing plan of using 
TIPS.

flies in bright weather embellished with gaudy feathers. Take the case of the March-brown on the Dee, and you have the principal exception. On this occasion our fly materials must very closely resemble nature. In our composition we are tied down to the element of size, i.e., to making our pattern only one size larger than the living insect, and we can only slightly enrich our make-believe with any extra show of colour. These restrictions, one and all, are of less moment in every other case, even including our imitation of the monster stone fly for use on the Spey. But as these matters will be dealt with presently, suffice it to say that salmon, side by side, rise to March-browns as well as to many other natural flies.

On some rivers we creep up in size to enormous patterns for ordinary use, as on the Dee; on other rivers we come gradually down in size, as on the Lochy and Ness, and on all rivers the fish get accustomed to the change and prefer it.

We also gradually increase the decoration of flies for the same sane reasons. The result is equally good, and as years roll on we find the fish appreciate the most luxurious patterns, such as would have frightened them to death had they been suddenly introduced. If this is not cducating the fish - an expression often ridiculed - what is it? Fancy the commotion a six-inch "Jock" would have created fifty years ago! Surely the time has come for none to discredit the fact that we teach salmon to take the smartest flies--lures with spicy wings, bodies unnaturally adorned, legs longer than living flies possess, tails unconscionable but still tails-and why, in these enlightened days, some people say these fish are not educated up to this treatment, and that they mistake our gaudy flies for minnows, or other live bait, Heaven only knows. 
With further reference to our system of "choice," passing over the "Sun Fly," perhaps the "fly of speckles" has made the most convincing headway of any. Characterised by a liberal consignment of teal, gallina, etc., the "Rough Grouse," the father of this set, is simply worshipped on drizzly days the whole way along the river Spey.

Inless engaged upon such a bold river as the Spey, the angler's next "tip" is very important. Before he follows another down a pool or most other Catches, he should allow at least a quarter of an hour to elapse, and then use a smaller and thinner fly than the one the fish have secn and refused.

In decp, steady flowing water, a silver body is wanted, and whatever it be, the fly should be fished as deep as possible.

The longer the hackle, the shorter the movement of the rod given to play the fly, the better.

In flaked water, a gaudily dressed, silver bodied fly, with a reddish hackle at the throat, seems to be indispensable.

In dark, porter coloured water, first use a dirty orange body, having a dycd black hackle along it, and then a black body having a light blue hackle running along likewise.

In snow water, which when fined down makes the river clearer than at all other times, transparent hackles, with a goodly supply of peacock's herl in the wings, are superior to all others. It is immaterial whether the body is composed of seal's fur, floss silk, or silver tinsel, a good silver coch-a-bonddu is the identical thing for the occasion.

If the weather is hazy, small dark flies are preferable. The approach of thunder, the presence of a heat-haze, or a white mist hanging low--all these conditions have hitherto been the signal for 
suspension of work; more so, indeed, than clouds with white tops floating in mid-air, or even a falling barometer. But as soon as a decided change sets in-a thunder-clap for instance, or the clearance of aqueous vapour in the atmosphere-the favourite fly of the river is the one to select without loss of time.

On the water beginning to rise after rain, put on "Thunder-andLightning," or a pattern of that description, and slightly increase the size as compared with your former fly.

For fish lying in deep water behind an upright rock, show them a bright body with double jungle in the wings, capped with three or four toppings. In this instance, play the fly by giving the rod short, sharp, shaky movements, and on detecting the rise strike fairly hard at once.

In districts where the bed of the river presents a dark appearance, dark patterns are required, reserving brighter patterns for beds of a chalky nature.

Where light is reflected, especially from holophotal mirrors which keep on throwing back the rays in one unbroken mass without perceptible loss, or even glinting from wet, steep-cut rocks, use fancy flies, glittering with silver tinsel, and, it may also be said, resembling the sunrise in the richness of their colour.

When the thermometer falls suddenly use thin, dark patterns, larger than those previously employed, though the water runs no higher. When it suddenly rises, announcing the approach of warmer weather, reduce the size considerably and select gaudy specimens.

As a rule, it is better to use a sombre fly before a showy one.

In trying for a fish which has already risen, change the fly, but do not put it more than one yard below his lay-bye. The second fly 
should be totally different in character, and a trifle smaller. Should the third attempt fail, allow a long interval and then try a Grub. But before giving in, present a very large dark fly, afterwards a very large bright one, and fish both quickly.

Examine, take note, and cndeavour to remember the run of the water in all taking Catches, and you'll soon learn to "spot" unkinowon lay-byes in flood time.

In these principles lie the greatest potentialities of our art. Genuine adherence to them will make a fairly skilled workman semiindependent of the ruling eventuality-disappointment.

SIDE Issues.-Sterne says, digressions are the sunshine, the life and soul of reading. Now, although a slight détour is made at this point by special request, it is not intended necessarily to depart very much from the line of argument, but rather to endeavour to advance the immediate subject before us.

A little while ago (October, I900), the post brought, from five or six different sources, a cutting from a paper which occasioned the attack upon current literature made by a young fisherman (page 20). It criticised in a singular manner the definite system of fly-work, founded on approved and unassailable principles, fully authenticated by competent judges, and explained at great length in "The Salmon Fly."

Although devoid of every trace of keen angling insight, and every trace of the simple precaution having been taken to investigate the subject at any time, the critic is entitled to generous sympathy and consideration by reason of the fact that he wrote in the most open and honourable manner, and not under the vagueness of any nom de plume. Neverthcless, his hasty conclusions afford just an 
instance of the harm done by enthusiasts who bring only a little knowledge to bear upon a subject which cannot be discussed properly except after a prolonged study of a number of infinitely varied experiences at the waterside.

The statements in "The Salmon Fly," which for some inscrutable reason, were despised by the critic - a gentleman who bears a name, Baden-Powell, that has won everlasting renown in other (and slightly drier) ficlds (a little "f" please, Mr. Printer)-were the outcome of long and patient observation. It may be stated in the most emphatic manner possible, that they had never been hinted at, or cien previously fresented to the Public in any shape or form, at least in the way of calling rivers "Grey," "Red," etc. They referred to the fixed policy of using certain flies on certain occasions - flies specifically characterised, as the occasion dictates, by fibres of this or that colour in the tail, body, and wings. They were based on stubborn facts (a) that salmon act according to certain predispositions; (b) that they take certain natural flies; (c) that when they are immovable as the rock of the river bed to-day, and give way to the artless lure of the raw recruit to-morrow, they are governed almost invariably by some direct cause, and do not act under the influence of mere caprice. And the author supported these facts by an overwhelming array of evidence, well-founded, and calculated to explain problems otherwise inexplicable.

These statements are stamped by the critic as rubbish.

It is very easy for the writer to exclaim "Rubbish," as easy as it was for the old lady to believe in the efficacy of that blessed word "Mesopotamia."

For the sake of the author's chain of reasoning which holds the 
system together, no less than for the satisfaction of the anglers who pursuc the system and feel hurt by the criticism, "it is necessary (as they put it), to offer an explanation in the new book of yours, at once lucid, fully substantiated, and of a kind calculated to leave absolute conviction upon the points affecting tle issue."

Indced, it is only natural for them to decline to allow the lessons of a lifctime, accepted with their warmest approval and full concurrence at the riverside, to be exposed to public ridicule by the airy criticism of the wielder of a facile pen.

If, however, the explanation seems to savour too much of personal reference, or cven to exhibit traces of vanity, the present writer is very sorry. But considering the importance of the system and the interests involved on all sides, what is he to do?

Altogether apart from the logic of facts, he has himself personally proved the value of the system by constant experiment. The result has been-since the truth must be told-that during three recent outings his own catches have so largely excceded those of the whole party working on the same waters, that he is driven to the conclusion that his own methods must be superior to theirs.

What else, he asks with that repugnance which anglers will fecl to be natural, is the meaning of such records as the following?

Thirty-two salmon out of thirty-four, five Rods.

Sixty-three salmon out of seventy-one, seven Rods.

Ninety-one salmon out of ninety-nine, two Gillies and six Rods.

The other fishermen, whose bags appear so small in these quoted records in comparison with his own, were equally good sportsmen. They used nothing but a fly, and were equally skilled wiclders of the rod as far as Overhand casting is concerned. 
It follows, that the only way the mystery can be explained-the only logical way - is that none of his companions brought to their task, as he did, the employment of his system of fishing, verified scores of times, and laid down in his book for one and all alike.

But of course the subject must be approached from other standpoints.

We now allude, for instance, to that part of the fixed principle, which so upset the critic, of putting a little bit of this material and a little bit of that in a fly. The following interesting example is only one of many that shows how accommodating the system is to alleven to those with no previous experience of it, and with no pretensions to be in any sense experts at handling the rod.

It should be said by way of preface to this example, that none of those "skilled wielders of the rod," mentioned in the former case, had caught in five successive years, more than four salmon at Carlogie in the month of May; also, that the tenant last May, fairly new to the work, had consulted me upon the dressing of flies which he should get specially made for those waters, and upon the system of using them.

Here is his letter to me, dated zoth May, Ig00:

"I found your variation of the Silver Grey such a splendid killer that I fear I stuck to it too long, and did not give your system of using the others, on stated orcasions, a fair trial. Jut

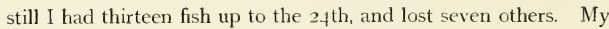
biggest turned the scale at $19 \mathrm{lbs}$.

$$
\text { (signed) JOHN BIDDULPH." }
$$

We now pass to more congenial arguments.

For what object did the author of "The Salmon Fly" say (Pp. 
250) that "a blue or any other coloured fly, deadly on one river, is repulsive to the fish on another. For that reason in a technical angling sense - we may say there are 'Blue rivers,' 'Grey rivers,' etc!"

II is object, obviously - to paraphrase his young friend's wordswas to throw a new light on the art of choosing a fly, and to raise this art to a much higher level.

To use general language, the recognition of Cause and Effectthis will bear repetition-arises when we experience, many times over, a number of successes with special flies, all recurring respectively under similar conditions of local tastes, of weather, water, temperature, etc.,-successes which bear a unique relationship of antecedent and consequent.

(It is worth while noticing here that fortune sometimes smiles on luck, for these successes may arise, though very seldom, from the ascidental choice of the correct style of fly, and may in consequence not convey the lesson that a more experienced performer would infallibly deduce from them.)

To select off-hand one or two examples among the many-the predisposition towards Grey flies, as commonly witnessed on the Lee, arises at certain seasons from nothing else than the huge, ever-present blow-fly, displaying speckled legs, body, and wings.

This was the cause of our introducing Silver monkey's fur for part of the toilette, and putting fbres of teal and gallina in the wings - an innovation which has vastly superseded the coarser, less spotted donkey's fur, and the bead-holding rabbit's fur of yore. The effect of the change, seen times out of number, is positively notorious, notwithstanding our amiable critic's emphatic statement that "strict 
dressings of patterns, the fibres necessary in the wing, the bit of this, and the bit of that (is all) rubbish." And in another equally unfortunate connection, relating to my calling rivers "Grey," etc., he states-of course without the slightest confrmation-that "such things exist more in the minds of the men who fish them, than in the minds of the salmon they fish for."

Untrained anglers love to get at the truth, and truth is established not so much by what men say as what they prove. So to continue.

The predisposition towards greenish bodies on the river Spey, transient but clearly evident, arises from nothing else than the everpresent so-called "green-king," gobbled up freely in its own short season.

The cause of our careful imitation of the natural insect, and of using nothing else for the time being, is equally notorious in this case too; and the effect, productive of a heavier creel, is stcadfast, convincing, and conclusive.

Once more. The predisposition towards Red on the Earn, arises from nothing else than the presence of what is called the "redunderwing," seen flying up and down the river in thousands early in autumn - and so on, ad infinitum.(See pages 25.4-5 in "The Salmon Fly," and kindly note the singular success recorded of a trained angler, whose practical science is beyond all question.)

It is, of course, open to fishermen to see several sides of a question. For instance, one lays down a system of fishing founded on fact, another says it's rubbish, whilst a third writes to the author of the system in a private letter, "you touched nothing in your five hundred pages of honest matter which you did not elucidate. After 
I read the book I began by getting thrce times as many fish as before."

Let it be said here, that the author of "The Salmon Fly" has always regarded himself as a student--he will ever remain one. In writing of his exploits, if he has given way to an irresistible undercurrent of effort and desire to carry the angler's mind above and beyond the popular practice of ensnaring salmon by hook or crook, it is solcly for the purpose of raising the sport to the highest branches of the art of fly-fishing. What he has written is to say this and this has he learnt, thus and thiss las he learnt it on the spot. All honest criticism based on actual experience will be welcome to him; and the more he has of it, and the sharper it is, the better in the end. But is it not a very unnecessarily strong statement for Mr. Baden-Powell to stigmatise as "rubbish" the results of diligent and systematic investigation upon all kinds of salmon rivers, in all kinds of weather under all sorts of conditions, with all kinds of flies?

In matters of this description, the plain answer is the same as that given in the well-known logical fallacy of Achilles and the Tortoise-Solitur ambulando, i.e, the problem is solved by practically working it out.

If individual workers have with infinite labour at the waterside been accumulating facts which indicate the direct way to "titivate" flies in a manner absolutcly reconcilable with the peculiarities of a river-flies far and away more killing than any ordinary pattern-it appears (I) as though further argument were unnecessary; (2) as though crery requisite of both theory and practice were satisfied; and (3) as though the problem in question were removed from the category of unexplained mysteries. 
So much for the technical skill exhibited in this new departure in fly-work.

In the case of salmon, we know that external objects impress themselves upon the fish in two ways. At one time, directly, through some natural agency--light, contact, force of current, etc. At another time, indirectly, as when they get the impression of a fly which nourished them in their infancy, not from the insect itself, but from a specific imitation containing something associated or connected with it, which, as experiment teaches, is an appropriate stimulation of their memory, one that revives the recollection of their favourite food and stirs them to action.

The natural impulse of salmon is guided by instinct, just as the infant in arms sucks the bottle. But as they sometimes take the wrong river, we cannot speak of their instincts as unerring. Very slight stimulation which comes into their "thinking apparatus"--e.g. excitement produced by an extra bit of blue, or an extra bit of red in a fly-sets them in a state of passionate activity.

How can this be "rubbish"? Of course it cannot be when we compare notes and reflect.

As a rule, the greater part of the ideas relating to fly-invention are not reasoned out by the student in the first place, but are imparted to him by the master-hand as part of his education. Not a few, on the other hand, have become so settled by actual experiment as never to be questionable, at any rate at certain periods; and they only decay by the substitution for them of new habits of thought occasioned by observation of some such evil effect produced on the fish, say, by over-thrashing, when, of course, the conditions which led to the making of the former "awfully killing fly" have become changed. 
It cannot be otherwise. And yet we encounter narrow-minded cnthusiasts-pitcously hoodwinked on an exceptional day by getting a fish or two with the wrong fly presented the wrong way - who burn for the heat of the fray, and openly declare they can hold their own with three or four Standard patterns against all comers! What a number of red-letter days pure accident must give these gentlemen! l'etter for them by far to leave the simple Ltopia in which they live, and devote all their spare time to studying the practical habits of the fish.

There is no doubt that the ordinary fishernan resents the view of there being any abstruse methorl of catching salmon, or any possibility of largely increasing the catch by what he probably denominates "new-fangled" innovaticns. It is highly probable that the ancicnt astronomers also regarded Galileo as a most annoying and crack-brained individual, whose innovations bade fair to upset the Solar system, and to introduce a quantity of very minute and unnecessary calculations into what liad been the very simple job of star-gazing.

Poor Galileo had to put on a white sheet and cry, "Peccavi." But it is recorded of him, that after his recantation on his knces he got up and said, "E pur si muove," in a quiet tone of voice, not audible to any of the Pope's familiars, to indicate that, though he had been compelled to say that the earth did not move, he was still of the opinion that it did.

It is in a similar frame of mind that the author closes this chapter, and not without the hope that the latter passages may strengthen the impressions of the loyal, change those of the sceptical who declare the system null and void, and commend themselves to all. 


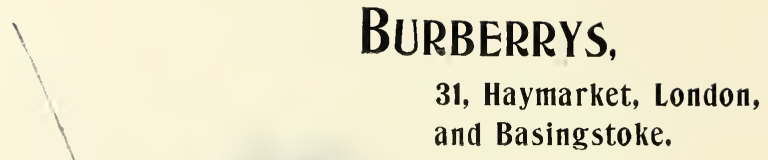

THE SLIP=ON.

The most permanently successful of a series of practical experiments in designs for Fishing Over-Garments, the Slip-on is to-day in higher favour than ever with Sportsmen. It covers the wearer completely from collar to gaiters, and gives absolute freedum for quick movement. It is impossible to speak too highly of its waterproof qualities. Very light, affording natural "armth, it is the one Overcoat for Sport.

"I have been here a month, and had only one fine day. Throughout the whole time I have never had a wet spot."-Signed, GEo. 11. KELSON (IIark-on-Tyne). 
CHAPTER III.

\section{METHODS OF CASTING.}

\section{THE OVERHAND CAST.}

It is generally supposed, and the supposition is founded on sensible grounds, that the ever-youthful Overhand has a right to clain the longest existence, and to hold the highest place of honour among all other methods. This right is never in dispute when the one necessary condition - that of ample space-presents itself so as to render the cast practicable and effective. At those times it can be made "cleaner" than other casts, and then it is the least likely to disturb the fish by the splashing of line.

It nevertheless becomes necessary to say that there are two different methods of making the Overhand, and that one of them is defective, inasmuch as it occasions the loss of flies, and sternly repels all overtures for a long line. 
This time-worn method, however, has a hold on the masses so great, that in describing the correct one, it is desirable to draw a searching comparison between the two.

The old school, accustomed to the same unvaried habit of facing the spot upon which the fly is intended to alight-a habit to be vigorously denounced - are naturally constrained to make a more or less semi-circular sweep of the rod in the background, with the result that the Hly often strikes the earth and becomes altogether useless. The risk run is decidedly less with a limited length of line, but still it is inseparable from the practice. Knowing this, some make the up-cast directly over their head, in which case, though security against loss or injury to the fly is provided, the most consummate skill is required to cover a distant fish.

The new school go to work in a manner totally different.

In these days, the one standing difficulty that presents itself to the uninstructed, is not so much the old question of finding a rod that will do the work, as of acquiring the modern method of using it.

That is the plain truth. Then, what about ourselves? Well, soon after we introduced the type calculated to send the line in the air out of harm's way, rather by the rod's action than by undue force, it remained only a question of a few minutes' practice to bring off the thrash-down at the right and proper moment. Of course we did not pursue the worn-out principle of relying solely on the sense of touch, but took up a position from which we could actually see what takes place from first to last. This change of front is the secret of the whole business.

It may, therefore, be taken for certain that, instead of facing the lay-bye for this cast, as of yore, the angler should stand sideways to 
it, by which means the line is clearly traceable throughunt the process.

Those who care to proceed in this manner will soon find that inspection is made easy and progress safe. Those who object, on the ground that it bores them to turn their head, will always be subjected to those untoward consequences attending the old practice, and will never understand or participate in the immense advantage introduced by the new.

This being the case, it is not only to the lesson, which they may now deduce from the system, that their attention is drawn, but above all to the additional and inseparable benefits connected with it. For instance, one rarely, if ever, hitches his fly in any obstacle behind him; whilst, apart from that, his chances of breaking the rod by attempting the thrash-down too soon or too late, are reduced to a minimum. Moreover, a greater amount of water, even up to twelve or fourteen yards, can be covered easily and properly. This "consummation, devoutly to be wished," cannot be over-estimated.

Now the initial proceeding in the practical demonstration of our method requires but little skill. To get the line sufficiently extended down-stream before the cast can be made, goes without saying. This is done by taking some of it from the winch and making a series of false casts in neutral waters, care being taken to depress the point of the rod at last.

Having arrived at this stage, the position of the hands is considered. As all know, one is placed above the winch and the other below it. But the exact position of the upper hand must be determined by the balance of the rod; the other generally comes in contact with the india-rubher button at the bottom of it. In this connection, one can easily imagine how that cumbrous, weighty winch 
of yore-such an implement, at all events, as necessitated an undue lowering of the upper hand-would complicate matters.

As soon, however, as enough line is set free, the up-cast is begun while the point of the rod is still depressed. If the rod is raised beforehand, the line cannot be forced high enough and far enough into the background - a stroke of policy which, in reality, is the heart and soul of the whole system. In order, therefore, to succeed in so doing - and in this operation success usually comes as a surprise-it is necessary-

(1) To assume the attitude, with regard to legs and body, as depicted in the picture.

(2) To studiously avoid jerking the rod at the outset.

And (3) To check the rod in the up-cast at the angle shown in the picture.

Ultimate success, provided the force applied is gradually yet rapidly increased and the thrash-down begun in good time, is then absolutely assured.

In the up-cast the hands swing together; and we must repeat that the point of the rod must not be allowed to travel further than the angle shown in the sketch before it is checked.

On checking the rod, the thrash-down is delayed long enough to let the line extend itself; but the interval is cut short in direct proportion to the quickness of the action of the rod. To dwell too long for the return is an act as perilous as to err on the side of impatience.

The strongest evidence of skill and tactfulness in conducting the line rearward, is best obtained by suspending the down-cast altogether. By this means the line falls on the ground, and then a personal inspection reduces the matter to a certainty. If found to be 


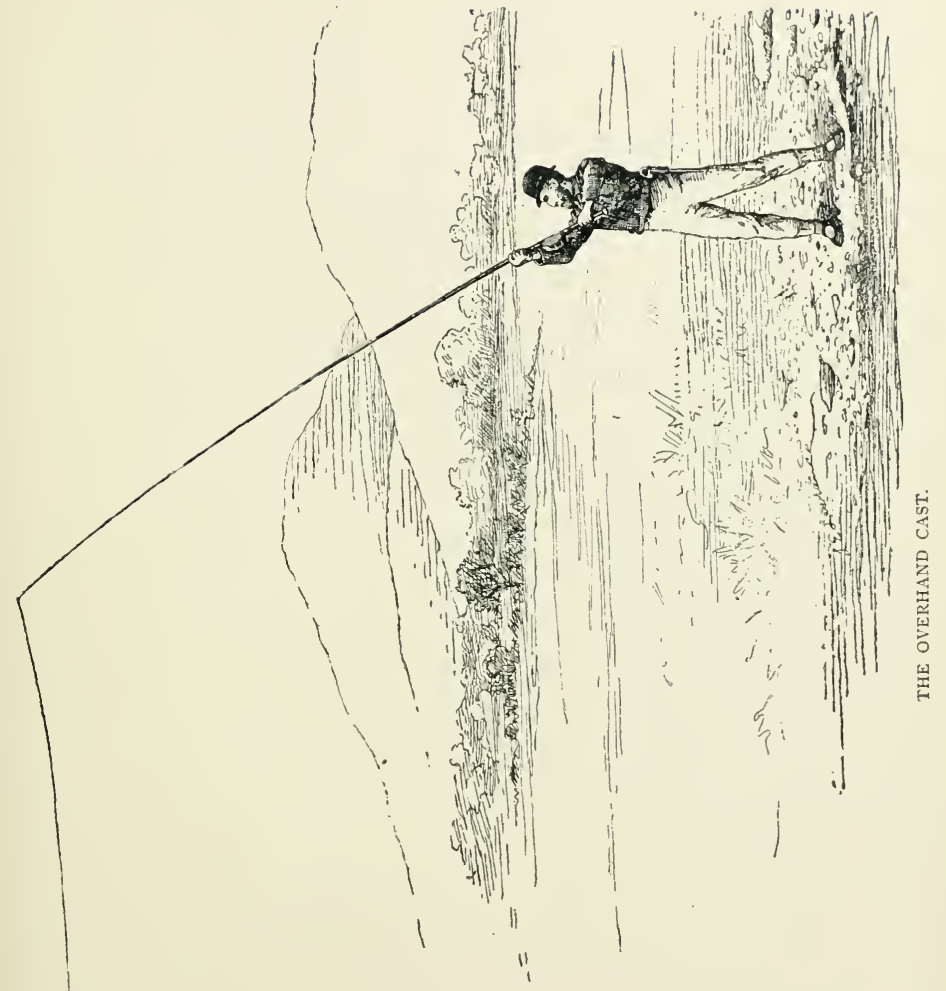


lying fairly straight and in a direction of the lay-bye, it may be taken for granted that the thrash-down might have been effectually made with comparative ease. If, on the other hand, the line is found to incurvate, it denotes that the rod has curved inwardly instead of having pursued a direct course.

The rod barely declines outward in ascent, nor inclines inward in descent; in fact, the closer it keeps to the course taken in raising it, the straighter, the lighter, and further will the line be laid on the water afterwards.

The only exception to this golden rule is brought by the wind when it blows down-stream. This condition, unfavourable to a degrec, nccessitates the otherwise objectionable semi-circular sweep of the rod, the radius of which depends on the strength of the breeze.

When the wind is in that dircction, the fly is very liable to be snicked off.

There is, however, another and perhaps a safer alternative; that is, to use a second fly, or "dropper," attached three feet or so above the tail fly. We hold strong reasons for using one fly only, and never recommend two. To begin with, it is less amateurish, but after all is said and done it is a pure matter of sporting sentiment.

Finally, if the rod is properly furnished with small upright revolving rings, the length of a cast may be considerably increased by what is known as "shooting" line. A previous description of the process seemed to please friends so much, that the following account of it may be appreciated by others.

The feat consists first in the angler drawing from the winch the length of line required; and, whtle doing so, making and placing coils of it, one by one, between the point of the forefinger and thumb 
of the upper hand. These coils, of about a yard in length from end to end, hang down in front of the winch and are lightly held there until the "point of tension" in the thrash-down is reached, i.e, when the line in its forward journey begins to tug the point of the rod. If at that instant the coils are dropped they will be dragged out by the rest of the line; but if dropped too soon, the middle part of the running line will belly down towards the water, and the "slack" will not be taken out at all. In making, say, a thirty yard cast, a four yard length should be shot; a thirty-four yard cast, a six yard length; and so on in proportion. To shoot ten yards through our upright rings is no great feat, provided the line is smooth, properly dressed, and of the right size and weight.

But in wading, when the coils fall from the hand, the current takes them out of position, when an acute angle is formed in the line at the point $\mathrm{A}$, and another at point $\mathrm{B}$, as shown in the accompanying diagram. The force of the current on the lower part $B$, prevents the

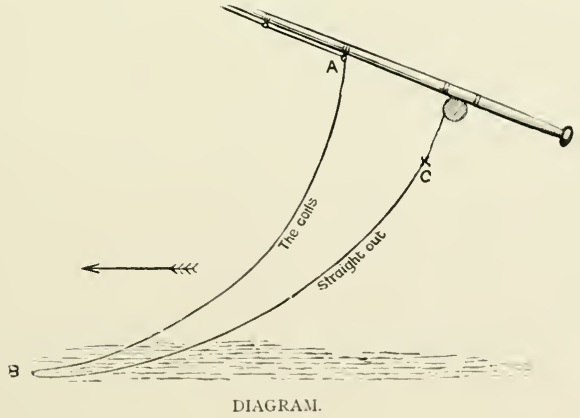


feat being accomplished. This is easily remedied by seizing the winch end of the dropped coils at the point $\mathrm{C}$, and with the lower hand so placed, giving a good snatch to bring the whole of the slack portion back under the bottom ring of the rod, when it will all shoot out as readily as on land. Thus it will be realised, and surely it ought to be remembered, how much the action of the rod can be preserved, and how much more water can be covered.

\section{THE UNDERHAND CAST.}

This method-far easier to learn than the other-is patronised not only by many when a long line is unnecessary, but also by those who, advanced in years, are either unable or unwilling to stand the strain imposed upon them in overhead casting. But here, again, attitude is an important factor, and varies according to the strength of the current. In easy flowing streams, for example, as on land, the angler can stand with his legs close together, and hold his body less sideways than is convenient in rapids, or practicable in the Overhand. He is also enabled to stand in the easiest position of all-bolt upright. In rapids, personal safety is considered before convenience, and the insurance of safety often involves an awkward position. The legs must be kept fairly wide apart, and on no consideration whatever is the back or front turned directly up-stream.

Having studied the Illustration in detail, the angler needs but a 


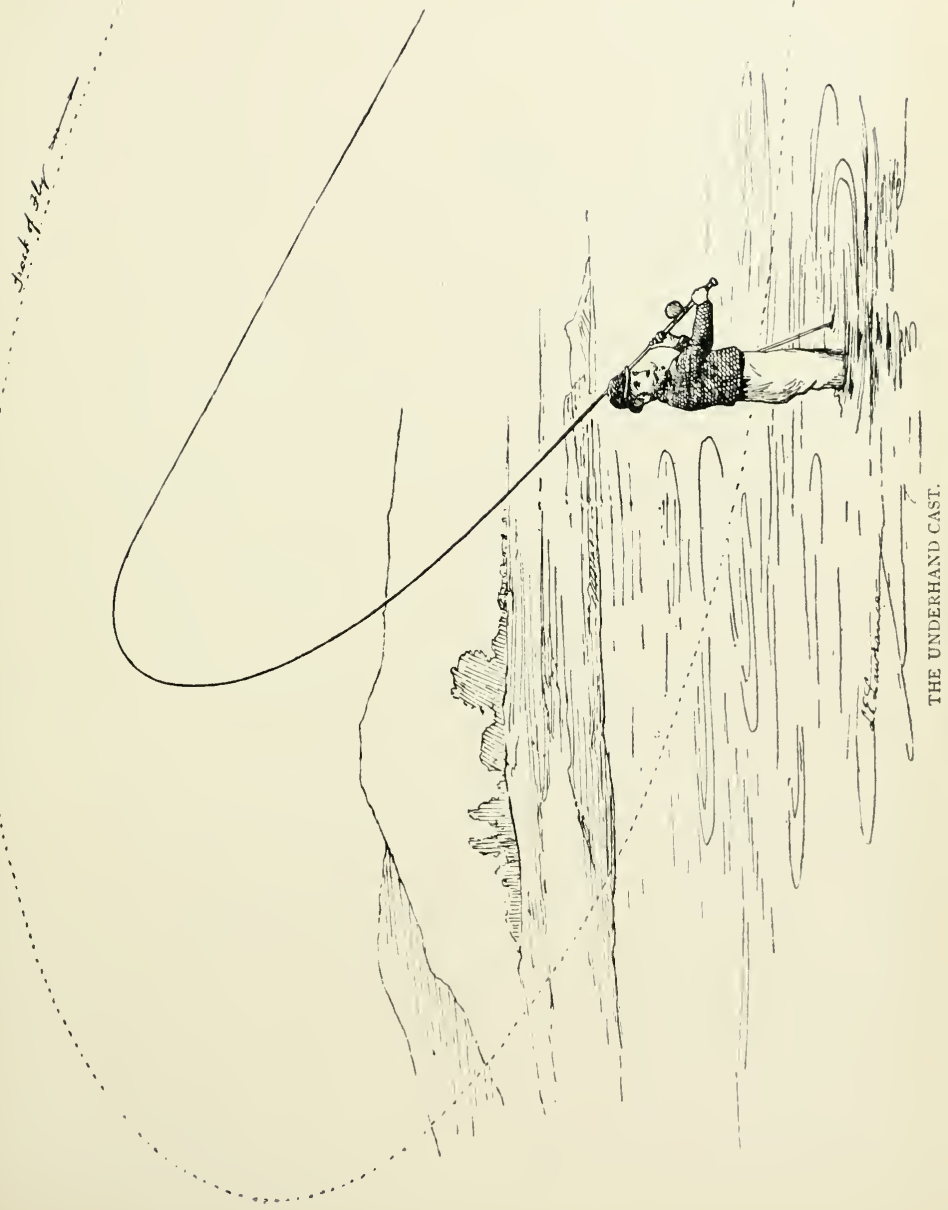


brief description of this method for further guidance. Even the novice would at once discern that the aim and object of the cast is simply to bring the fly from the water so that it travels only a certain distance $m$ the background. It follows that the force required in partially extending the line as shown, is much less than in the Overhand.

If the angler brings the rod up at an angle of forty-five degrees, he will get at the amount of force to make the fly take the track traced in five minutes, or certainly in ten.

Contrary to the principle of dwelling in the up-cast, as in the Overhand, the rod continues its even, firm, regular movement until thrashed down; and not the sign of a pause, nor the sign of a jerk is to interfere with the steady swing of the arms beforehand.

It is no disadvantage to renew a cast while the line is somewhat deep in the water; on the contrary, failure is far less likely. When the line is well below the surface, one fecls rather than secs it responding to the action of the rod, which is kept going fast enough never to lose the tug of the line.

In starting the thrash-down use butt action, pretty much as in the Overhand, and increase the pace, finally letting the rod reach a horizontal position pointing towards the lay-bye. In other words, no checking takes place at the finish. It follows, then, that the rod is thrashed throug/h with that amount of force which makes the point go nearly down to, but not in contact with, the water when the work ends. 


\section{THE SPEY CAST.}

In former days, it was the common practice on Spey-side to "reel up" in boisterous weather. This cessation of work always seemed to arise from certain general defects in the tackle, such, for instance, as a willowy weakness in both rod and line. That, of itself, would place beyond the bounds of possibility the many brilliant innovations in the cast, which are now adopted by those who have studied and practised the latest developments.

To these apparent defects were devoted years of personal attention and work, with the happy result that, after numberless trials and alterations at the riverside, success in fashioning a special style of rod, not only capable of carrying a suitable line, but of complying with all the requirements associated with this much-coveted method, was accomplished.

It may be interesting to recount a few details.

Many years ago, during a prolonged visit with a friend to the then inconparable river Spey, it occurred to us that some means might be devised to obviate the local custom of striking work in windy weather.

"Surely your beautiful Spey cast," we observed to a practised hand, "should not be restricted to calm days an:l light favourable winds?"

"Well, gentlemen," replied poor old Cruiky-once the heart and soul of Wester and Easter Elchies, and the dyen of Aberlour- "If you can't get the line well away, what's the good of wasting time and wearing out tackle?"

"But," we replied, "would not a heavier top joint propel a 
stouter line than yours, and make it cut through an adverse wind?"

"It might, perhaps; but we don't use such heavy laden tackle in the Highlands as you gentlemen in the South."

Be that as it may, the writer soon endeavoured to put an idea of his own into practical shape. On his return home he looked up an old "greenheart" which had belonged to his father, and, having the necessary tools for manual operation, began then and there to re-model the rod in his own workroom. After much deliberation on the science that treats of the laws regulating the power of moving bodies, it was considered that the action fixed upon would make the Spey cast even more interesting and effectual than ever. In the first place it would not only enable one to work a comparatively heavy line, but the weakness, arising from the top joint curving backwards, would never come about. Nor was this all. For it was thought that by the intended reduction in thickness at the butt, and by leaving more wood than is usually seen at the bottom of the upper joint, the line could not only be propelled in the ordinary way more easily, but when necessary, as in windy weather, could even be made to cover distant fish, by means of a direct throw.

This innovation shall be made more evident presently, but therein lay the supreme advantages over the traditional style of rod.

To accomplish successfully our self-imposed task, it was determined to get, by repeated trials, the exact action required. And after a delicate use of the plane, many times over, the rod was tested in different winds, and finally approved.

With regard to the weakness just mentioned, it may surprise many to learn that the top joint of some of the Spey rods is actually made with a backward curve, under the assumption that the power of 
it is increased. We need not enquire who formulated this notion, but we must not shut our eyes to the fact, that the strength of the joint is really reduced. The sclieme itself, by-the-bye, is by no means an adequate exposition of Highland notions, therefore it demands the application of a much abused word-it is unique, in so far that it has no local parallel.

Why do Spey rods so soon bend backwards in use? Our answer off-hand is ready and simple. They do so because the force used in the local manner of propelling the line is considerably more than in lifting it. As a matter of course, it follows that, sooner or later, the rods must show corresponding signs of weakness.

Is a further instance of a similar sort of weakness, consider the inevitable downatard curve which is commonly seen in the top joint of a rod used only for the "Overhand." This arises from diametrically opposite causes; for, in casting overhead, the force used to lift the line and send it towards the rear the distance it lias to go, is far greater than the force required to drive the fly to its destination. The argument, in our opinion, is incontrovertible; it ought to be convincing, and no more doubts and uncertainties should be entertained.

But what of the system for which our new style of Spey rod was devised? We shall now see.

The Spey cast is chiefly remarkable for two distinct facts: (I) That in transit, the line pays a brief visit to the water; (2) That the cast is entertaining to some, exasperating to others, yet the idol of all.

Nost of us know, that it is no small matter to be a great anil skilled performer of the "Spey," for in accordance with the stern decree of Fate and Circumstance, the cast is liable to become 
strangely complex-full of occasional changes requiring swift realisation and treatment, and then fuller of pitfalts in the path to a sound elementary knowledge of its marvels.

Those who best know will tell us that it were well for the student to pay no attention to certain tricky variations which suddenly and inevitably arise. It is easy enough, they say, for some individuals to get into the knack of the earlier form of the cast, even at sight. But as to the multiplicity of embarrassments, now involving this acknowledgment, and now that, with lightning rapidity, e.g., when the violence of the elements has the bad taste to fly in the face of science, to say nothing of covering a fish at right angles, then only a past master of the craft, with personal gifts of a special kind, can do justice to the possibilities at the command of his rod, and to the inspired mind that worked the whole system out.

Seeing that no man can specify the exact degree of muscular power required, there is admittedly one drawback, even in describing the earlier form. For instance, some people never imagine how little power is wanted until the moment of realisation on the scene of operations. Others, who overstrain the rod, fail. Certain it is, that in giving too much force at starting, the line is lifted too far for the thrash-down to be successful; and, in giving too little, not far enough. But still, in practice, the earlier form of the cast is a great relief after other methods, as very little effort of the muscles is needed to accomplish it.

A little practical experience on the following lines may soon make the obscrvant student proficient.

In practising the "Overhand," for example, use sufficient force to thoroughly extend the line in the background ; in the "Underhand," 


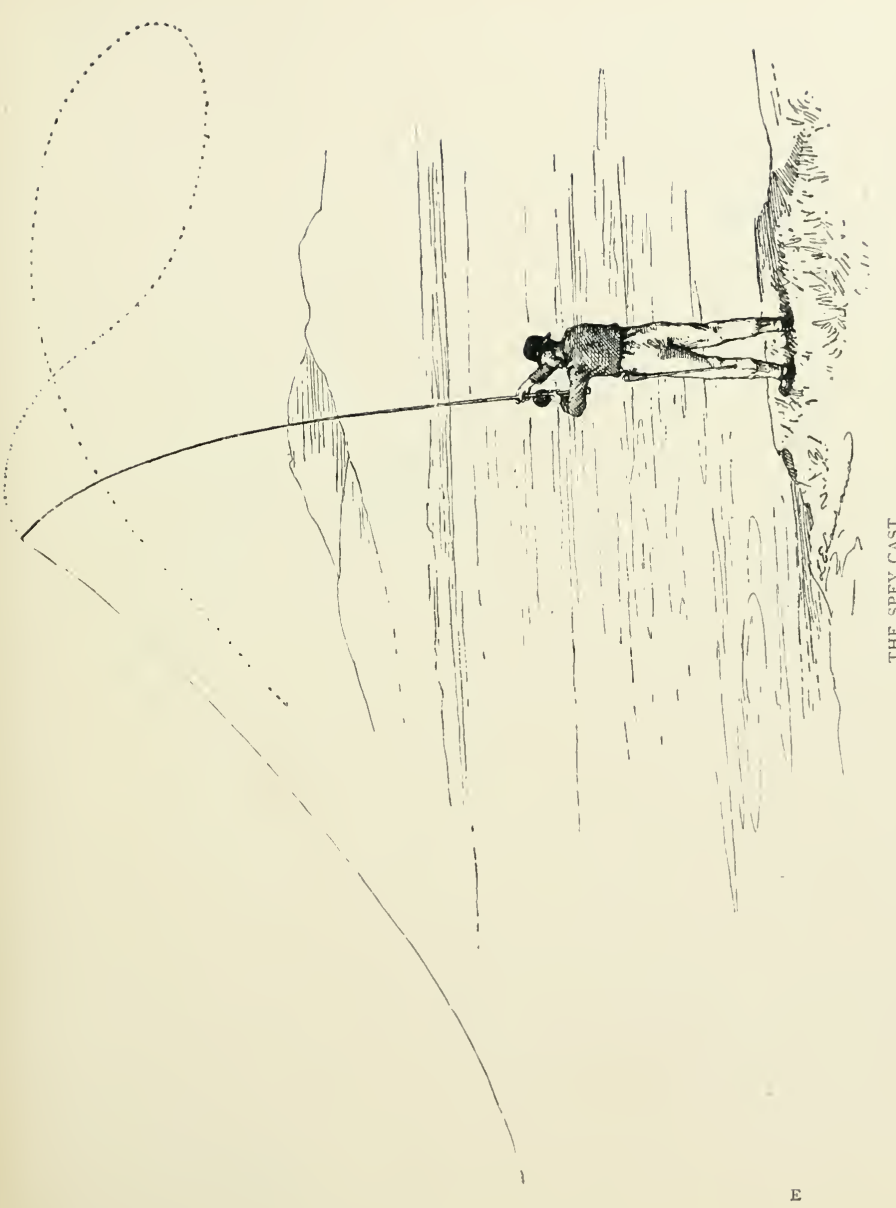




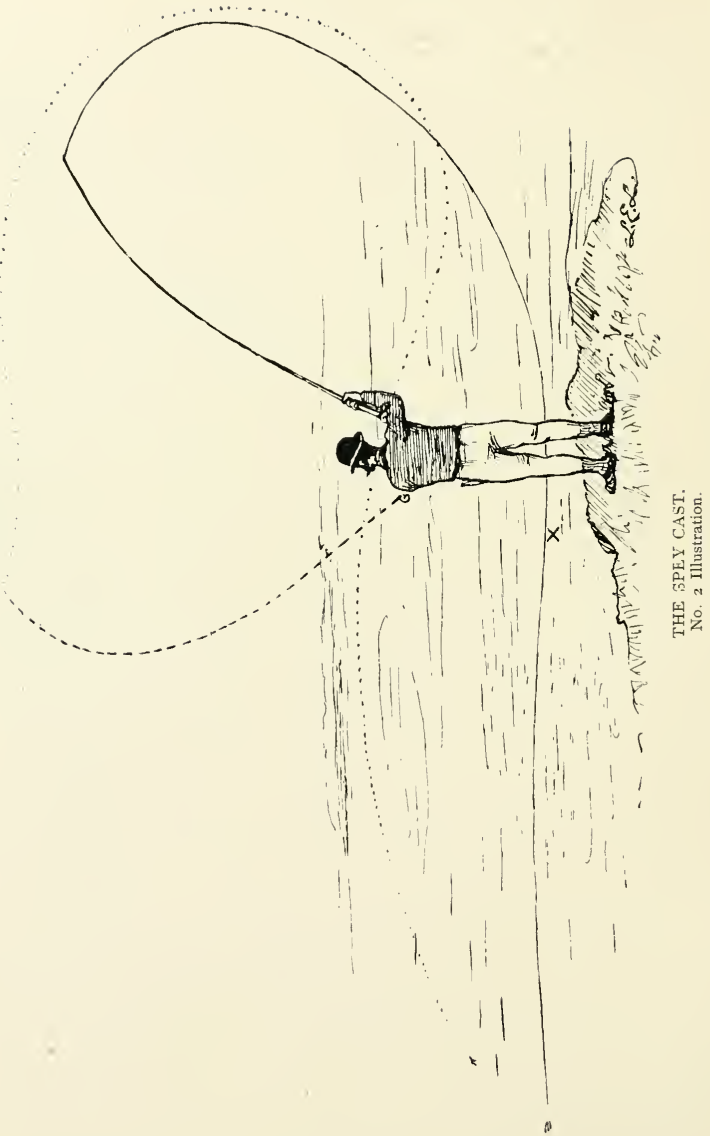




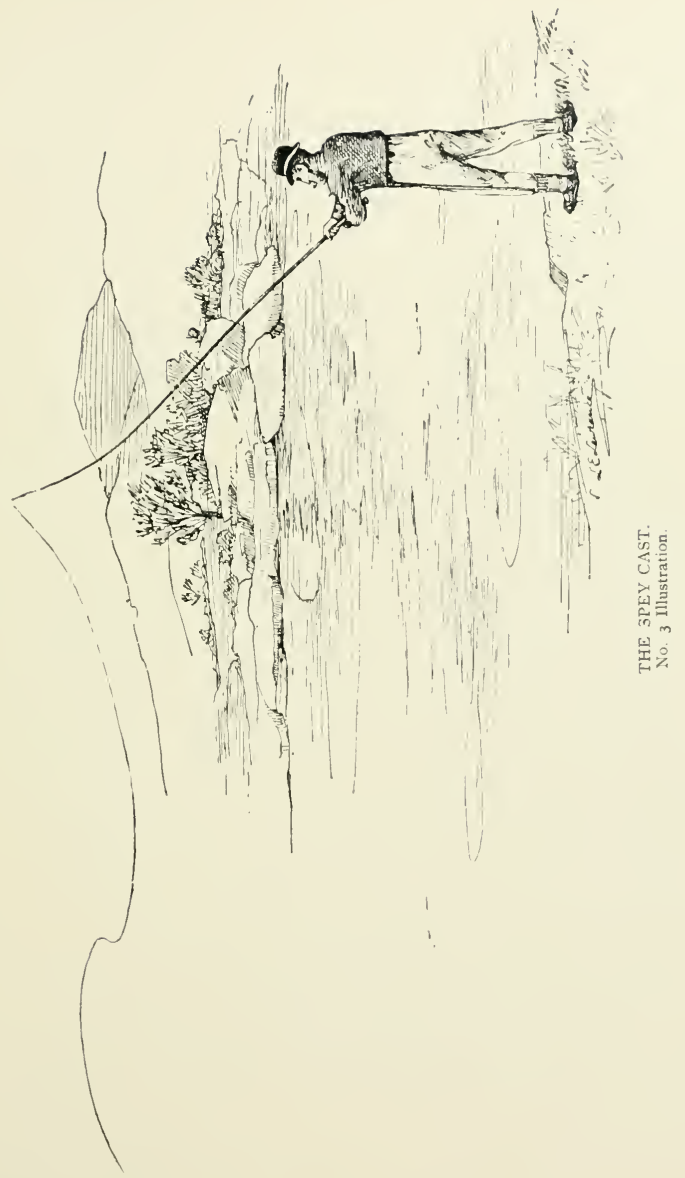


use force enough to extend the line half the distance; and in the "Spey," merely use enough to drop the fly beside you.

(Note that you are obviously intended to understand that, but for the early influence exercised over the line by the thrash-down, the portion that "visits" the water beside you would remain in it.)

It must, however, be admitted that the question of force puzzles people in general. But from this standing conundrum, which, like the Socratic dialogues, raises a problem incapable of any positive solution, we turn gladly to observe that in Spey casting there are ta'o ways, that the operation begins with as little delay as possible, after the rod is clcatcd, (shown in Illustration I); and, that the rod does not descend below an angle of forty-five degrees until completing one of the two down-casts.

Of the two ways, process $\mathrm{A}$, for example, necessarily compels a rather long length of line to run along the water beside the fisherman all at once. Process $B$, allows a very small portion to do so-not beside him, hrwever, but higher up the river. $A_{1}$ is practised in steady, flowing waters; $B$, in fast, rough waters. But if the untried hand desires to excel in the cast, it is most important that he should first read and thoroughly digest all there is to do and howe to carry it out, and not until then shonld he practice till he masters, bothe right and left handed, the frocess $A$, when hi may apply himself steadily and actizely to the conrse of opcrations in 1 .

These words are emphasised by reason of certain observations not uncommonly made on verbal description.

"Oh! I slaall never understand it. It can't be explained."

"Nonsense, you won't take the trouble to grasp what is said."

"Well, you talk about the line on its inaterd journey, and say 
the rod first moves outarards. Isn't outwards opposed to inwards?"

"You were told that by using the word outwards, we meant away from the fisherman in a direction which would make the line come inwards."

"Ol, alı! I forgot that."

"You must forget nothing."

Ilowever, leaving for awhile the thrash-down, what has the fisherman to do in process $\Lambda$ ? - which he would do well to read twice over.

The answer is, that he has to lift the line out of the water so that some ten yards of it next the fly is brought in contact with the surface beside him (say at the point $\mathrm{X}$, which represents the fly in lllustration 2), and there made to skim along past him a short distance, from left to right, in order that the thrash-down may be rendered safe, practical, and effectual. In its passage towards him, the line should travel as near the sufface of the river as possible

That, in the briefest of words, is what he has to do; the rest is mere child's play:

But how is this to be done? That's the question.

The leading movement of the point of the rod is neressarily against the current, outwards, cownwards, and away from the person in a right hand direction. In pursuing its course, the rod comes round in a pear-shaped sweep towards the person till it reaches a point in the air, which would be indicated by the right arm extended slightly above a horizontal position, and slightly in front of a line made by the two arms extended as on a cross. $\Lambda$ s soon as this point in the air is reached, the fly, away down stream, quits the water, at which moment the thrash-down is commeneed and carried out, obliquely across the 
body fron right to left.

Observe (I) that if the thrash-down is started later, the curved part of the line may possibly range astern as far as the fly is made to circuit in the Underhand-at any rate, too far for the orderly achievement of the object in hand. (2) That the line should be brought round within, or but very little outside, the track taken by the point of the rod; (3) That there is no pause whatever in the rod's movement, which is one incessant and undivided motion, not varying in pace until the moment comes for the thrash-down. And remember, that even resolute adherence to these tactics may yet be rendered futile by the intervention of the wind.

The thrash-down, however, is practically a thrash-through, seeing that the rod, as formerly stated, is not checked at the finish.

In this thrash-through, the centrifugal force (which emanates from the generating centre of the butt, i.e., where the strength is applied), continues its course along the rod, expelling the line, and exhausts itself during the transit of the fly from water near the fisherman to its destination.

The second and more effectual way differs only in this: That, in renewing a cast when the rod has been elevated as before, instead of dragging the line along near the surface, it is made to take an extremely sinuous course higher from the water (see dotted line, Illustration 2). This is accomplished by a slightly varied moacment of the rod at starting. In the former case, the line is first animated by the rod moving against the current, outwards, downwards, and away in a right hand direction. In the present case (see Illustration 1), the line is first set in motion by slightly raising the point of the rod in journeying outwards, from which position, however, it diverges in 
precisely the same manner as before.

The point to which the student's attention is specially called is this: That in certain instances as, markedly, in the case of very rough waters, defeat would be inevitable if too much line were allowed to run along the surface at any given time. It stands to reason, that choppy waters and rapids are very liable to plunge the floating line into confusion, and dash it to a depth from which the rod could not recover it in time to complete the cast. By reducing this floating portion from ten yards or so to a few fect, the current has much less chance of "qucering the pitch." And it is precisely to the slight initial movement of the rod that this reduction of floating line is due.

The question as to where this same portion strikes the water, now remains to be dealt with. For the experienced, who habitually pitch upon the right spot with unerring accuracy, it might be decided as a moral certainty; for beginners, as a possibility depending upon a possibility. For instance, a wild and increasing descent of water entails the necessity of casting with more and more speed. Is it not, therefore, perfectly plain that the point of contact varies, and takes place further and further up stream? while the distance is, of course, regulated by the degree of strength applied.

The difference between the two ways- $\Lambda$ and $B$ - may appear to the uneducated eyc as being very insignificant, but the effect produced on the line at starting in B is, at all events, sufficient to establish the belief, that by this "slightly varied movement" the hest results can alone be obtained.

In either method, the line can be cast along the water from the butt of the Spey Improved Rod in the usual way, or, in case of necessity, as for instance, in rough weather, propelled through the air 
(as represented in lllustration 3), by an increasingly powerful throw from the top joint.

This throw, impossible with the original Spey rod, is quite easy with the modern type. llence it may sately be affirmed, that the beneficial effects of this new style of rod are now made "more evident."

It is the wish of many more than one to say that Farlow, who has supplied this rod for some little time, so thoroughly understands the action required, that on one recent occasion, a butt having been fractured, he forwarded a new joint which wanted no alteration whatever. In this emergency he is in front of all rivals.

To go back to our former observations, we shall not attempt to exhaust the catalogue of difficulties arising from time to time, nor is it necessary to enumerate them all. But in the limits assigned to further comment, it is desirable to mention that we are occasionally compelled to reverse the position of the hands. It is not very easy to read the signs which suggest this change, but when the wind, crossing the water, blows the line actively engaged towards the inner side of the river, to put the lower hand in the place of the other is a matter of dire necessity. On these occasions, the line is frist brought towards the right shoulder (as usual), by working with the left hand above the winch and the right below; and then, on bringing the rod round in due course arer onc's head, from right to left, the down-cast, with the hands so placed, is readily effected.

This variation is perhaps the only one in which the uninstructed, notwithstanding their acuteness of perception, are liable to galling and unceasing defeat.

For this ideal cast, further than it has now been described, there 
is this yet to be sad. The "Spey" is not so " clean" as the Over or [nderhand, yet it is often surprising what can be done with it. On being master of the method, which the angler will find is the most fascinating of all, even those ormamental reaches, densely shut in by trees, and sometimes teening with fish, can often be very easily worked. And it is just under these conditions, when a long line is imperative and all other casts are either impracticable or ineffectual, that its value is most highly appreciated.

\section{THE SWITCH CAST.}

This cast is transacted in the foreground. No portion of the line ought to reach a point behind the rod when tilted at an angle of fort $y$-five degrees beyond the angler's right shoulder.

It will therefore be seen, that although it can only deal death and destruction within a comparatively limited area, the Switch is eminently suited for places where the space to work the rod is even less than at those adapted to the Spey. The places where it has to be used, to put it plainly, are those in which clustering boughs, or upright rocks, close in upon the water almost immediately behind the angler, and interfere with the full play of the line in other methods.

The nature of the cast is as follows:

With the line extended down stream, the rod is brought up to and past the position secn in Illustration 1 , and when it reaches an angle of forty five degrees in the background, the thrash-down is made without interval, and without causing the line to "circuit "more than two or tinree yards behind the angler.

But when the rod is elevated, and the line is brought in contac: 


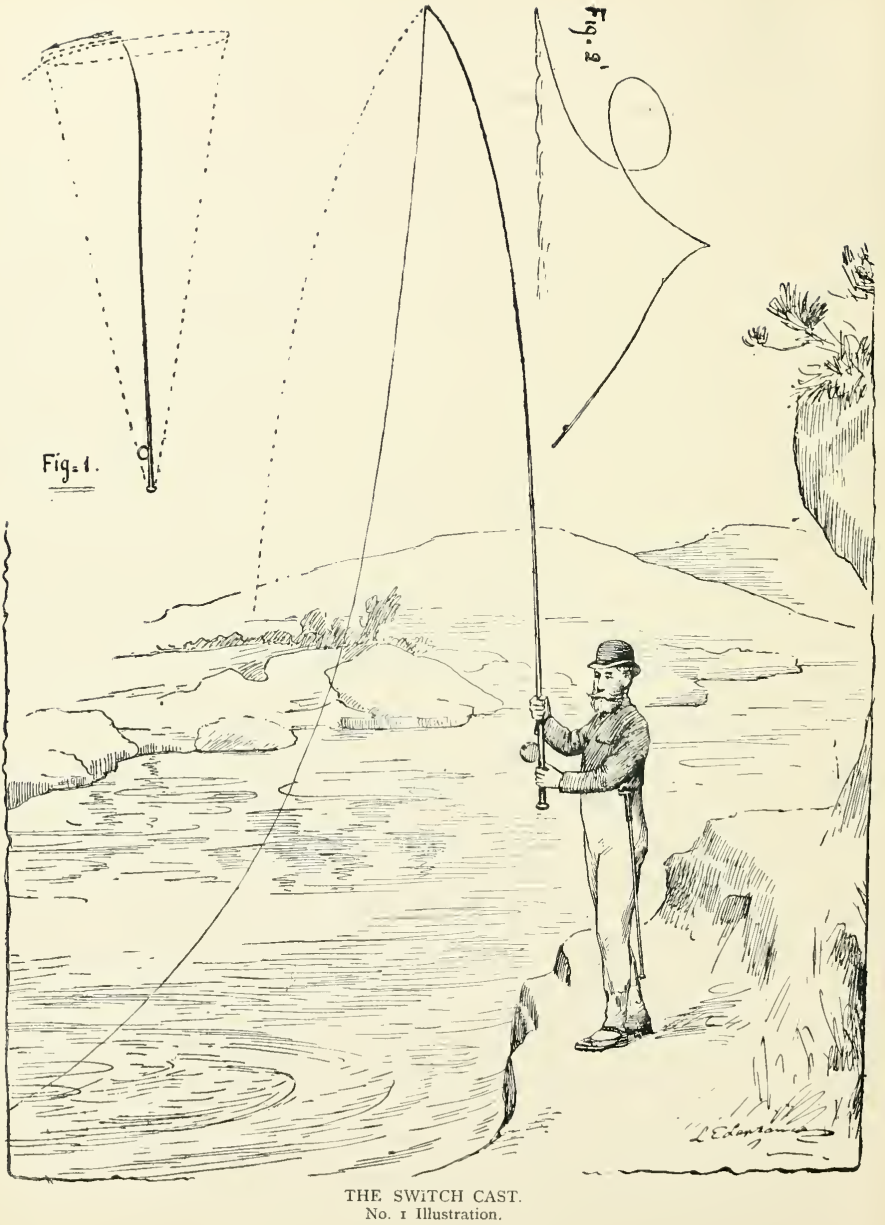




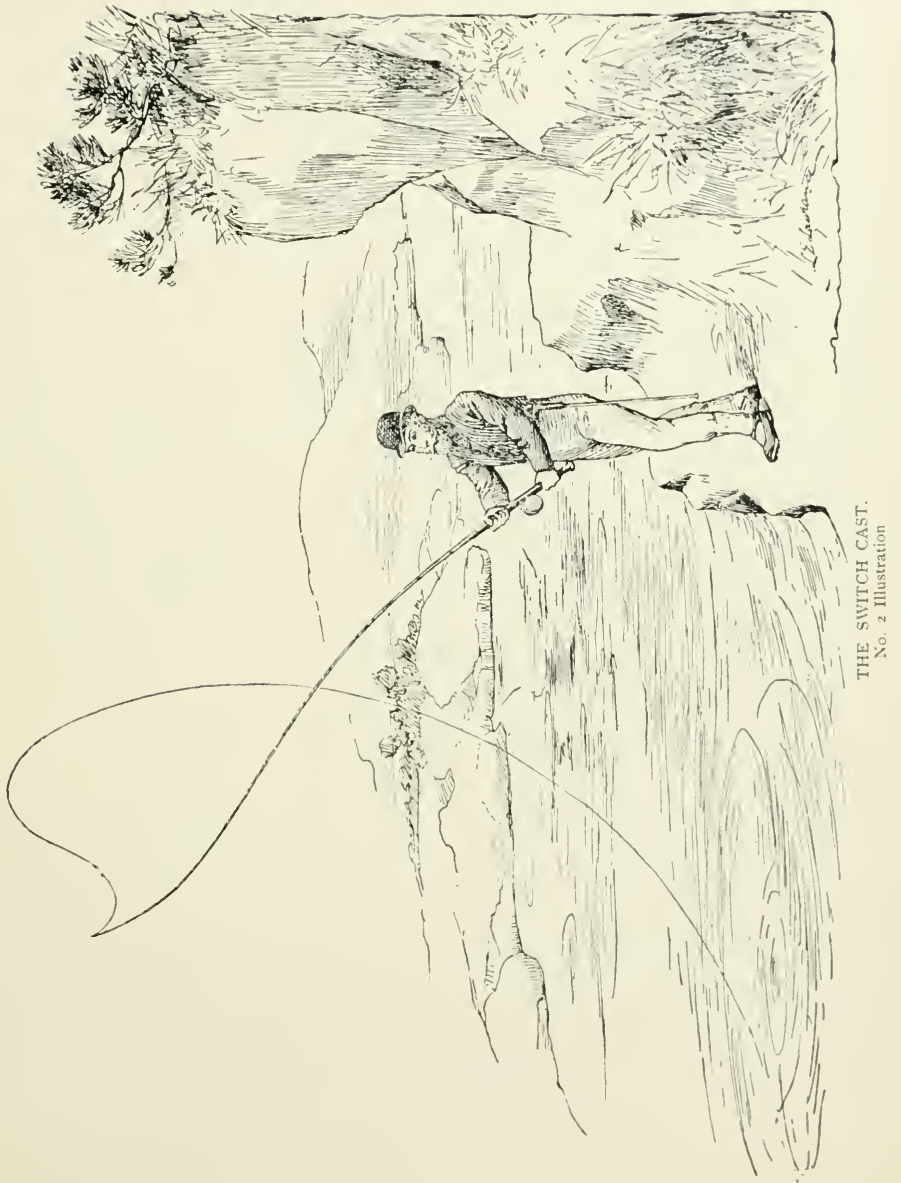


with eddies, helping it on rather than holding it back, the line will belly inwards so much as to require handling in a different way. The object is to make the line belly outwards (as shown by the dotted line), so that, in making the thrash-down, it tugs the point of the rod. This is achieved by a little trick called "The Peter." This trick merely consists in twitching the point of the rod very slightly forward, and bringing it round in a very narrow oval, from right to left above the head, when the thrash-down can be successfully effected.

Besides this use of the cast, Switching is frequently resorted to for the sake of relieving the monotony of promiscuous false casts, when in any cast the line is so badly buried that it will not come up without seriously trying the action of the rod.

Those who have received no preliminary training may like to know that the down-cast is made by thrashing the rod through as already explained. The merest tyro would acquire a definite knowledge of the process in five minutes' practict.

\section{THE WIND CAST.}

This cast is seldom or ever adopted except under very exceptional circumstances. When those blasterous gentlemen, Libs, Notus, and Auster are fighting out their battles on the surface of the waves, the timid and prudent fisherman is better indoors. But if he, is determined to persist in the face of such difficulties, he will do well to acquire a definite lnowledge of the IVind cast.

It consists of an upward pull of a most forcible character, of a kind that hoists the line straight up above the head. The instant it gets there the fisherman's business is, with a strong thrash-down, or thrust, to send it straight forward again. As a matter of fact it 


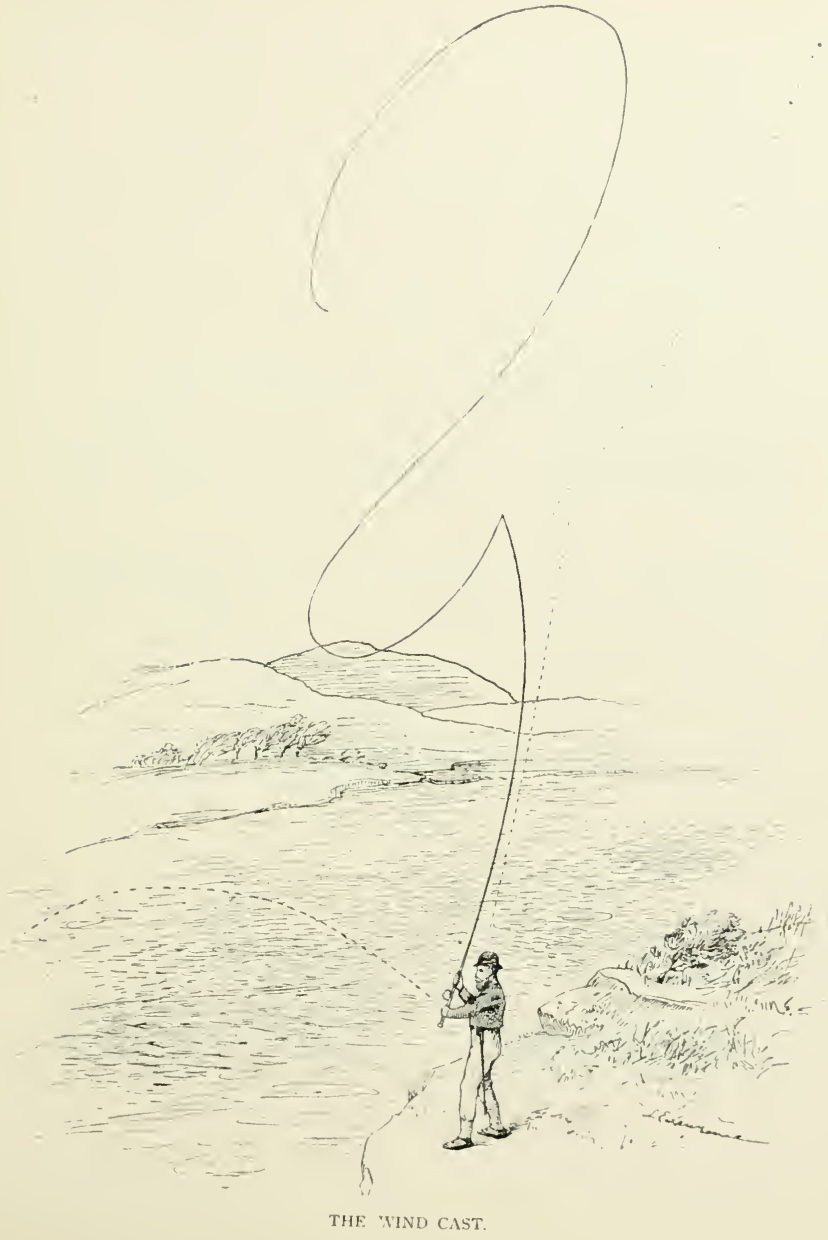


resembles, in some degree, the business of the King of France in the story who marched up the hill with 20,000 men, and when he got to the top-marched down again.

If the line is lifted so as to take the course indicated by the dotted line in the Ilhustration, the thrash-down requires less force to bring about better results than if the rod were manipulated in any other way. In fact, by no method can the line be made to reach its destination in such a perfectly direct course, provided that it is not lifted from swirly waters, or that a sudden gust does not interfere unduly with the process of the operation.

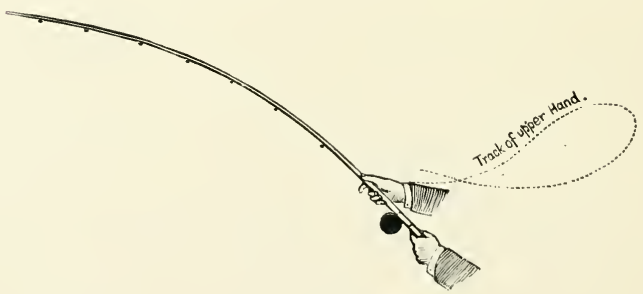

DIAGRAM.

To attain the initial force for the up-stroke the resistance of the water has to be utilised, under which condition it is a case of "pull devil, pull baker." Facts must needs be faced, but still this style of casting-the latest born of Time-is looked upon with a much more favourable eye by tackle-makers than by fishermen, and should only be adopted by the latter when they are determined to kecp at their work rather than go peaceably home. 
38 AWARDS AND GOLD MEDAL, PARIS. Ig00.

\section{Read what "The Field" says:}

"It is to Messrs. Hardy, of Alnwick, we owe the supremacy we have achieved as Rod Makers. . . They have left alt Competitors hopelessly behind."

\section{HARDY'S FAMOUS}

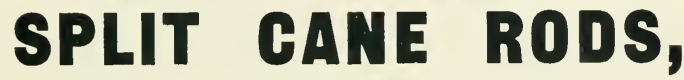

WITH AND WITHOUT STEEL CENTRES,

AND THE

"ALNWICK" GREENHEART RODS

The "KELSON" Improved Spey Rod, 17ft. $3^{\text {in. }}$

See Page 133 in this Book.

The "HI=REGAN," an Extra Powerful, ifft.

The "PENNELL," an Extra Powerful, $14 \mathrm{ft}$.

The "Halford Priceless," the "Houghton," the "Pope," And other Special Dry Fly Trout Rods.

\section{SALMON FLIES}

Tied with our Untarnishable Tinsels.

LARG ILLUSTRATED (ATALOGUE, FREE!

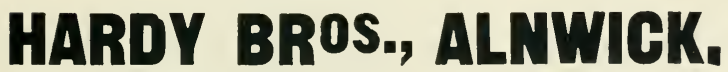

Edinburgh Branch: $\mathbf{- 5}$, South St. David Street.

Manchester 13ranch:-14, Moult Street, Cross Street.

London Branch:-61, PALL. MALL, S.W. 


\section{BURBERRYS,}

\section{1, Haymarket, London, and Basingstoke.}

\section{THE WEATHER=ALL.}

Embracing the characteristics and best features - the roomy, easy fitting Shoulders and Slip-on Sleeve. Recommended of "Slimber" Combine or Coating "Urber" Combinc. The Sleeves and Shoulders being most exposed to wet are protected by Burberry's Weatherproofed "Urber" Silk or "Urberette." The Weatherall, so constructed of "Slimber," weighs easily under two pounds, and can be carried in a Satchel (supplied) of a few cubic inches.

"As rainproof as Mackintosh; a Coat that leaves nothing to be desired"-THE FIELD.
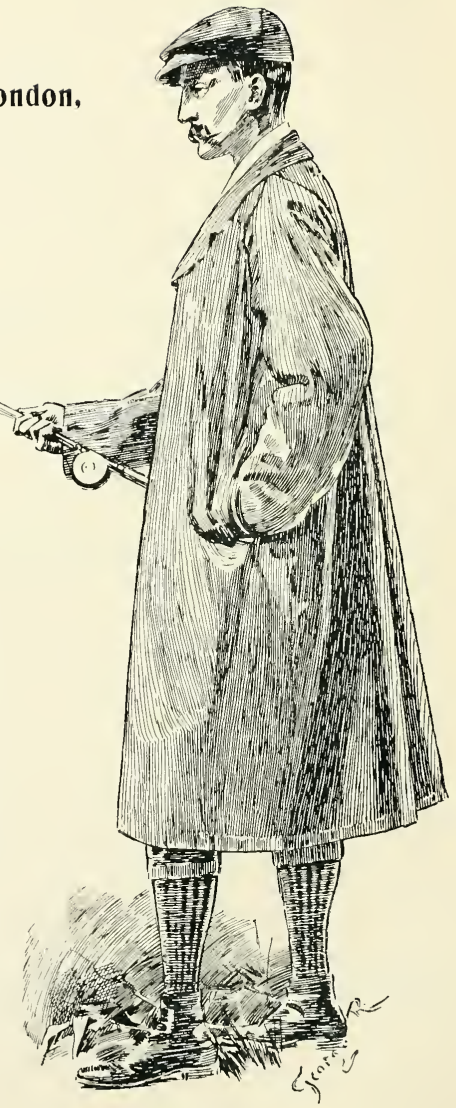
TIPS.

CIIAPTER IV.

\section{RIVERSIDE HINTS.}

Oblivion quickly shrouds the majority whose exploits have never been brought before the public by means of the Press. At the same time, nien have lived and achieved things which flash back on the memory as vividly as in the age when they were our daily talk, and which no author of angling records would willingly let die. Instanees could be cited, but one in particular is admissible here, because it serves to increase, in an admirable manner, the significance of certain points in this cliapter.

The hero of the story-known as the "Professor" to his intimate associates, but whose identity is not of the slightest consequence possessed a strange individuality. Of high birth and considerable wealth, he had a retiring, if not a recidedly mornse, disposition. In London he shunned not only the society of his kind, but actually went 
out of his way to avoid the lady of his heart. In fact, he wrapped himself in obscurity, and killed time by attacking with much skill, passages of Spohr and other classical composers on a "Strad," sweet in tone and of untold value.

But though his ability as a musician surpassed that of the average professional-besides his violin he had a remarkable tenor voiceonly those whom he constantly and lavishly entertained at his distant fishing establishment, realised the fact that his knowledge on angling matters equalled, if it did not excel, that of any other mortal living.

The writer once had the privilege of seeing this gentleman closely engaged at the riverside. On that memorable occasion, he not only demonstrated in a wonderful manner the niceties of the fisherman's craft, but in the evening, having obtained by a quaint coincidence, the consent of the lady he wished to marry, he amazed the room by insisting, with characteristic shyness, on the ceremony taking place in private.

The tale is, however, profoundly instructive, not without humour, and yet, alas, deeply tinged with pathos. But perhaps certain details should be given in order that the student may fully appreciate the conditions under which the actual achievements occurred.

One word to begin with.

To sit in some pleasant place, either bower or bothy, within the hearing of rapid waters and splash of salmon; to be in the genial company of some painstaking student, ever ready for a few hints as to the best method of overcoming a stubborn fish, has always been the delight, in fact, one might almost say the highest privilege, of the professed exponent of the art, who, notwithstanding that he displays the practical side of his nature in having a necessary stock 
of flies, is ustally blessed with a quiet and sentimental disposition.

Ilow often has a spectator unburdened his soul in this wise: " Mh, sir, you're out of luck to-day. You're fishing well enough for anything, and if they won't take that fly of yours they'll take nothing."

No doubt, it is the part of the cducation of a gillic-at least a good gillic - to encourage. But it would be far luetter for lim to say : Yes, you have covered the pool right enough, but to speak the truth, you entircly failed to present the fly in such a way as to induce the fish to acknowledge it in any form whatever.

Students, as a rule, make the same old-fashioned sort of cast, and let their fly travel in the same old fashioned sort of way on every occasion. Now there is a variety of methods, measures and manocuvres, every one of which is best for its own special purpose.

For instance, suppose a pool has the following characteristics, viz.., the first five and twenty yards at the top, a straight rough-andtumble piece of water, tranquil on each side, followed by a succession of imperceptible eddies, which, in a manner of spcaking, are perfected by the fact that the current here flows somewhat slower; while the lower part consists of one large "slack" well within reach, above which the main stream divides, one half flowing towards the opposite side, the other coming towards the bank we are on.

A pool of this sort has many lay-byes, and three separate Catches in ply according to the season, and the height and colour of the water. Fish would rest in the Slack at the tail, when the water runs high; in the middle part, when of medium height; and when quite low, at the top section. But for the purpose of illustration, how should the pool be fished?

On starting operations at the head of the water, whatever 
description of fly is used, it must on no account be allowed to pass in front of any one single lay-bye head first. This would assuredly happen under the foregoing conditions unless some precautionary measures were taken, because a portion of the line would be carried away by the rough water, and "bellied" some distance below the fly.

Let us be quite clear on this point. There, on the crest of the swift, wave-like current, romping between the fly and the fisherman, some yards of the line are swept along at full speed, naturally dragging the belated fly, not broad side on, but head down stream in a course quite different from that it should take. Left alone, the fly could not. possibly right itself soon enough, that is to say, not until the stream had carried the line across into neutral waters. Accordingly the whole proceeding would be worse than useless. It would not only fail, but scare the fish, and probably bring on a "fit of the sulks," thus reducing, if not ruining, the chances of success for some time to come.

What, therefore, are the precautionary measures necessary?

To put it briefly, the cast has to be "mended." By no other operation can the fly that falls beyond the rough water, where it ought to fall, be properly presented.

The method of mending a cast, though simple, requires practice, and is generally found least difficult to master on water where it is most wanted. The object is to get that part of the line, which is being bellied by the rough water, back, or rather well beyond the place where it originally fell, so that the fly is compelled to take a correct course. This is managed, as soon as the line falls on the water, easily and effectually, by making a quick horizontal movement of the rod inwards, and, with plenty of wrist action, a smart semicircular swish back again. It is notorious that there is considerable 
disagrement as to the utility of this operation, but as a matter of fact, it is the salvation of the whole business, and yet only the prelude, as will be presently shown, to a sustained effort to meet further contingencies. To omit the performance at the pool in question, would simply mean that your fly must always go the wrong way and never stir a fish into action at all.

If the policy of "mending" is something of as conundrum to anglers at home, men quite up to or even above average form, what about the rank-and-file on active service? Their defeat is absolutely certain. This is not prophecy, but the logical outcome of the facts and factors of the case.

What volumes could be written on "divided opinions"! To be candid, there is hardly a mechanical action found necessary to be adopted, hardly a single stroke of policy that now makes clear a hitherto obscure problem, on which we are unamimous.

IVitness, for example, the widely different ideas expressed on the modern system of choosing flies. How often the majority of men are seen struggling with their fly-books in a sea of doubt! On this subject, however, we have already enlargect in Chapter II., where it has been set forth in great detail, so as to show how experiments suggested by cliange, of weather and temperature present themselves differently to different minds, and consequently induce one set of men to pin their faith to schenes of one kind, while others are led by some variation of circumstances to swear by manceuvres of a different "cast." So long as the noble art of fly fishing engages so many and various minds in its pursuit, so long will differences of opinion arise, and the old proverb of "Quot homines, tot sententia" will be verified ancw. This, however, does not prevent us from asserting that 
amidst the apparent chaos certain well defined principles will be seen to stand out.

To return to our Catch. By the time the mending operation is done, the fly will have reached the current, and then while coming across, its pace can be regulated by a judicious management of the rod that keeps the tackle taut. For example, the pace can be checked by holding the rod still and depressing the point, or hastened by bringing it round to the near side at the exact speed desired.

The salmon, let it be understood, would lie close to the edge of the rough water on one side or the other. Those fish meaning business on the far side will jump at the fly full-drive the instant the rough water accelerates its passage. But as the fly would decrease its pace on reaching the inner lay-byes, common sense dictates that, in coming through the more tranquil water, artificial means must be adopted to keep it not only on the move, but up to the speed required. Consequently the rod must be brought round by a "sustained effort," as already said, to the near side, and at the right and proper time.

To continue, we are all more or less aware that fishermen are often the creatures of circumstances far beyond their control, but it is certain, if anything is certain, that in the event of salmon jumping short, the angler must retire for a few minutes and mount a fly one or two sizes smaller, or cut off the gaudy "sides" (probably of Jungle and Summer-duck) from the one he is using. Should this plan fail, a fly totally different both in type and colour should be tried. Two casts with the changed fly usually constitute a sufficient test.

When winged flies are no good, many are apt to overlook the fact that a Grub often has a successful issue. However, prior to giving in, allow an interval to elapse of from ten to fifteen minutes, even 
longer if a flash of brighter weather is approaching, and then treat the Gish to a passing view of their favourite lure, that is to say, the "Purple King " on the Spey, the "Gordon" on the Dee, elsewhere, probably "Jock Scott" or the "Penpergwm Pet."

If on these occasions it is found necessary to use one of those old Standard patterns, it should be full-fledged and three or four sizes larger than any of its predecessors. In addition to this, the frsherman should stand further away from the water, hold the rod high in the air, to avoid "bellying" as much as possible, and fish the fly quickly.

What one man can do at these puzzling places another can. The superiority in personal initiative, and the ability to apply what one knows to new and unforeseen contingencies, are, and must be, the prerogatives of the master hand. By close attention to minute matters of detail, the importance of which is generally so little understood, the angler's success is of a decided character, and is shown to the best advantage at these particular Catches. When salmon are there, and rise in the mamner known as "heads-and-tails," one ought to be able to make them take a fly of some sort.

On coming to Catch No. 2, where, as formerly stated, the rough water flows more steadily, the line must be dropped lightly into the eddies on the far side, short steps should be taken between each cast and the fly should be comparatively small and quiet in appearance. In this Catch also, save early in the Spring, the salmon would lie on the edge of the current, and when the fly falls in the oily water beyond, they will see it a long way above them. The farther they come for it, and the faster they travel, the more surely they take good hold.

But, as already intimated, here the method of tactics is materially 
changed. Instead of having to mend the cast so as to defeat the action of the water and reduce the speed of the fly, advantage is taken of the current to hasten it.

In doing this, allow enough of that part of the line nearest the fly to have free access to the current. Take care that the rod is held at such an angle that only a due proportion of line catches the current, when the small fly will "play" with unerring accuracy, and in the most alluring manner possible. In the absence of spasmodic efforts with the rod, it will come steadily across without a jump or even a twitch.

Latter-day experiences have shown that no early attempt should be made to play a sombre fly in this sort of water by any method whatever. And it is as well to bear in mind that a short, sudden movement of the fly, at times imperative, is a mode of presentation always kept in reserve.

Sometimes, no doubt, the average angler, while giving his warmest wishes for success to some prominent brother of the rod, has felt a touch of envious regret because, through no fault save inexperience, he is doomed to miss many chances which the more experienced fisherman will bring off. As aforesaid, the success of a really first-class man is usually of a decided character, but with his small fly on dull days - the fly scantily clothed in the most unpretentious style - it is simply wonderful. On bright days his modus opcrandi differs altogether, not only in so far as the choice of fly is concerned, but also in the manipulation of the rod. His fly, gaudy to a degree, is in keeping with the smartest pattern of the river, and being large, it is made to travel unusually fast. Should it be composed of seal's fur adorned with short hackles and a change 

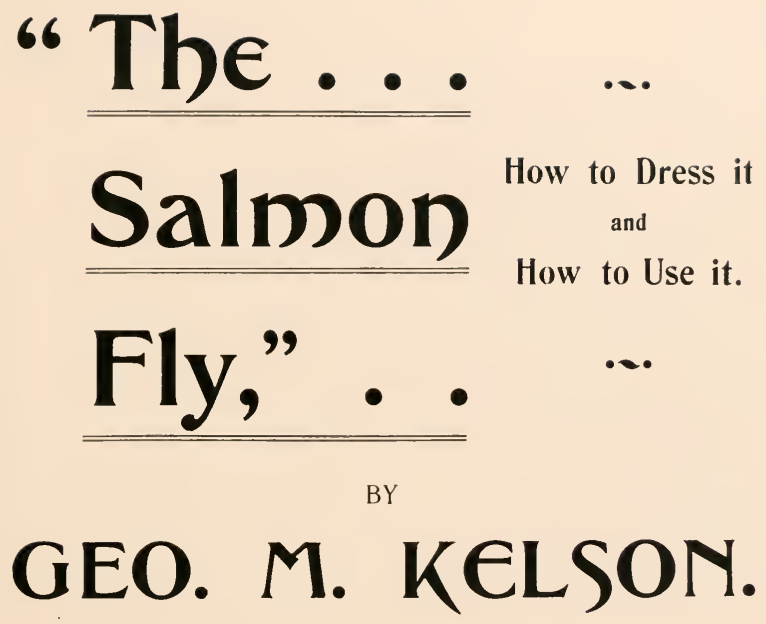

(See Press Opinions, p. 162).

To be had at

Farlow's, 191, Strand, and direct from the Author, 25, Victoria Street, Westminster.

ONLY A FEW COPIES LEFT. 

becomes neccssary, his choice simply resolves itself into the question of "contrast." In other words, he mounts a long hackled specimen having a silk body, casts a little more at right angles across the water, and holds the rod perfectly still while the lure works its way.

L.ong hackled flies are never played by the ordinary give-and take method. The action of the water alone, however slowly it flows, puts quite enough life into them.

Wi now pass on to the "Slack," No. 3, where as the descriptive appellation denotes, the water from begimning to end, at least twenty yards in length, hardly flows fast enough to carry the fly along.

While this condition makes the place very hard for almost all to comprehend, the singular fact is, that the really productive ground lies eighteen yards across at the extreme cnd, and this is quite cnough to embarrass the most skilful performer, and baulk all anticipation. It is, in truth, just the very spot where mistakes and miscalculations lave becn and will be madc. Even our experts may go wrong, as they have done under less trying conditions.

Now, somc men say that success at most pools comes, as often as not, to the first in command: but while defeat is by no neans necessarily, or always, a proof of incompetence, lct us consider what chance the second would have at water like this, that had been flogged in the ordinary way by a merciless hand.

Surprising as it may scem to all but the initiated, the fact remains, that unless the second comer be fully acquainted with, and capable of demonstrating, well-nigh every dcvice to which we are occasionally bound to resort, he might fish on till doomsday. Proficiency in casting and choosing flies may render useful service, but without other qualifications defeat is inevitable. Victory at these subtle places, 
surely enough, is reserved only for our so-called "generals," and is less astonishing to the rank-and-file than the manner in which it has been gained.

We are to understand that the water in question had been improperly flogged, but to distinguish more clearly the different effect of the right and wrong practice of treating it, we had better draw a brief comparison between the two.

To begin with, the usual habit of fishing regularly down the water would be, for fisherman No. 2, absolutely useless. Then consider this. It is generally supposed that the sloping outlet on each side of such a place is always well worth a trial ; but punishment given to the far side would complicate matters in no small degree, seeing that the compulsory operation of picking up the line over the tenanted lay-byes at each successive cast, would most likely frighten the fish to death. Moreover, notwithstanding that it is an every-day practice to use a dull looking fly in stillish waters, the real secret here is to mount an exceptionally bright pattern with a body composed entirely of silver tinsel.

This is about all that need be said, not only to show how severely the second in command is likely to be handicapped, but also that elaborate conditions require elaborate policies.

Of course, there must be a good deal of the conjectural about what your predecessor has been doing, and a little information thereon would form an essential element in determining what to do yourself. What one would like to know amounts to this: The sort and size of fly previously used, the number of times the water has been thrashed, whether sticks were pitched in for the little terrier to retrieve (this is not caricature), and what is still more important, how long a rest the 
place has had. These matters comprise information which is almost indispensable.

To introduce the more definite particulars, an instance of ascertaining such desirable information - a vivid instance, one might say-recently came under personal observation, and is sufficiently interesting to be worth recounting in more or less detail.

While on the way towards a pool, the characteristics of which have supplied the materials for our present consideration, a young sportsman (not the one mentioned in the opening sentences), approached in wet waders. On exchanging words, we learnt, not from him, by the-bye, but from the gillie-that the Slack, "literally alive with fish, had been thrashed for three whole hours." After getting a number of details relating to the procecdings, a distant figure appeared, strolling steadily along with rod in hand. Feeling certain that we were making for the same pool, and being close there ourselves, we waited till he came up. On he came, and said: "You seem to be courteously waiting for me?"

"Certainly," one of us replied.

It was the lonely gentleman himself, and he then put a question or two which came somewhat as a surprise.

"Kindly say why you give way. Was it because you saw that 1 was a stranger, or, knowing that some other shap lad been here beforehand, you meant to give the slow a thorough good rest before trying it yourself?"

Evidently, this was a man remarkably well-informed, and of no end of salmon fishing experience.

Being unusually interested by his remarks, we, or rather 1 , expressed much pleasure in giving way under the circumstances, and 
hazarded an opinion that it would be wholly impolitic for anybody to put a fly over the pool just yet.

"Ah! just so," and with one comprehensive glance which seemed to take in the whole situation he continued, "then I hit on the reason just now, didn't I ?"

"You did, and that's what struck me so much. At any rate, if you come into the bothy till the storm is over, you shall hear all about the 'other chap,' as you call him, and decide what to do."

It was a blinding snowstorm. We had no sooner sat down than another incident occurred, the result of which increased my curiosity.

Bang went a champagne cork!

"That sounds well," he shouted, "but I say, if those fellows can wade on their side it's all U. P., for I took particular stock of this pool in passing by ; I twigged it at a glance. ('At a glance,' eh!) My gillie Charles lived near here and told me about this singular piece of water last night. This morning I sent over to his lordship, asking permission to put a fly down it. I may just tell you that a lady staying at the Lodge is an intimate friend of mine; but after all I should be far better pleased to see you have a shot at it yourself."

"Not for the world," was the reply, in a tone of unshaken firmness.

The sky soon began to clear. In the meantime, Charles (his gillie), having been industriously engaged in getting the tackle ready, stood "at attention," and while clutching a $16-\mathrm{ft}$. rod that carried a No. 4 line, to which was attached four feet of thin but round salmon gut - the precise tackle for the occasion-he glanced smilingly at a batch of thin-bodied light-winged flies intended for the bottom of the Slack, and remarked-"They'll soon be showing down there, the 
clouds will all disappear before very long."

"Don't interrupt, Charles, for I see a chance higher up, and it would be idle to speculate in ignorance upon the fly required, which will be easily selected when I'm in possession of all the facts. I want to hear what else you have to say. . . ." (turning to me).

Niter explaining what had transpired, he questioned me on the nature of the boulder at the nose of the Slack. "Is it always there, or is it a logan?" For of course you know that the choice and method of using a fly at these places depends upon where the fish lies. If the catch is close up, one's fly is very different in character from the sort wanted for a fish lying some distance below a boulder transported from its native bed."

"Yes, always there, and a very deceptive rock it is."

" $\mathrm{Ah}$-ah" (he continued) "somctimes no good reason can be assigned for choosing the wrong fly, or presenting it the wrong way, but still there are times when victory is organised out of such mistakes. Any way, it would puzzle the devil himself withont information to deted a hedgehogt in such deep water as this, and I guess it is one."

At last, after a prolonged chat over the pros and cons, the sportsman created astonishment by taking from his waistcoat pocket a varicty of "Louise" having peculiar qualities.

"Croodness!" (I observed) "then you have mastered hedgelongs, have you; but what would the anti-evolutionist say if he happened to sce this fly of yours?"

* N B. A logan, often of large size, is a boulder that rocks at certain heights of water, and then it is casily detected by a slight discolouration caused by its action. It has a ridge at the base which may poise the stone so as to rock from sicle to side, or lengthwavs.

+ Hedgehogs are fully dealt with in Chapter II 
"That is just what I should enjoy. To prove the effect of these special patterns to such people, is the only chance of making an ineffacable impression upon them. It would, indeed, be a keen satisfaction to me to have an opportunity of doing so, for there is no sport in which precipitated action is more pronounced, and more unyielding than salmon fishing."

"And when one considers" (I continued) "that an infinitesimal number appear to be aware of the existence of the law of advance-the law which must be respected and maintained-it seems almost characteristic of our national want of clear thinking. Still, these matters do not affect the full significance of the truth one iota. Whatever be said to the contrary, every new special fly, that establishes itself so thoroughly as The Sun Fly and others, is simply the product of evolution, which in its turn is the product of environment. However, I am fully of the opinion that 'the language of flies,' differing as it does in different places, could be reduced in a very few years to one uniform kind, provided a given set of principles were enforced and practised generally. As things are, the highest success can only be attained by discovering, not a policy to be initiated but the policy to be pursued. It follows, therefore, that the highest success newadays depends entirely upon the correct reading of the technical points which control the methods of procedure; and to become familiar with these points, varying as they do on this, that, and the other river, necessitates incessant travel, incessant investigation, and a thorough knowledge of the effect of flies under all conditions."

"That is the secret of the whole thing" (he replied) " in fact, one wants to be brought up at the feet of Gamaliel at such times as these." And on mounting the fly designed for his purpose, he whispered:- 
"Come along with me, and

"One minute, it may seem superfuous, but just tell these pecple outright why you prefer this one little catch."

And he hammered out an answer, hanging with tension upon crery sentence, and emphasizing words by a smack on the deal table with closed fist. "This pool must be a mystery to most. Happily we have both fully passed the novice stage, passed the class of men who merely trade upon tradition. We know it's uscless to try to fight the battle of to-day with the tools, the methods of yesterday. WV must fight here on a totally different policy to that of olden times. No matter how well a fellow is equipped, no matter how much he minderstands the use and effect of flies, or llow woll he propels them, here he must fail unless he is a clever student of the new methods. The peculiarity of the situation may some day make itself felt, even to the Man in the Street. The essential condition at this one spot is to consider what is likely to happen. Listen? If I get a fish at the boulder, well and good. If I don't, I'll talic good care to stone it well, for as soon as I start at the tail, some of the tenants lingering there will assuredly move up. One of them, as you know, might fancy the spot if it is unoccupied, and everyone knows that a fish will take a proper fly directly it leaves one place and reaches another, whether far or near. Of course, I don't include 'potted fish."." "

The professor had so far plumbed the mystery for himself, any way, and his movements were watched with intense interest.

Avoiding hurry, he stationed himself some twenty yards above

* Potted fish are those which, having lnitered behind, are so well cducated by being constantly thrashed and occasionally hooked, that they will rarely rise lo flies or take baits of any sort. 
the boulder, regarding the prospect around him with subdued delight. After making three casts, pulling out a yard of line each time, he waded out of the water as quietly as he waded in. Stepping on shore he said, with becoming equanimity, "difficulties afford opportunities, and, if tackled as such, may be overeome. Now, sir, shall we get a fish out of there yet?"-glaneing at me with a smile of wistful interrogation, and shying a huge stone or two slap into the catch.

The exact reply does not come to mind, but it was to the effect that, as he had managed things so thoroughly in agreement with my own views, it would not be long before he put a fly over the tail, and then he remarked: "How incredible it seemed that, in salmon fishing, as in every other field of sport, people in general were so averse from basing their line of aetion on principles of any sort or kind. Of course, as we see here," he added, "events may so shape themselves that an immediate change of policy becomes imperative; nor do I deny that any study which appeals exclusively to the imagination, is wont sometimes to lead the best living judge into delusion."

"Just so," we both nodded; and I ventured an opinion that, all forms of plilosophy must begin from some standpoint, while by way of further approval, I observed that experience had slowly but surely revealed the incontestable fact that certain flies preserved their beneficial effect under the same circumstances and conditions as those under which they previously succeeded.

"There he is, sir, keep your waders on," interposed Charles, who was immediately commissioned to remount "that very same fly."

A fish had actually crept up into the same little catch already. In less time than it takes to say what happened, a salmon scampered up stream with the hook in its jaw, jumped, and away it went none 
the worse for the interview.

"Thought so, the rascal took me on the surface and didn't turn to fight."

But what a fine example this affords of the effect of a special fly! What an excellent lesson to those too pronc to give way to the puerile idea that only three or four flies are all one wants! "Louise," specially adorned, is one of the best patterns for these places.

This was not the only lesson afforded at the pool by any means, yet very forcibly has the scene so far illustrated a change of policy it were folly to ignore. It practically amounts to this: That while the average performer fishes his every-day fly in the usual manner, some distance in front of a salmon lying in ordinary catches, the master hand, alive to the fact that at "hedgehogs" he has to present his lure straight as an arrow and close over the nose of the fish for it to be seen and recognised at all, selects a certain pattern characterised by those specific elements that have many times been the backbone of his former triumphs. And this we need not hesitate to accept as a fair example of modern diplomacy and progress.

Charles, disappointed and using the truest drawing-room language, sneaked to the bothy unseen and prepared the table for the mid-day meal. "Come on in, gentlemen," he soon called out, "you'll have a good few minutes to yourselves now, as the threatening stormclouds above mean real business this time. Lunch is ready for you, and besides, his lordship is heading this way to talk, talk, talk."

The usual complimentary observations over, including a few words extolling the tactics the fisherman had pursued, the proprietor asked him to fully explain the peculiarities of the Slack, and by what method it should be fished, excusing himself on the ground that so 
many of his friends failed there.

"If the explanation is to be in the least profitable," these are the words he used, "it is absolutely impossible to tell you without seeming, not only to call in question the actions of a gentleman, who, to say the least, made a fearful commotion here from half-past eight till half-past eleven, but also that of the official under whose direction your pools are generally fished."

This appeared to have an unusual effect. The language, though measured, was convincing in substance; the words were spoken in deadly calm, and listened to in deadly calm also; but there could be no mistaking the significance which lay behind them.

"Pray go on, never mind that," retorted his lordship, who in a whisper to me intimated that he believed he had met a man of common sense, and with a very uncommon amount of knowledge on angling matters; "pray go on," he repeated, "tell me just what you think is wrong."

"Very well. To place, safely, half-a dozen men on their proper pools in three miles of water is no easy undertaking, I admit; but to put a novice on a Slack, where the betting is twenty to one-_-

"What! On his catching a fish?"

"No. On his spoiling it for another who understands how to get one; to allow, I say, a novice to approach such water is to reveal a weakness of judgment no words can express. No wonder your water gives bad returns."

"Ah," observed his lordship, "we're not up to all that here, hut your indictment is the more forcible because it is delivered in a cool, temperate, and business-like manner, free from the appearance of all selfish motives. My foreman, though a good shot, is a poor fisherman ; 
still, he prides himself on being impartial, and tells me he likes to give all a chance in turn."

"Yes; but, as you rather imply, the common and widespread mistake of priding one's self in that way arises from a lack of knowledge, foresight, and judgment; and, mind you, it invariably results in leaving the larder empty, though the run of fish be never so large."

This revelation fell like a bombshell on the ear of the noble lord. It made a profound impression upon him, and, turning to me, he acknowledged that my vicw, which on previous occasions had becn expressed, had received complete confurmation.

Continuing, the veteran said: "It would be difficult to measure the damaging effect produced this morning; such a Catch as this always abounds in points of interest, which, even under favourable circumstances, usually tax one's resources to the utmost limit. Nevertheless, the preliminaries of the scheme for getting a fish 'on' at the lower part are easy to compass, but to keep him in custody there, to prevent him slipping 'off,' calls for a line of action, fatal as a rule, but absolutely inseparable from the only effectual policy. IIowever, I shall begin by telling your lordship that my turn came just now with no good results, but still I hope to show that, by adopting a widely different scheme presently, a similar mishap to that which occurred can, and may be avoided."

"Lost a fish, did you?"

"Yes, at the boulder; and so, for the present, I must devote my attention to those rising at the tail. Allow me to suggest that if you can convince yourself by ocular demonstration of the separate schemes suitable for each place, it would save me from entering into a long 
and technical explanation."

"Very well, they are often jumping at the tail, but I am told that a fly there is next to useless; at any rate, when they do come at one, all my friends, with the exception of one old hand, let them get away."

"Well, I am pretty sure I could get them to come when they had not been scared beforehand, but the job is to hook them, and after that to hold them. If a fellow gets hold of one and it goes up stream -it will want a lot of coaxing to do that - the fish is doomed, but if it goes down stream, which is a much more likely alternative, his tackle is doomed, as the seedling alders there prohibit all pursuit."

" $\mathrm{Oh}$, the alders shall be cut to the ground within a day or two."

As a fine fish had been lost through them some few days previously, this decision of his lordship was most acceptable, and was about to be so acknowledged, when the hero of the day exclaimed, with convincing animation, that "four feet should be left standing to form a screen for your friends during the coming grilse season."

"Now," said the Laird in dignified solidity, "let us see the way you fight the battle out yourself, for the sclieme you alluded to must be well worth witnessing."

Familiar with the long-sought secret of stopping a runaway fish by giving him line, the old campaigner, who had waited patiently for a bright interval, eventually hooked and managed a fish with wonderful accuracy. He first had to half-distance the rapid, the sloping character of which rendered it rather difficult to wade. At the farther corner of the Slack he then dropped his lightly dressed "Silver Grey," and in an instant demonstrated the operation indispensable for keeping the fly up and going - a mechanical act, the successful execution of which marks more than could anything else, 
one's skill and efficiency. By aid of a mathematically precise movement of the rod towards the near bank, and of a gentle drawing in one foot of line at a time, the fly sailed, though as yet to no purpose, right across this piece of almost standing water, in a natural and most alluring manner. Then the angler struck a course sideways and made for the bank. "Fortune," said he, "seems to frown on me, but should she favour me next time (and at this spot fortune, as well as intelligence, must always play a considerable part), I shall have a better chance of unsheathing the gaff a shade higher up than I should have had here; at any rate, the fish will have room to turn, and then there woukd be a better chance of putting the hook home."

Alive, alert, and free from unwarranted optimism, the persevering sportsman, after a nip of whisky neat, "for the water is icy cold," changed his fly for a similar pattern somewhat larger, and then planted himself quite three yards higher up the river than before. Turning an car, deaf as an adder's, to his host crying vivaciously " the fly is miles too big," the wily angler, whose tactics turned out to be identical with those previously observed, drew yet another blank and shrewdly remarked: "Bother that retriever! I wish the keeper would pack him off to the place where the angels come from, or shut him in the bothy. The salmon can see every hair of the smallest dog floundering about on the bank like that."

Presently, when the fly in its second passage across reached the middle of the catch, the angler checked the movement of the rod to make the fly stop short. Then, in the most encouraging tones, we heard: "Now's the time, gentlemen, mind and keep a sharp look-out!"

After a brief interval, a moment or two of breathless excitement, 
one slight tug of the line, compelling the fly to jump a little forward, resulted in favour of the fisherman. "There he is! Got him-got him! My, what a weight on this fine tackle!"

True enough, a salmon had got well hold of the fly, obligingly turned, dived to the bottom, and indulged in a fit of the sulks. Then compliments began to fly.

His lordship excitedly observed: "Could anything in this lovely world of ours afford such a slice of fortune, as my luck in meeting with this extraordinary man! He simply inspires confidence. He gives one the impression of being surrounded by a certain nimbus of imaginative suggestion. His remarks leave the conviction of grasp, application, thoroughness, and complete mastery of essentials. . . . . No wonder my water has given such bad returns," continued his lordship, who had winced when the Professor spoke of the blunders made in sending men to their places, but who now made a remark that betokened a quickness of observation. For he cried: "Bravo! You avoided disaster with consummate ease; you stopped his slipping 'off,' as you said, by the ingenious device of dropping the point of your rod at the supreme and critical moment when, otherwise, I suppose he would have started to go down stream. . . . . I see him -I see him! I hope you won't lose him now, for the ladies are coming along, full of excitement."

"Ah," chimed in the angler, "but it's a little premature to speculate with any confidence upon the ultimate result, because the rascal is hooked in the back. Any way, I won't excite him, nor make any rash attempt to endanger success in the end."

The salmon had jumped out of water close to us. IVe distinctly saw that he was hooked near the back fin, and that he was not as 
large as we expected. Every face turned towards the angler. Every ear strained to hear what he flashed out on the advantage of fine tackle. But, perhaps, the tactics pursued should be explained while the fish lay sulking.

With the rod scarcely bending, the angler backed inch by inch nearer the shore, and soon stepped on terra firma. As good as his word, instead of exciting the fish-a practice always to be strongly deprecated - the Professor stood still as a mouse for fully ten minutes. At the expiration of that time, the fish evinced a determination to make up stream. To the very ncck of the pool did it sloot, marking its course by a marvellous succession of "ducks-and-drakes" the whole way up. At cvery leap the point of the rod instantly curtsied. Nothing could be nicer, or more opportune.

"It's mine now for a pony. I never mind the hook being where it is in a pool of this sort, so long as some one is with me in waders."

This significant remark came forth in tones of such easy flow and soft modulation of voice, that an unenlightencd spectator might well have thought he was listening to the simplest of platitudes. I slipped on my wading trousers in the bothy. The ladies, dull and vexed because they knew what hooking in the back usually meant, looked in each other's faces and read one unspoken thought there common to all-disappointment.

“If my fine gut doesn't get cut by a rock, I'm thinking it's strong cnough for the job," urged the Professor, perfectly at home in the particular treatment of the whole business. Then somene lent a little encouragement, by remarking that the rod could not be in better hands, and that one of us would go at once and station himself in the rapid below, as sooner or later the fish will have to be stcercd on the 
bosom of the heaving waters, straight down towards him and the gaff. "But," he continued, " it may be twenty minutes before I can get him to ride the current motionless."

"Never mind, go one must, and there one must stop, for who can say how long the scramble may last before a fish, hooked in like manner, will bob up here and there and drift down stream with no further strength irr him."

To be very explicit, from two or three minutes' chat with the ladies en route, and "from information received," suspicion was roused in more ways than one. At all events, the channel through which the day's fishing had been granted was as plain as pikestaff.

All continued to go smoothly. The audience, chiefly unaccustomed to the sport, stood by and kept perfectly quiet. Nothing, in fact, interfered with the Professor in the execution of what is usually considered a ticklish task. From the distance the fish was seen by the gaffer to rise to the surface again and again, always displaying that increased weakness which foreshadows the inevitable ending. It had been so played-given line when floundering about, and shown the butt when settling down-that in him not a single kick remained. And then, dead-beat, he rode crosswise on the current towards the assistant in the waist-deep stream, whereon nothing remained but to deliver the coup de grace with the commonest of ease.

Restrained in triumph as inflexible in disaster, and no less nobly proof against the insidious temptations of success than he was proudly

- unshaken at the boulder under ruder trials of adversity, the modest angler now faced the audience and extorted the admiration of all.

"Ah," observed his lordship, "it has indeed been a great and signal victory; the work we have witnessed is of importance, and 
shall transform all my plans in future."

Many sustained cheers sprang from the sunny row of openly happy ladies, especially from one radiant with delight and bubbling over with rapturous enjoyment at what she saw and heard.

The Professor bowed his acknowledgments. Onc of the two grandmammas present beckoned the gaffer aside and whispered some praises of the lady who, he was given to understand, had been engaged for years, and yet had only seen "this wonderful mixture of kindness, manliness, and wcakness once during the whole time."

The gaffer simply repeated the words, manliness and weakness, interrogatively.

"Ycs, and we all know that manlincss and weakness in him are so allied, that they who judge him by his exploits here, sce but the single side."

There is the story in its simplicity. The regular succession of facts are faithfully recorded. Consent was given to publish them, under a promise to withhold names and places, and hide from view certain other matters so as to defeat all recognition.

But how sad the sequel! And yet the gencral rcader, if there be one, may like to peruse a modified account of what followed on.

To put it briefly, all dined together at the Lodge in the evening. Long before the ladies left the table, a lengthy conversation on flics, and the modern system of using them, had taken place. All present were equally attentive, equally silent (with one exception). equally strained in the desire to catch the exact meaning of every argument adduced. The hero of the day impressed us more than ever with the idea that he was no mere knight of the carpet, but a fisherman who knew all there is known about the whole business. 
But withal, as inferred, this was not the only impression he made, far from it. For once during the conversation-this marks the exception - a particular lady arrested attention by pronouncing with an all-conquering smile and that silent blush "none else might understand than hearts allied," that she felt as if she were on the bank of the river and watching the very operations which were so clearly and convincingly explained. She, moreover, right nobly endorsed her fascinating remarks by confirming a written promise made to sacrifice both hand and heart!

But - oh irony! - it was not to be. Our gallant hero contracted a chill tramping home wearily in the lethal mists of midnight, and although he had avowed with startling clearness that the marriage ceremony should not long be postponed, the avowal, after all, received no confirmation in the temple of Hymen, but fell into the hands of the recording Angel of Death. Our friend passed away like the shadow of a sailing cloụd!

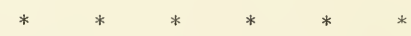

It may, however, be advisable to revert for a few moments to the matter of a salmon being hooked in the back.

- We may thoroughly rely upon it that the chances of getting such a fish in the manner described, are considerably in one's favour. But should the fisherman be alone, what is his only safe plan to pursue in such an emergency?

Certainly not to endeavour to hasten matters at the beginning by using brute force, but rather to put on a due amount of strain and get 
into a conmanding position as quickly as possible. In other words, to get nearly opposite the work, where the battle must be fought with the rod moderately bent until the fish comes passively to the surface, and no longer plays the game of hide and seek. At that golden moment the drift down stream begins. Then, under given conditions, the fish will probably abstain from diving until made to do so just prior to taking a last farewell of his native element.

The conditions which govern the operations from that time onward, are dependent upon material circumstances. The effect of a clear course in modifying the conditions of transportation, is in nothing so important as in the absence of trees and bushes, over which the line could not be taken by the "steersman." An inordinate strain consequent upon an increased rapidity of the water is easily compensated for by giving line. Exposed boulders intervening are as a mere nothing in general. On coming to one, from which it would seem dangerous to haul the fish, it is advisable to slacken line. But it requires an adept in these manouvres to guide a fish through a rapid, so as to keep up a perpetual uniformity of strain; whilst it would amount to a work of supererogation to pretend to describe the hundred and one policies to pursue. Suffice it to say that the lighter the fish is held the better.

On reaching the spot desired at the shallow water, the strain must be suddenly relaxed, when the fish will sink to the bottom, and, if he has any heart left, will wriggle into a position facing up river. The angler now hastens on and wades into the water twelve to fifteen yards below the fish, and takes care to get into a direct line of him. AII he has to do then is to hold up the rod as before, and while the fish, utterly exhausted, floats down to him, he winds in line so as to 
keep up the strain, and finally uses the gaff.

In case the fish cannot be followed to a shallow place, it is better, precarious though it be, to submit to the only time-saving alternative, namely, to hold firmly on and chance the tackle bearing the strain.

To show, however, what can be done by the safer method, perhaps one's own experiences should be recalled.

Fishing on one occasion at Carlogie, I steered a salmon of I $8 \mathrm{lbs}$. a distance of five hundred yards or more before reaching a place of safety. The fish, hooked behind a boulder fifty yards above "Jock Ray," was gaffed at the very bottom of "Clay Pots." The formation of the river and the run of the water simplified matters, and yet it was necessary to let the fish sail through the "Calm Pool " at least sixty yards ahead of the rod.

Upon another occasion, during a visit to the Usk - a river which, in my opinion, is exceedingly well preserved-a row of high bushes necessitated a longer line than that. The fish sailed from "Weaver's Pool," all the way down to the shallow water just above "Church Meadow." It weighed 24 lbs., and was hooked late in the afternoon of the last day of the season $\mathrm{I} 88 \mathrm{I}$. 


\section{J. C. CORDING \& CO.'S}

\section{SPECIALITIES FOR SALMON FISHING.}

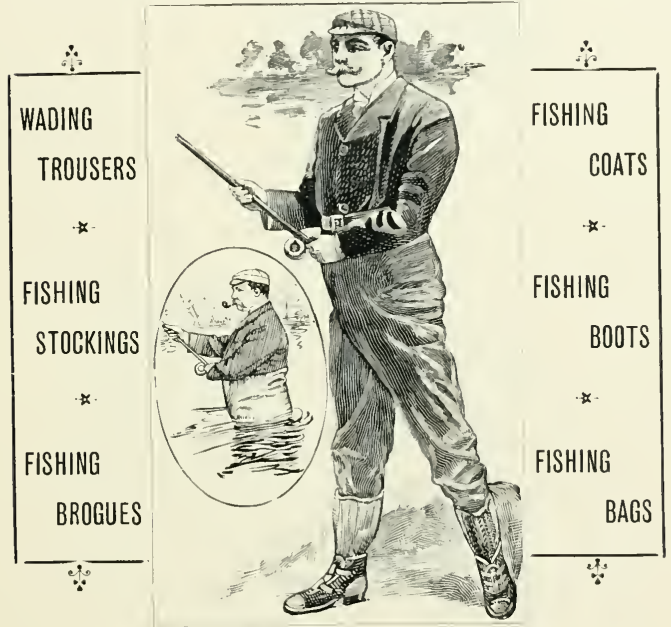

AND EVERY WATERPROOF REQUISITE FOR THE RNGLER.

Improvements from suggestions of practical Fishermen, and the experience of many years.

THF "FusD" as long ago as 1870 remarked of our goods:-" As regards quality. they have been too long before the public to fail in that respect."

Only Addresses: 19, PICCADILLY, Corner of Air st., w.; and 35, ST. JAMES'S STREET, Corner of Jermyn St., w. 


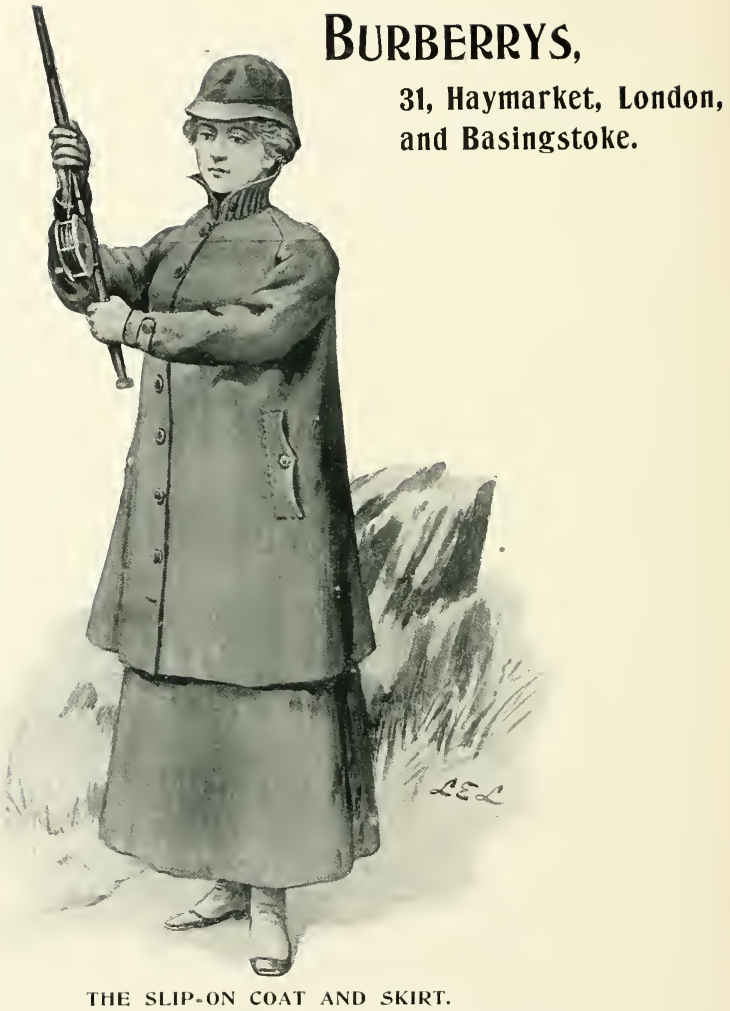

Recommended of either "Gabardine" or "Shimber" Combine; the former where thorns, brambles or gorse have to be contended with, the latter for exteme lightness. Either Combine may be relied on in place of Macintosh, and is healthful to wear, fine or wet. Fishhooks will not hang up in them. The Outfit is light and free; warm without weight and proof without heat.

"Garments for hard wear and sport, giving perfect freedom of movement."-THE QULEN. 


\section{CHAPTER V.}

\section{WADING.}

Fishermen are aware that not a little depends on the make and material of our waders. The heavy trowsers of yore, with straps and seany feet, unquestionably gave rise to a deal of dissatisfaction, from the fact of their liability to injure the constitution. In thick waders, even men skilled from practice are constantly overwhelmed with fatigue, and realise most fully that they are stuffy and far too oppressive for physical endurance. This heing the case, it affords me as much pleasure to write, as it will give the angler to read, that a light material, which offers inducements and not obstacles to one and all alike, has been introduced, at Newcastle-on-Tyne, by Mr. H. A. Murton. The crowning feature of this materia!, which passes under the name of "Murton's 53 T," rests on the fact that it is absolutely devoid of any tendency to create excessive perspiration which, in the past, has often been it fertile source of vexation, and sometimes very 
deleterious to health. The real benefits derived from the new texture are so cncouraging, and so obviously manifest, that the question as to whether the waders made of it will or will not last quite so long as the antiquated stuff, is rendered unworthy of consideration. One thing may be predicted with absolute certainty, and that is, that all stout waders, including those of sateen which once ruled the market, will soon become obsolete, and that the modern sort, which have a salutary effect, will quickly assert their superiority, increase in favour of the people by leaps and bounds, and defy all competition.

With regard to brogues, some prefer boots, others shoes. The latter are to be commended, as the ankles have free play-a consideration not to be despised on coming against a hidden boulder, when rapıdity of motion is usually one's only salvation. The soles made for my use, by Cording of Piccadilly, of course with heels, are three-quarters of an inch thick, the nails are very large and not pul too close together.

A water-tight boot for those, who from choice or necessity fish from the bank, is almost indispensable. We all shift our waders and don our ordinary walking shoes, or the knee-high "Springfield" boots supplied by The London Shoe Co., on moving to a place better fished from land than water. Griffen's (Reading) Preservative keeps them soft and water-tight for years.

Wading is easier than it seems at first sight, despite the scribe who contends that :-

"The wisest and best some fear may show,

And wish to stay, though they resolve to go, Sometimes resolved to face the gulf, and then

Wade to the bank and there stop short again." 
At any rate, in rapids an alpenstock should form part of our impedimenta, as the firmer we hold ourselves the better for us in all respects. It has already been shown, that to secure personal safety, we must stand sideways with the legs set wide apart; but in advancing on no account should the front leg take the first step. Tho front leg fecls the way after the other leg is fixcd, and then the foot "digs in" and plants itself till the next move.

In getting back up stream, lean the body well against the current, travel sideways and drag the alpenstock towards you from the rear before each step. Avoid treading on boulders, and you will probably escape a ducking.

In crossing a ford move slowly and plant the wading stick down stream, slightly in front.

Should any difficulty arise in the case of quicksand, clear the sand away with the gaff, so as to raise the heel first.

Guard against ice and other floating debris by frequently looking up river.

Wading in thick waders is less injurious in Spring and Autumn than in Summer. In cold weather, plenty of underclothing makes one feel warmer in the water than ouf of it. In hot weather, seize every opportunity to air the waders, for the effect of the moisture, which invariably escapes from the body, is liable to result in the entire loss of the legs when forced back upon the pores of the skin. Fortunately, however, the thin waders absolve us from this obligation.

Beyond all information from even cleverly-written instruction, the novice should carefully observe the actions of an adept.

Memory-that inexhaustible source of pure refreshment- 
mournfully brings back the philosophy of a busy brain which, like the sun by night withdrawn from mortal eye, no longer pursues its trackless flight in exploring the mysteries of our art.

But who has not lost a friend?--who indeed!

Haslam-poor fellow!-used to advise his guests to take notice of a certain individual, and doubtless that same individual deserved all the study and admiration enjoined by the King of Carlogie in his bright Highland home. But for all its eloquence and adaptation, his written instruction pinned up in the hall did but slightly indicate the way in which that wonderful wader (familiariy called the "B," after the little insect that wings its way anywhere) taught "the art of order to a peopled kingdom."

But the "star wader" of Rothes, puts to shame the wildest wonders-the mightiest magic of Deeside knights. For among the most astounding antics in waders, according to Archibald Forbes in his letter (20 June, ' 91 ) to the Field, this remarkable performer gets through inaccessible depths of the Spey by treading water, and in addition to this, casts a long line on the way!

The secret, however, of the performance of this feat was not revealed, or what a time we should all have! The amusing and undaunted writer-in his capacity as a "dead certain" correspondent in the art of war where he may justly have been regarded as "facile princeps" - found himself slightly out of his depth by the side of a salmon river, where only his fervid imagination can have saved him, and his friend, from being whelmed beneath its swirling current.

In ordering wading stockinss get them made six inches longer than usual, or so that they reach the top of the legs.

After use turn waders, of either sort, inside out at once, and 
when dry turn them back again. IVaders are better dricd out of doors than in front of a firc. When they have been used for a fortnight, wear them for one day turned inside out.

India-rubber boots cannot be turned, but the lining is quickly dried by heating a pint or so of small beans and putting them insidc. If after this treatment the lining is still damp, repeat the process.

It is an engaging sight to witness the refined manners of a lady accustomed to handle a salmon rod, and put out a line by the different methods of casting. No doubt this is scen to the best advantage in bank fishing, where the question of dress is more a matter of fancy than of necessity. Were it not for a certain deeply ingrained conservatism in adorning themselves with apparel so unadapted to easy exertion that physical exhaustion readily sets in, we should enjoy their company more frequently.

The two things ladies most need are full freedom of action, and a material impervious to rain. It is, therefore, with confidence that the fair reader's attention is drawn to the accompanying engraving.

In very cold weather a tweed jacket lincd with flannel is most serviceable. This is shown by the illustration on the right hand side of the picture. In wet weather a waterproof cape of gabardine is worn over this jacket; so that with the skirt of the same material a lady is well protected from the elements, come what may. The " field" boots, of brown leather, specially made for this purpose by The London Shoe Co., are a combination of boot and gaiter. They fasten at the top with three straps and buckles, and are laced over the instep. They are made with rather wide welts, and a sole nearly half-an-inch in thickncss; in fact, these boots are suitable for evcry condition of weather and give complete satisfaction. 


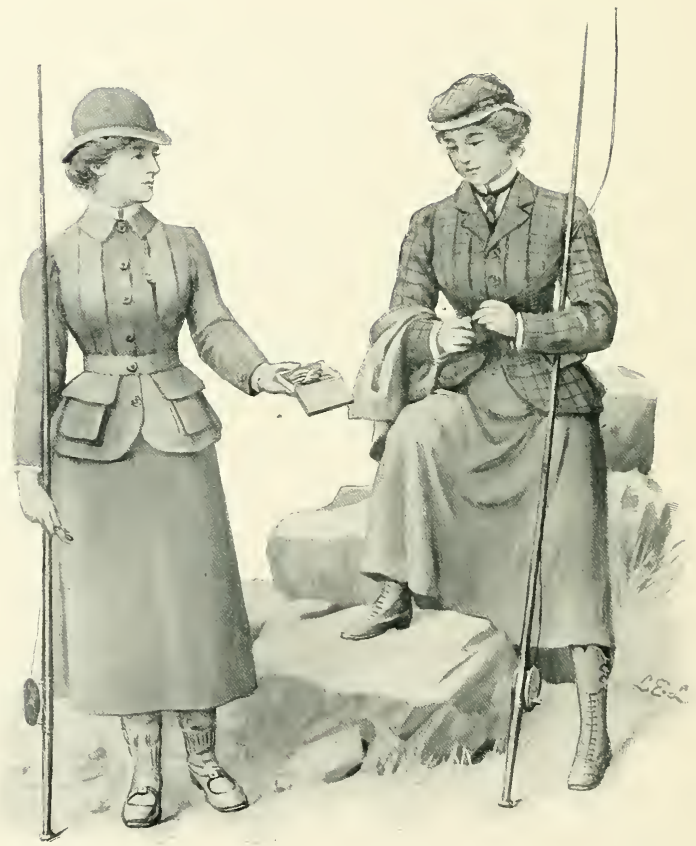

COSTUMES ADAPTED TO WADING AND BANK FISHING. 
For wading many ladies of my acquaintance prefer rubber water proof below and twecd above-a combination which is commonly called "half waders," and originally introduced in Norway. The lady on the left hand side of the picture, attired in a thoroughly up-to-date costume, patronises these waders, over the feet of which are the socks, made by Joscph Glemwright, of Wark on-Tyne, and the shoes by Cording, of Piccadilly. Her jacket (having pockets sufficiently large to hold Farlow's Aluminium Fly Box) together with her cap and skirt, are of Burberry's Gabardine. This material is far superior to any rubber waterproof. For its many advantages see page 152 .

\section{THE}

\section{LATEST SYSTEM OF DRESSING LINES.}

In connection with this branch of the subject, if any one matter of daily annoyance has occupied our attention and absorbed our thouglits more than another, it surely must be laid to the charge of that malignant complaint known as "knuckling." A knuckled line not only baffles the best of us in working a short length over a pool hedged in by trees, but paralyses every effort to cover distant fish resting in open quarters. Permanent troubles, such as these obviously require a good deal of close examination; and in my own endeavour to find the decirling factor here, the matter has never been 
allowed to drop out of sight. Dressing lines is an occupation always intensely interesting, and yet, to obtain complete mastery over the whole business, it seemed, as it has proved by my own experiments merely a question of getting a suitable oil properly refined, a safe and sound method of applying it, and then making the surface smooth and glossy with materials specially made for the purpose.

In all respects this has been achieved in a manner at once gratifying and satisfactory.

Salmon fishermen may remember an ingredient mentioned in the first edition of "The Salmon Fly," in which the dresser could steep his line and get it ready for use in a few weeks. Following the particulars, given in detail, came another method of preparation by means of a single cylinder air pump, together with a better material than the other for dressing purposes. Of these two plans, anglers generally understood that the former-a dolce far niente kind of business, fit only for old women of both sexes - would, without doubt, give way to better expedients. In respect to the latter device, so capricious are the ordinances of Fate, it came to pass that the sort of air-pump in use did not reach the expected success. I myself anticipated a complete cure for the complaint mentioned, but experience proved that the process only prolonged the life of the line for a certain number of years.

As shown in the engraving, we have here a double cylinder air pump. Let me hasten to put on record the different effect of this 
machine, which can be had at Baker's establishment, 224, High Holborn.

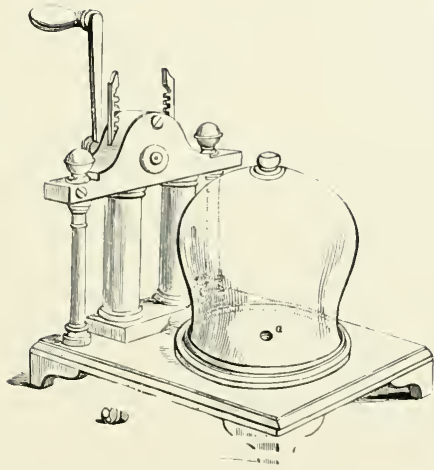

THE DOUBLE CYLINDER AIR-PUMP.

On trying the two pumps together with the "Kelson Lines"beautifully made in all sizes for the trade by Morris Carswell, 90, Mitchell Street, Glasgow-incredible as it may sound to the uninitiated, it was soon seen that the double cylinder pump extracts more air from the line, and conscquently that more oil finds its way into the silk. In this respect, obviously, it must have very important results. Nor docs it require an intimatc knowledge of the intricacies of pneumatics to offer an explanation of this somewhat remarkable fact. 
By the former pump, for instance, only a certain amount of air could be extracted, because at a given stage the power required to work the piston is greater than a man can apply. But in the double action we have the mechanical advantage of a "rack and pinion," together with the resultant thrust of the air on the descending piston which assists in driving the other piston up. Hence, the object of impregnating the silk to the very utmost is effected by creating a vacuum as perfect as possible. And this receives ample confirmation by reason of the time being considerably prolonged in the process of drying.

At this point it is desirable to note that rods, lines, winches, etc., are sold to the public in London and elsewhere as being of my own type or invention; but let it be distinctly understood that I am not pecuniarily interested in the sale of any single article associated with my name. "The object, therefore, in recommending the lines just mentioned, which can be had at any tackle shop dressed or undressed, will be perfectly obvious to all.

In dressing them there is a first and second process, i.e., the body dressing and the polishing. If the highest standard of excellence is to be attained, neither process should be hurried, except on one occasion to which allusion shall be made.

In the first process the line is packed in the tumbler sent with the pump, and sufficient oil poured over to cover it. The tumbler is then put on the table of the pump and the glass recciver set over it, as shown in the engraving.

Great care should be exercised in packing the line in the tumbler. On taking a new one from the cardboard box, get your servant to place his two forefingers through the coils, as yet undisturbed, so that they shall assume a vertical position. Now carefully cut away the 
little ribbons that tic them together. You can then pull and pack each short length in the glass without setting up a number of twists, and creating ultimate mischicf. If the line were uncoiled at right angles, the twists made in it would result in making tlic line kink when used, but this does not occur provided the line is free from all twist when hung up to dry.

As you progress in packing the line, push the amount deposited cvery now and again down into the glass with a piece of metal cut in the shape of a broad chisel. By this precaution sufficient room is madc for the froth which appears soon after the pumping begins. Make the oil rather hot before pouring it into the tumbler, and kecp the coils beneath the surface by means of a picce of tin, scolloped and perforated.

When this part of the work is completed, remove the screw from the centre of the brass table and place the tumbler with its contents upon the aperture. Now give the bottom rim of the receiver a thin coating of mutton fat, or tallow candle, and place it on the brass table in position. In doing so, gently press and turn the receiver backwards and forwards so as to secure the closest possible contact. Then begin to work the pump.

When the bubbles rise to about half-an-inch from the top of the tumbler suspend operations, or else an overflow will take place. Left in that state for a few hours the bubbles will gradually disappear, for the simple reason that a perfect vacuum cannot be obtained. But, and this is the exception, you may expedite matters at this one period by unscrewing the valve below the handle. This lets in the air, the weight of which instantly crushes the bubbles and drives the oil into all parts of the line whence they came into cxis- 
tence. So far, so good.

The next move is to refix the valve, when the pump can be worked as before and just as often as circumstances necessitate. If, for instance, a reasonably good vacuum is obtained, all beads and bubbles will cease to appear after the pump has been worked six or eight times. The bubbles and beads will decrease in amount as the work proceeds, but the receiver should not be removed until they cease to appear either in the oil or upon its surface.

The student, who regards this business as being too tedious for him, may rest assured that he cannot get an ideal dressing by any other known means.

The line has now to be dried out of doors, but it is better to leave it in the dressing for a fine day than to hang it up in wet, or even in damp, weather.

First cut three fairly stout props, say, as thick as a walking stick. These are to support the line and prevent it from stretching. Also get two stout sticks, say, as thick as your wrist, and fix one into the ground chosen for the purpose. Now, without wasting an atom more line than can be avoided, tie the end to the stick, man's height, while your servant holds the tumbler beside you. Leave him there while you fix the props in a straight line with the stick, about thirteen yards apart.

In taking the line out of the oil, get him to hold it lightly between his thumb and forefinger placed just above the tumbler, so that while he walks back towards the first prop the surface oil drops into it. Upon reaching the prop place the line in the fork yourself, being careful not to allow the wet dressing to come in contact with the ground. Continue to take the line from the oil in the manner 
described, and finally tie the other end to the far stick.

In six or eight days, according to the condition of the weather, the dressing will begin to set, and then certain portions are likely to appear somewhat lumpy. Should this be so, catch the line gently between the fingers of both hands and, with it so held, walk down the whole length and back again. In thus smoothing the surface do not rub off too much liquid. The operation may require repeating in wet weather, after which the line may be left to dry. How long this drying process will take is hardly possible to foretell, because so much depends upon climate and atmospheric conditions.

Should rain fall in torrents while the surface oil is wet, the line will probably assume a frothy appearance, and then you must use a duster instead of your fingers to rub it smooth. But while even a heavy rainfall will have no injurious effect ultimately, the duster may necessitate another application of oil to fill up the interstices of the plait. In giving this thin coating, use your fingers, though a piece of rag will answer the purpose almost as well. In any case the line will takc some few months to dry, even in air destitıte of moisturc like that on the north side of the Grampians.

The chief point to bear in mind is that all further work must be deferred until this body-dressing is absolutely dry. In order that you should not be mistaken on this point, the following sure, but rather severe test is given. Press, say, half-an-inch of the line at the middle part by liolding it between the forefinger and thumb of both hands. While thus hold, press the line by bringing the hands together as though you were trying to open the plaits of the silk, and repeat the opcration two or three times. If the plaits turn at all white in appearance, the dressing is still moist; if you cannot move 
the plaits by this means, you can begin to rub the line, and so prepare it for the polish.

The object here is to rub in such a way as to preserve the roundness of the line, and not make it oval in shape at any part.

Procure a piece of thick felt, sprinkle it with powdered pumice stone, double it, place the line in the pad so formed, and proceed strictly in accordance with these instructions. With the fingers of the right hand moving backwards and forwards, rub the surface of about two or three fcet at a time; but remember that while so doing it is imperative to twirl the line energetically, to and fro, between the finger and thumb of the left hand. If you twirl quickly, the line will maintain its shape. After rubbing the portion mentioned five or six times in the manner described, "move on"-as the gentlemen in blue say-and replenish the pad prior to further operations.

As soon as the surface is thus made perfectly smooth, closely examine it the whole way, to see whether the interstices present a hollow appearance. Should this be so, fill them up by the application of another thin coating of the same oil. This coat will be quite dry, if the weather is sunny, in a few days, when the final process can be safely commenced.

It has now been ascertained beyond all doubt that the method of dressing and polishing adopted at the present time is by far the hest ever tried. The line can be used in less time, and keep in better condition for a much longer period. The special materials we use are only to be had at Naylor Bros.', James Street, Oxford Street, London. All dressers must clearly understand that in order to checkmate both knuckling and stickiness it is absolutely necessary for them to obtain their materials at this establishment. So superior are these goods to 
all others, that no reliable results can be had without them. In fact, if Naylor's materials are not used the body-dressing will remain in a sticky condition for years and years, in which case the polish would not dry. A sticky line must have a thin coat of tercbene, which should be put on and rubbed with the fingers as in polishing.

To polish a line, get a one-ounce bottle, and fill it three-parts full of the special copal. Mix nothing with it. Shake the opened bottle so filled against the ball of the right fore-finger, twirl the line as before, and with the wetted finger working backwards and forwards proceed to cover a few inches of the line all round. Repeat this performance quickly until a length of nearly three feet is moistened. Then, while the twirling continues, rub that much to and fro smoothly and evenly, but take the fingers away directly you feel the least sign of stickiness. To run over the whole line in this way occupies a little more than half-an-hour. The first coat should dry out of doors in a day, provided the weather is bright and warm. The second coat must not be applied until the first is quite dry. Three coats may be given with advantage should the line seem a trifle light for the rod.

The appearance, the excellence and durability of a line depend upon the treatment of it. In order to preserve the plaits from decay, and be able to put the line "where you please," it should be reversed on the winch after two months' fishing. At the end of another two months, it should be run off the winch, fixed out of doors, and polished as before.

Any portion of the salmon line is liable to come in contact with the rocks so violently as to inflict a breach of its skin. The wound, only superficial, should be healed at once biy giving it a few coats of 
the oil with a camel's hair brush. Use as little oil as possible each time. When dry, rub the patch to get it level and give it a coat or two of polish.

If careful attention is paid to these matters, and Naylor's materials are used, the body dressing will not be sticky, and the line will never knuckle. Of course, the line should be dried after use, and at the end of the season taken off the winch, coiled and hung up in a dry place.

SPECIAL Note. The copal, which has been decided upon after numberless experiments, is labelled Thin. But as the amateur rarely gets his line smooth enough for polishing, one or two coats of the other sort, labelled Stout, should be previously given, in which case much time and trouble will be saved. 


\section{BURBERRYS, \\ 31, Haymarket, London, and Basingstoke.}

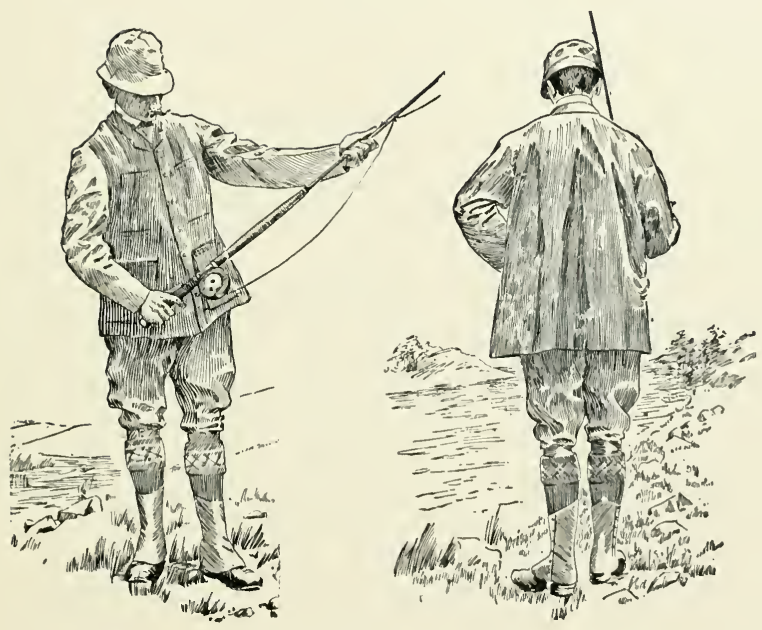

\section{THE ANGLER OUTFIT.}

Consists of short Slips-on, a sleeved Waistcoat and $\mathrm{KB}$ Brecches. Freedom is unique. Pocket accommodation ample and convenicnt. Protection absolute. If the weather is hot, the Slips-on may be dispensed with; it weighs only a few ounces; can be carried in one of the pockets for use if required. For Bank or Boat Fishing nothing could be nicer, and if wading the waders cover the waistcoat, while the Slips-on may be worn in or outside them.

"We never had anything more comfortable and at the same time so rainproof."

Fishing Gazfte. 


\section{CHAPTER VI.}

\section{KNOTTING GUT CASTS.}

Select eight strands so that when they are all tied together they shall form a gradual taper from end to end. After soaking them for twelve hours in soft water, coil four double strands separately, and put the two thickest at the bottom of a tumbler of water. An easy plan of keeping the coils apart from each other is to put a penny piece upon them, one after the other, as they are immersed. Begin by knotting the two finest strands. Coil this length and put it into another tumbler of water. Continue in a similar manner throughout.

The process of knotting may be described thus:-Lay two ends together so as to overlap each other as much as six inches, and hold them between the left finger and thumb. Catch hold of the under part of the lap and fold it back behind and above the work, so as to make a loop which is to be held with the left fore-finger. Now bring the point of it up towards you under the work, earry it on and place it twice through the loop from you. You will then have reached the 


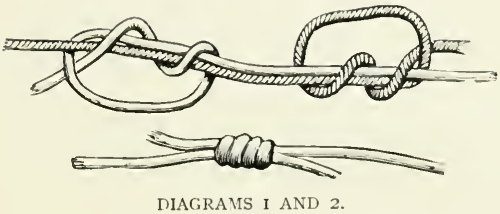

stage represented on the right hand side of the upper diagram No. I. Witlout loss of time take hold of the end of that portion and pull it fairly taut, but not hard enough to bruise the gut. Observe that in this operation the portion forms a figure-of-eight of itself. Then reverse the work, left to right, and repeat the process at the other end. As soon as that is done catch hold of the two strands, away from the knot, and give a short, sharp pull to make the knot taut. Nip off the waste with scissors.

If the knot is not close and neat as represented in the lower diagram the probability is that too much time was taken up in the tying, in which case the gut would become too dry. On the other hand, it may be that the pull given to complete the knot was not sufficiently sharp. At any rate, another soaking will be necessary before a second attempt is made.

\section{KNOTTING EYED HOOKS.}

As I have been asked for the correct method of " mounting " a fly dressed on a turn-down, metal-eyed hook, the following illustration is 
given, not, however, without some reluctance, as these hooks are wrong in theory and worse in practice. In use the fly with a metal eye droops its tail, the one with a gut loop holds itself up and works straight. It is claimed for the former that the eye is stronger than a gut loop. But this is a misapprehension. If the treble gut, from which the loop is formed, is of good quality and sufficiently twisted,

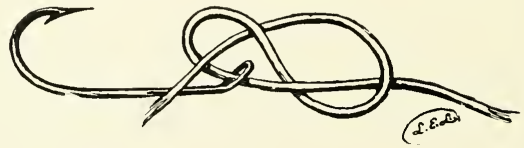

KNOT FOR THE METAL EYE.

and if the loop itself is thick enough and small enough, it would last longer than the materials of the fly however well it were dressed.

Hold the eyed hook in the left hand upside down. Put the point of the gut up through the eye, take it round on the far side and bring it towards you under the line, then up and over the line on the near side; carry it on towards the fly on the far side, put it through the loop thus formed in the gut, and bring it on the near side of the hook, as illustrated. Hold the point with the left thumb nail while the knot is drawn nearly close, then put the other loop of the gut over the eye, hold it down on the eye with the right thumb nail and pull taut.

The knot for the gut loop is easily tied and untied, and is far superior to all others. With this knot the fly always works propely. 
In tying it, hold the point of the hook downwards, so that the loop assumes a horizontal position. Diagram 1 shows the first part

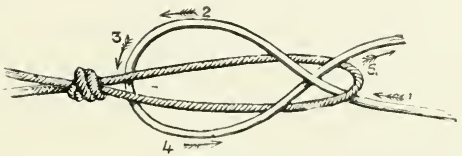

KNOT FOR THE GUT LOOP.

Diagram I.

of the process, which requires no written details. When that part is ready, pass the gut line from the near side at hottom under and round the short end shown above it in the illustration, bring it over to the near side, and then bend the short end back with the right forefinger and push it underneath the loop of the fly and through the loop of the gut formed in the first part of the process.

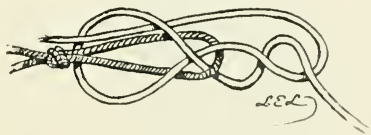

Diagram 2.

Degin the work by placing the left fore-finger and thumb on their side of the loop of the fly. Put six or eight inches of the gut line up through the loop, and place it over the nail of the left fore-finger, where it is to be held by pressing the ball of the middle finger upon it. With this precaution the work is facilitated. 


\section{WINCHES, Etc.}

If nothing in the shape of fishing tackle has come to stay, it seems that the last thing to go will be the Patent Lever Aluminium Winch. When one comes to consider the advantages of this invention, it is not surprising to hear that Farlow, who had my permission to take out the patent, has not received a single complaint of it from any of his customers. Upwards of three thousand of them are in use, and this speaks volumes for the maker's work.

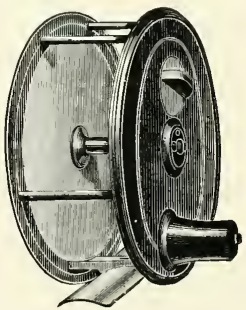

THE "KELSON" ALUMINIUM WINCH.

Made of alloyed aluminium, this winch can be regulated to any stiffness at will. The alloy used by Farlow, who is the sole maker, so hardens the aluminium that it stands the work quite as well as brass. Comparatively, it is very considerably lighter in weight. The one 1 have is one of the first lot made, and though it has been in constant use for years it is none the worse for wear. This may, in some measure, be accounted for by the fact of its being "silent," i.e., without a ratchet-wheel. It measures $4^{1 / 4}$ inches in diameter, weighs 
only 13 ounces, and carries 150 yards of line, that is to say, $f^{2}$ yards of ruming line "married" to a thin back line (see page $1+9$ ).

Another contrivance to stiffen the winch has been introduced by IIardy Bros., and though it only affects the drum when the line is drawn out, there is no question as to the advancement in worth. Their profusely illustrated cataloguc, which can be had on application, gives the engraving, together with all particulars for working the regulator. The same firm have a new wincl called the "Silex." However, this is for spinning, and although this book is not intended to descant in rich, mellifluous verbiagc on that unbending branch of salmon fishing, the winch is by far the best of its sort I ever came across. As I have thus briefly alluded to slaughtering fish by this means, mention should be made of the Aerating Bait Can which Mr. Basil Field has considerately passed on to one of his clerks.

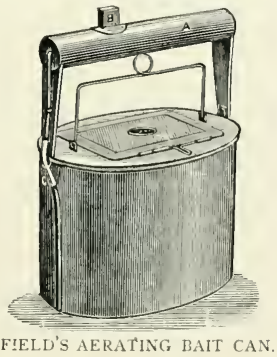

This can is an ingenious invention. It keeps bait endued with life during a long journey in the warmest weather, and thereby surpasses all others. 


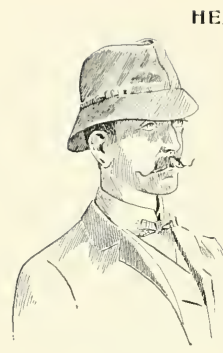

"THE FIEJ.D."

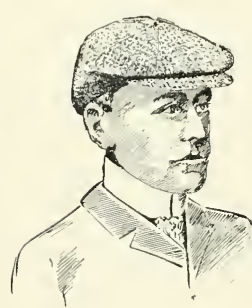

"THE GOLFER."

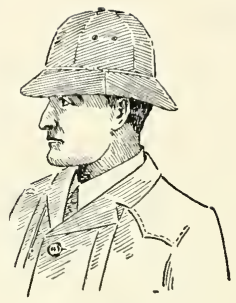

"The SPORTSMan,"
BURBERRYS,

\section{1, Haymarket, London, and Basingstoke.}

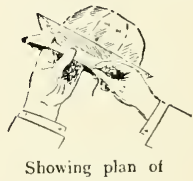

DOUBLE BRIM.

"An exceedingly light fishing hat-as perfect as anything of the kind could be. The double brim answers adınirably; the gut collars are kept secure from the effect of light and damp (their greatest enemies), and always ready for use."-THE FisHing GAzeTTE.

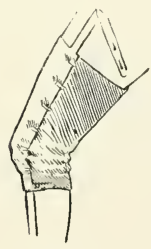

KNEECAPS.

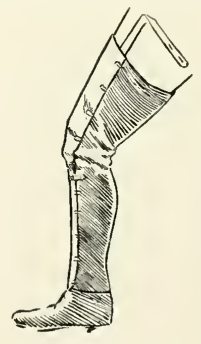

LONG GAITERS.

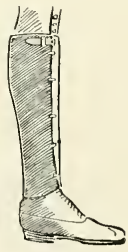

GAITERS.

LEG GEAR. - THE FIELD says :- "Kept out the cold and wet, were comfortable, and did not cause perspiration." 
TIPS.

CHAPTER VII.

\section{MODERN IMPROVEMENTS.}

\section{CANE RODS.}

The "Spey Improved Rod," to which special reference is made in this volume, is sure to excite the curiosity of the many, if only ior the reason that the Highland method of casting is "the idol of all."

Those who have waded through the particulars in Chapter I are already aware that this rod, made in cane and greenheart, and constructed on special lines, facilitates the Spey cast generally, besides rendering possible the proper performance of certain variations which have brought the cast to perfection.

"The severest critics of the 'Spey' (say Messrs. Ilardy) do not reside near the river; the residents, staunch hitherto, arc content with their own original tackle." These manufacturers also inform me that their firm "has succecded in getting the desired action in 
cane," and declare that the possibilities of this new model, as compared with local specimens, are well nigh incredible."

In this opinion I gladly concur. The predominant feature of the rod is its exceptional capacity in rough weather. In recent trials I found that it showed a marked power of defying adverse elements, the line cut its way through a very opposing wind without flagging. It may now be said, without fear of contradiction, that these manufacturers have reached a point in their work which is perfect, or all but perfect. Their locktast ferrule, fitted to the rod, is simply excellent. It is distinctive in style and quality, and known as the "Lloyd Treble Grip Joint," which, it need hardly be said, is patented.

Without a trial of a really practical nature, how comparatively valueless would be such an opinion of a rod as this. There are some articles of ours, recently introduced, which the master's eye can detect as being worthless-a hook, for example, with an up-turned point-but it passes human wit to determine the value of a rod by merely looking at it. Not long ago, such a glowing account of something in the way of tackle appeared in print as to induce a friend of mine to lay out money. He did not like his bargain at all, and in my opinion the public are too often led to make mistakes of this kind.

At the moment of forwarding the M.S. of this book to the printers, another firm at Alnwick, Messrs. Nettleship and Co., send a new cane rod of their own make for my opinion and review. I could have had a better opportunity of judging had I cast a fly with it, or tried the action with a line on a lawn. It is, however, easy enough to see that the rod is well put together, and that the action comes well down to the winch fittings. This is an especial feature-one which most rods do not possess. In these respects it pleases me very much. 


\section{STEEL-RIBBED RODS.}

In contradistinction to the remarkable progress at Alnwick in cane is the new departure at Ashbourne in greenheart. Messrs. Foster, the well-known manufacturers there, have introduced a stecl vire net-work that fits over their own made rods as well as those of other firms. The Field of October 12, 1900, spoke very highly of "this ingenious invention," and after a clever description, Mr. Cummings went on to say: "The rod is of the highest grade in rodbuilding, and the wood used is of the finest quality, well-seasoned and straight grained." Then the Editor observed:- "The one sent (to him) is a very handy, strong, and light little weapon. It has most excellent ferrules, a kind of cap on the male ferrule overlapping, and effectually keeping out the wet."

Writing from Ayr Barracks, Quarter-Master-Sergeant C. Stephens says:- - I am delighted with the rod, it has had a good trial, and on no occasion was the rod in distress."

The Assistant Secretary of the Piscatorial Society, Mr. A. H. Rolt, expresses himself to this cffect:- "The rod has answered perfectly for years."

The Rev. F. IV. Tracy remarks:- " The best rod I have ever handled."

Owing to what appeared in the Field, I sent for one of these rods, and so far as one can judge of the action indoors it appears to be correct. The rod was sent by me to a brother angler to try, who wrote afterwards and said:- "ln my opinion Foster's rod equals yours in balance and power, but I don't like the ferrules at all." 


\section{THE IMPROVED LONG-SHANKED HOOK.}

These hooks, made to my order by Allcock and Co., Standard Works, Redditch, are sold by Farlow of I.ondon, Blacklaws of Kincardine O'Neil, Hardy of Alnwick, and Garden of Aberdeen Made of the best steel, they are forged and hammered at the sides, so that the wire is reduced in thickness and yet increased in strength. They have other advantages. In the first place they can be used in larger sizes, and this is of supreme importance on such rivers as, for instance, the Dee and Spey. Again, as the point déclines rather more than usual from the shank, they hook and hold salmon f:tr better than the old sort; in fact, the barb often goes clean through the flesh. During the Spring of 1896 , for example, the gillie at Carlogie, William Dunn, gaffed over thirty salmon for me, and in nearly every case found that the point of the hook had passed completely through the mouth of the fish. In addition to this, not to mention other instances when being alone, in the Autumn of 1900, Mr. R. H. Benson, fishing with me, witnessed a similar result time after time. This well-known angler and many other of my friends dress all their flies on nothing else. They range in size from six inches downwards, the largest being No. I and the smallest No. I 7 ; and it should be said that my success has been considerably increased since using them.

Except in a few instances on the Tweed and Usk, anglers are gradually discovering that thin-bodied flies are the most effectual. And when it comes to using larger patterns-in which case with the old heavy irons it was impossible to make a very thin body or cast beyond a limited distance-fish lying five-and-thirty yards away can be covered without any wonderlul display of skill. 


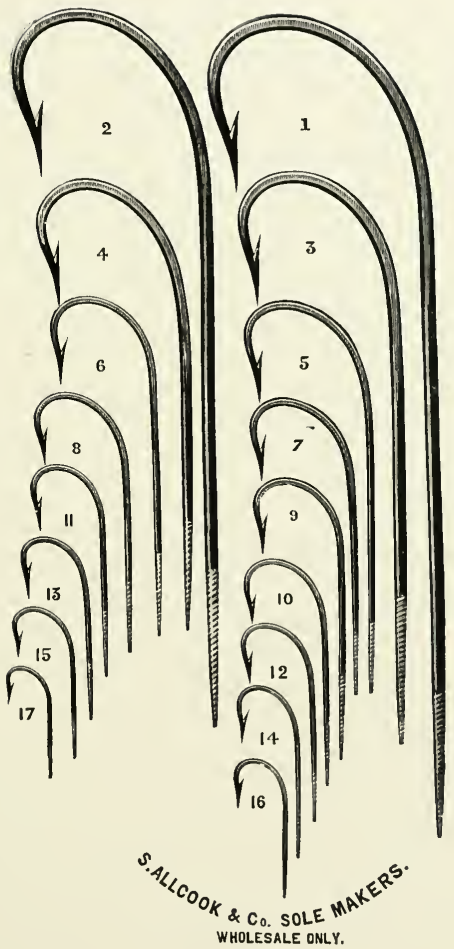

THE "KELSON" HOOK.

(Long Fine Wire-Narrow-Forged) 
With reference to the largest size used, a writer to one of the weekly journals contradicted certain remarks sent to the paper by me from the North of Scotland in the Spring of ' 96 , and said that :"Mr. Kelson misleads the public by talking about his success with six-inch flies"--or words to that effect. One would hardly think it necessary, but this opportunity is taken of again stating that nearly all the salmon alluded to in the early reports from Carlogie of that year, were taken with flies dressed on these identical hooks measuring exactly six inches in length.

I would here like to ask if this is a legitimate method of controversy.

A story is told of a saloon bar in the wild West of U.S., where entertainments took place before a somewhat rough audience of miners and cowboys. A notice was hung in a prominent place to the following effect :-

"Gentlemen are requested not to shoot at the pianist, who is doing his best."

I sympathise with that unfortunate pianist very much; and I do not think the method of the gentleman who thus criticises me is much more legitimate than those brought to bear upon him.

If I had propounded some elaborate theory depending upon nice arguments admitting logical error, and my opponent had impearhed the validity of the sequence in such arguments, it would even then be rather a strong statement to say that I was misleading the public. But the case is different. I state a plain fact that I caught a large number of fish with a fly measuring six inches. I certainly did so, and there are witnesses of the fact, who are still alive, and capable of testifying to the same. An exact replica of that same fly, measuring 
six inches, hangs at this moment on the wall of my library. Moreover, at certain periods of the ycar, it is very difficult, if not impossible, to catch salmon on the Dee with flics much less in length.

This gentleman, thereforc, must be accusing me of being an cconomizer of the truth. What carthly object I can have in doing so I am at a total loss to imagine, and I do not think the cause which, I presume, we both of us have at heart, viz,, the adoption of sounder methods in salmon angling, can be promoted by the methods of criticism that do not appear to me to be far removed from the crude retort of our schoolboy days.

Reverting to what has just been said of these hooks and the advantage of thin bodies, very few of us even dreamt that flies of that size would come into fashion. The old sort of hooks were so thick, the cobbler's wax on the tying silk necessitating several layers of floss to avoid discolouration, which immediately followed wetting was so unsuitable, that some reform seemed impcrative.

As soon as Bambridge, of Eton-on-Thames, introduced his excellent white wax, and the improved long-shanked hooks were brought out, it was at once found that a single layer of floss, or little more, produced all the effect wanted. But still, for general purposes, cobbler's wax is the best of all. 


\section{STANDARD FLIES (Extra).}

\section{EVE'S FANCY.}

(Miss M. Eve Allgood).

Tag. Silver twist and scarlet silk.

Tail. A topping and fibres of Summer duck.

Butt. Black herl.

Body. Two turns of medium blue floss, followed by dark blue seal's fur having a dark blue hackle along it.

Ribs. Silver tinsel.

Throat. Dark blue hackle.

Wings. Four or five toppings.

Horns. Red macaw.

Miss Allgood's favourite fly on North Tyne.

\section{NUNWICK.}

(Rev. James Allgood).

Tag. Silver twist and light blue silk.

Tail. A topping and an Indian crow.

Butt. Black herl.

Body. Two turns of scarlet floss followed by scarlet and light blue seals' furs in equal sections

Ribs. Silver tinsel.

Hackle. Light blue from blue seal's fur.

Throat. Light blue hackle. 
Wings. Teal, gallina, and tippet in strands; grey mallard, golden pheasant tail, fibres of Summer duck, mallard, two strips of swan dyer scarlet and a topping

Sides. Jungle.

Rev. James Allgood's special fly on North Tync.

\title{
THE RED TAG.
}

\author{
(Rev James Allgood).
}

Tag. Silver twist and scarlet floss.

Tail. Ibis and two strands of Summer duck.

Butt. Black herl.

Body. Two turns of crimson floss followed by scarlet, crimson and light claret seals' furs in equal sections.

Ribs. Silver tinsel.

Throat. Light red claret and light blue hackle respectively.

Wings. Tippet, gallina, and golden pheasant tail in strands, grey mallard, swan dyed yellow, light blue and crimson; bustard, and mallard.

IIorns. Blue macaw.

An old standard pattern invariably used in October on North Tyne. In large sizes a red claret hackle runs along the seals' furs and a topping added to the wings. 


\section{EM PRESS}

(KeL.SON).

Tag. Silver twist and yellow wool.

Tail. Four golden Bird of Paradise (or Cock o' the Rock) and a thin strip of ibis and Summer duck.

Butt. Black wool.

Body. Oval tinsel, two parts, and violet seal's fur, one part.

Hackle. Violet hackle along seal's fur, ribbed with oval tinsel.

Throat. Blue hackle.

Wings. Two strips of dark brown mottled turkey, golden pheasant tail, grey mottled turkey, two broad strips of swan dyed rose, peacock's herl, Amherst pheasant tasl, and two toppings.

Horns. Blue macaw.

Sides. Jungle.

When this pattern was introduced at Carlogie several years ago, it became a great favourite up and down the river. It is purely a high-water fly, and almost invariably kills in the month of May when dressed on $2 \frac{1}{4}$ inch hooks. In 1895 , on the home waters, it accounted for fourteen salmon in three days, with an unusual average of $14 \frac{1}{2} \mathrm{lbs}$. Empress is best suited to porter-coloured water.

All these patterns are usually dressed, at Aberdeen, by William Garden, I22A, Union Street, whose strip-winged flies, by-the-by, are second to none in the country. Indeed, it may be interesting to note that I possess an Akroyd of his, the wings of which are still intart and seem insusceptible to splitting after nine years' wear. 
IIPS.

\section{THE SILVER SCOUT.}

(Ketson).

Tag. Gold twist and light blue silk.

Tail. A topping.

Butt. Black wool.

Body. Silver tinsel (flat).

Ribs. Gold tinsel (oval).

Throat. A light blue hackle and gallina.

Wings. Of mixed fibres, having a forndation of tippet strands differing in length. Two or three strands of tcal, ibis, gallina, powdered blue macaw, summer duck, peacock wing, bustard, black turkey with white tips, golden pheasant tail, swan dyed yellow, red and bluc, mallard and a topping.

Horns. Blue macaw.

Head. Black wool.

This is a useful pattern in sunny weather at times when "Jock Scott" is in general use. Another of this sort is the Silver Jock.

\section{THE SILVER JOCK.}

(KeLsON).

Tag. Silver twist and yellow silk.

Tail. A topping. 
Butt. Black herl.

Body. In two equal sections. No. I, silver tinsel (flat). No. 2. black seal's fur.

Ribs. Silver tinsel (oval) over silver tinsel, and silver tinsel (llat) over seal's fur.

Hackle. A natural black over seal's fur.

Throat. Gallina.

Wings. Black turkey with white tips, golden pheasant tail, pintail, swan dyed yellow, red and blue, mallard and a topping.

Head. Black herl.

This fly is now dressed with horns of blue macaw and sides of jungle.

\section{THE IMPROVED ALUMINIUM FLY-BOX.}

Many a fly has been spoilt, by injury inflicted on the point or barb of the hook, while taking it out or putting it in a metal box when the mercury insists upon sinking below freezing point and the state of the temperature benumbs the fingers. All this trouble has been over-ruled by the practical accomplishment of a simple but ingenious invention, light in weight and singularly suited to the purpose. 
The box, as shown in the engraving, is marle to hold both single and double-hook flies. The inside has a cork ground with fissures cut a convenient distance apart. All one has to do is to hold the

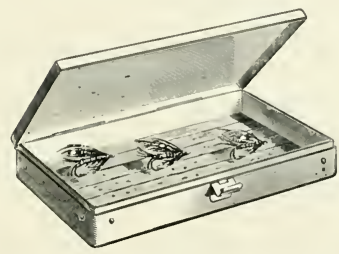

FARLOW'S ALCMINIUM FLY-BOX.

body of a fly and press the bend of the hook into one of the narrow clefts. It is as easily taken out. The flies do not penetrate the cork itself, and no amount of shaking will make them ship out of position. The one I use measures $7^{1}+4$ inches in length, and $4^{t}$ in width, ard in my opinion it is superior to anything of the sort in the market.

\section{THE PROPER GUT LOOP FOR FLIES.}

In fly making there is, of course, a difference in the quality of the materials employed. The difference between good and bad 
feathers, seals' fur, etc., is comparatively trifling, and such that is nearly, if not quite, unnoticeable to the inexperienced eye. There is a greater difference in the mechanical ingenuity and skill in placing the finer wing materials in regular succession from the foundation to the topping, but the greatest difference is scen in the make and formation of the loop, upon which, more than upon anything else, the life and behaviour of the fly entirely depend.

A long loop soon hinges, and consequently causes the fly to droop its tail, in which case it is less attractive and soon becomes useless; whereas a small loop, properly tw̧isted with sound gut, will last longer than any other part of the fly. The thickness of it is, of course, an important item.

If the dresser applies himself closely to the following directions, instead of his loop being the first cause of complaint, it will produce the natural effect of rendering the play and animation of his fly more realistic.

Let it not be supposed, however, that because so much importance is attached to this item, and because so few trouble themseives to discriminate between a good and bad loop, that the question relating to feathers, etc., is of little moment; on the contrary, it is well-known that proper feathers are the most alluring to the fish, and should have the highest claim on the dresser.

The size of the gut absolutely depends on the size of the hook selected, and it is just here that one cannot be too particular. 


\section{SIZES OF GUT FOR TWISTING FOR FLY LOOPS.}

Names and Standard

Length of

Measures of ciut.

Hooks.

Fina

for

1,2 in

Regular

do.

58 , to I in.

2nd Padron

do.

118 , to $11 / 4$,

Ist Padron

do.

$15 \%$, to 2 "

and Marana

do.

$21 / 8$, to $21 / 2$,

Ist Marana

do.

25,8 , to 3 ,

$4 / 5$

do.

$3^{1 / 8}$, to 358 ,

$3 / 5$

do.

$3 \frac{3}{4}$, to $41 \%$,

$2 / 5$

do.

$41 / 4$, to 478 ,

$1 / 5$

do.

5 " to 6 ,

SPECiAl Note. The gut should be of the finest quality. In twisting it, use a weight not less than $3 / 4 \mathrm{lb}$. $\Lambda \mathrm{s}$ soon as the pearshaped piece of wood, in the grooves of which the three strands ride, is removed, seize the weight with the right hand and spin it three or four times rapidly so as to get a good tight twist. While doing so, rub the length up and down firmly, in order that the latter twists set up may be evenly distributcd. Previous to removing the weight, catch hold and keep hold of the length at the middle with the left finger and thumb; then, without slackening the tension, bring round the weight up to the top, and urge the two halves of the length to twist together with one flip of the left fingers.

I have to express my indebtedness to Messrs. Allcock and Co., of Redditch, for their assistance in supplying me with the means of determining the exact thickness of their gut required for the various sizes of hooks. 


\section{THE STANDARD LINES AND TRACES.}

It is, no doubt, familiar to all who take a genuine and intelligent interest in arranging their gear, that uniformity in casting largely depends upon the construction of the tackle. If the line is not equally balanced at the fly end, complications set in and spoil sport. Let the rod be what it may, the line cannot be properly extended, and experience has proved that the fault lies with the trace. When, in common parlance, the dissenting portion "persists in turning back and looking at you," the trace, which is plaited, and infinitely better than the twisted makeshift, is either too heavy or too long. The effect of this disorder has been witnessed thousands of times, and many must have realised their inability to satisfactorily account for it. But if the accompanying instructions are definitely accepted, all uncertainty in rigging the standard line must come to an end.

The largest "Kelson" line wanted in these days of all round progress is marked No. 3. For a well-balanced rod less than 17 feet in length, a No. 4 should be used, and No. 5 reserved for low, clear water in May, June, July, and August.

The standard traces are kept in stock at 191, Strand. Their respective sizes were selected and numbered, under my supervision, to suit the size of the lines and to correspond with their numbers. Instead of attaching them in the ordinary way by means of loops, they should be married, and this is effectually accomplished at the above establishment for those who like to have the work done for them. But it must be remembered that some six inches at the thick end of these traces are cut off for a line which has not been polished in the manner recommended in this book, or for one which from long use 
lias decreased in size.

Of the standard back-lines, by far the best for securing swift control in emergency is the "Standird, Waterproof, Braided Silk Line," manufactured at Redditch, and supplied to the trade by Messrs. Allcock and Co.

Personally, I use 100 yards of size $\mathrm{F}^{\text {; }}$, and consider it better than the larger or smaller size.

\section{THE HERCULES GUT CASTS.}

The advantages of using good gut are so obvious, and so universally recognised, that it is almost unnecessary to expatiate on them. To every one engaged in salmon angling a really reliable gut cast is not only advantageous, but absolutcly necessary for insuring against loss of fish.

These special casts are supplied to the trade by Alleock and Co, Redditch, and can be lad at Farlow's, 19I, Strand. By stceping the gut in an excellent preparation, the qualities of softness and pliability are so considerably increased, that the mischief usually arising from the process of knotting it into different lengths is completely avoided. This preparatory treatment not only gives to the gut extra strength and flexibility, but protects it from the injurious action of air and light, and, what is stıll more important, enables it to withstand the rough usage of the lielts. This, in my opinion, is the best possible testimony to the fact that the essential propertics of this gut make it more than ordinarily suited to our purpose. In fact, myself and 
friends have so thoroughly tested the various sizes with such good results, that we consider it the best in the market.

No. $1 / 5$ is very strong, and is reserved for use in high water during Spring and Autumn; but when the water falls and clears, No. $2 / 5$ is used.

Nos. $3 / 5$ and $4 / 5$ are better adapted to small rods. A large number of salmon fell to my rod in the Autumn of Igoo without fretting or chafing the gut to the slightest degree.

\section{"KELSON" RODS AND LINES.}

The opportunity is taken of stating that the so-called "Kelson" rod, introduced to the angling public, in 1858 , by Farlow, was originally fashioned by myself. It came about this way. A little previous to that date I dressed an old silk-and-hair line by steeping it in boiled oil, with the result that the treatment made it too heavy for the style of rod then used. During a visit to the river Shannon I found the line went better with a Castle-Connell rod, which, however, failed to please me in making the ordinary overhand cast. I thought out the action required and gradually worked down an old thickbutted $20 \mathrm{ft}$. greenheart to get it. The desired object was eventually obtained, and Farlow had the rod to finish.

A little incident that occurred in my presence just afterwards may be recounted. A customer calling for a new rod remarked that he hated the Kelson pattern. "Well, sir" (said the Manager, Mr. 
Davies) "I rather think you make a mistake, but we shall sec. Would you like to look at a No. 108 rod we are recommending?" Upon inspection the customer replied, "Oh, this is a beauty!" "Just so, sir," (observed the Manager) "that is Mr. Kelson's own pattern and his own rod."

At that time there was no other rod in this nor any other shop that did not possess a thick butt and fine top. The new patiern soon caught on, and in these days, for some incomprehensible reason, it goes by all sorts of names.

The first to introdıce the present style of line was Mr. W. Wells Ridley. I quickly followed on with the so-called "Kelson" line. The only difference between the two is that mine are plaited rather tighter than those Mr. Ridley used to bave made. As with the rod so with the line, for other names have been given to it.

To find the result of my labours has so far met with approval is certainly pleasant, but if those who have interested themselves in the matter of tackle would endeavour to get, in any way their fancy takes them, the system of fishing as set forth in my books more generally adopted, their efforts would be better appreciated by one and all alike. All the same, it would seem that, in common justice, publicity should be given to the fact that rods called the "Houghton," the " $\mathrm{Hi}$ Regan," etc., ctc., are nothing more than the " Kclson " rod pure and simple; and that the lines called the "Olinea" are practically the same as my own.

The " Spey Improved Rod,' another pattern of mine, introduced to facilitate the Highland method of casting and to avoid the usual necessity of suspending operations in rough weather, has a totally different action, and is only suitable for the Spey style of fishing. 


\section{GARMENTS.}

Messrs. T. Burberry and Sons, of the Haymarket, London, have introduced a riverside coat designed by experts on the subject with which they deal. Rain runs off the surface of the cloth, which soon dries. The outer texture (Gabardine) protects the body from wind as well as wet. The inner texture (wool) maintains the warmth it produces - neither fabric interfering with the ventilation. The coat is a combination of two thin materials-superfluous doublings and interlinings are avoided. Well-arranged pleats expand to every movement in casting, and assure full freedom of action.

As I was informed on reliable authority that the material is the popular demand of the hour, a coat made of Gabardine was soon put to a sharp test; and though my own experience of it does not extend over any lengthened period, I an entirely converted from the prevalent idea that a rubber mackintosh is a necessity. Rain continued, more or less heavily, throughout the month of October, Igoo, but on no single occasion could a wet spot be felt or found beneath the garment worn. The comfort derived from the coat, in either dry or wet weather, could hardly be credited without a trial.

The improved fishing cap, by the same firm, has a double brim The underpart, fitted to carry flies, is protected by the upper, which shoots rain off the neck. The cap is light and cool in wear.

Of these garments, Mr. W. Baden-Powell writes:-- "I am sure so well-known a salmon angler as Mr. Geo. M. Kelson hardly needs a word from me in regard to the good qualities of Gabardine for fishing. . . There is no more bothersome thing while wading deep, and expecting fish, than to lave to come out for a mackintosh. . . . 
With this coat over waders and braces you can stand any amount of wet."

Mr. R. H. Benson says :- " The Burberry suit is comfortable and convenient. A wet sponge quickly removes all dirt. I have worn it for shooting and fishing during the last three years and never been wet."

\section{THE USK BASKET.}

This basket, or frail, introduced by Colonel Rocke, carries one's kit, fish included. In the event, however, of a good catch being made, one's waders are slung outside at back. The leather pad, shown in the engraving, rests on the shoulder, and it is stuffed with horse hair.

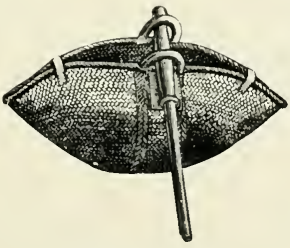

THE USK BASKET.

Farlow makes these baskets of green rushes, which afford an extra element of strength. 
Some anglers, objecting to luggage, prefer to carry their fish by the method depicted below. They provide themselves with a few lengths of thick string.

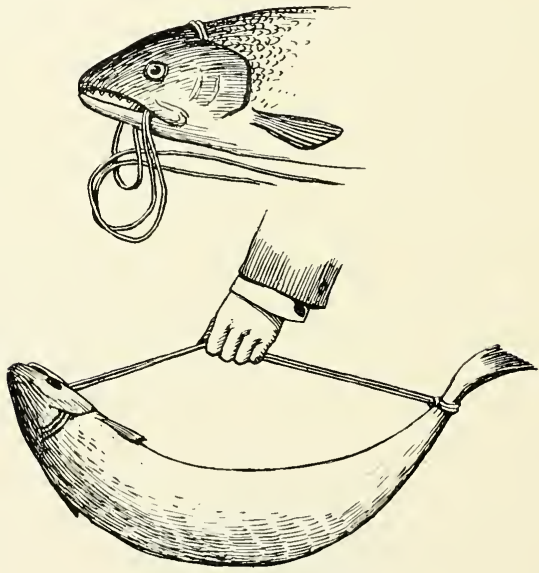

FISH TIED FOR CARRYING.

For this dodge, first double a length of string and tie the two ends together. The opposite end of the loop thus made is passed, by the latest method, in at the mouth, out at the top of the gill-cover, over the head, in the far side gill, out at the mouth and brought rourd under the chin to the near side. The knotted end is then passed 
through the loop which is seen in the drawing. Now make a halfhitch at the knotted end, put the loop, thus formed, over the tail and pull taut.

This is an improvement on the old method, seeing that the string cannot slip over the nose of the fisli and part company.

* $\quad * \quad * \quad * \quad * \quad *$

Messrs. Redpath and Co., Tweedside Works, Kelso-on-Tweed, the well-known wholesale fishing rod and tackle manufacturers for the continental, home, and colonial markets, have, like some other firms, made rapid advance in late years in all their separate departments.

The more recent effect of the progress of this firm is, perlap;, due to improvement in fly work, which has raised them in the front rank of this important handicraft. Indeed, it is a relief to be able to: purchase salmon flies, not only dressed with the best materials, but also true to pattern. The retail trade will be glad to know that these distinctive qualities cliaracterise the work of the staff of dresscr. employed by this Scotch firm.

\section{AN IMPROVEMENT ON HERON HACKLES.}

An excellent substitute for heron hackles is to be found in large quantity on the Crown Pigeon-in French, the Gourah. The lackles 
on this splendid bird resemble those of the heron, but they are superior in colour, finer in fibre, and infinitely more mobile in the water. The bird is to be had at L. Martin's establishment, 8 , Place de la Madeleine, and 34, Avenue de l'Opera, Paris. It costs only four francs.

\section{BLACK VARNISH FOR FLY HEADS.}

Fuse $3 \mathrm{llb}$ of Egyptian asphaltum, and when liquid add $1 / 2 \mathrm{lb}$. of shellac and I gallon of turpentine. This varnish is a great improve. ment on ordinary spirit varnish. It lasts longer, and does not change colour in the water. Smaller quantities can be made by decreasing the proportions.

\section{IMPROVED TINSELS.}

Some time ago, Messrs. Hardy Bros., of Alnwick, informed me that all their salmon flies are dressed with tinsels which are absolutely untarnishable, and wrote:- "We have tested them in every possible way, and guarantee their continued brightness. . . This, we consider, is a most important development." And so do I. Even from my own experiments with the different sizes, though of short duration, it may confidently be stated that the claim made for these tinsels is amply justified. 


\section{FARLOW'S PREPARED SPLICING TAPE.}

Althougl this valuable article has been introduced some little time, the mvention has only recently been perfected. By using this tape, a rod can be "put up" almost as quickly as if it had ferrules The fresh importation consists of some broader tape, dressed in the same material, for placing between the splices, so as to prevent any possible loosening of the joints. When used in mild weather this tape will keep the rod firm throughout the season. During cold weather, the tape should be slightly warmed before use, and, if necessary, the ends tied down with thread. It may be as well to add that the tape should ke worked towards the point of the rod, and run slightly spiral so as not to quite overlap. If the splice is not quite true, tightly bind two inches of the tape at the lower part with a wax-end.

\section{THE}

\section{FIRST DAY OF THE NEW CENTURY.}

As we enter this very morning into the long unknown avenue of the Twentieth Century, and reflect upon the directions of advance in angling knowledge which have characterised the latter years of the Old Century, we are naturally proud of the accumulative force and effect of our discoveries and reforms. Although the goal of the Old Century will be the starting point of the New, a long vista of possibilities opens up before the reflective mind, and a deal of the non- 
proven must for ever remain a mystery. But while we have had our failures and made mistakes, while we are still submitting to close investigation several matters of detail and shedding new light upon familiar problems, yet to look back on events in the order of time is to read a grand, unparalleled history of achievement, whose final issues may be resisted somewhile yet, but can never be averted.

So many years of progress in practical matters, as well as in theory, have now passed by. Any forecast of our progress fifty years ago would have seemed the wildest of dreams. We have found that method, unlike luck, does not lead us astray; on the contrary, to acquire a busincss habit of proceeding methodically, is to turn many a seeming impossibility to the best possible advantage. Our principles, the result of steady thought and the observation of facts, are grouped together, and await only a fair and reasonable test. Every trial eliminates some tempting form of error, every failure is a step to success.

Our primary business to celebrate the first season of the New Century, is to pursue as far as we can the system under which we enjoy a higher level of prosperity than anglers have known in the course of their previous existence. Our second business is to see that our progress suffers no check.

The question arises as to what steps should be taken to ensure this.

It might be interesting to some, even with other matters pressing upon them, to turn to the future and contemplate what the next few years can possibly bring forth - to inquire whether it is reaily true that the logic of events can possibly work out for them the big problems of the age with sufficient clearness. 

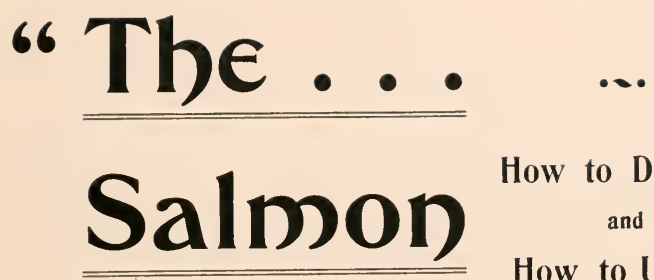

How to Dress it and How to Use it.

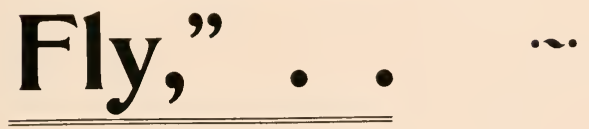

BY

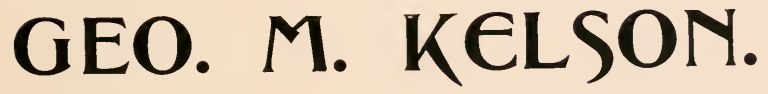

(See Press Opinions, p. 162).

To be had at . . .

Farlow's, 191, Strand, and direct from the Author, 25, Victoria Street, Westminster.

ONLY A FEW COPIES LEFT. 

But is there not a more satisfying measure to adopt than this? It seems so. The casier and more lucrative way of proving the system-the original system, be it said-is by steady and regular practice, and the surer method of prescrving our stock of knowledgc is by setting our shoulder to the wheel and constantly adding to it.

This being the case, it is not presumptuous, but reasonable and becoming, to declare that, while the passage of the Old to the New Century finds the fisherman better equipped and better prepared to carry him toward the actual attainment of visionary ideals, there are many able men who might work out some of the remaining propositions for which no great originative power is required.

To men of this stamp nothing could he more acceptable than to be posted up in current events. It is, therefore, and always will be extremely agreeable to me to offer them the benefit of my own experience. That the record of contemporary facts is of much value to them, I have had ample opportunity of learning. I have also observed that even the recruit in their ranks given to enquiry at the riverside, is often a good learner, and that a good learner very soon becomes a good workman, investigator, and theorist.

Should he look for a specific explanation of the reason of our rapid advancement, and ask what special observation has engaged our attention, the answer naturally is: That he must proceed patiently and persistently on lines that have been carcfully laid down for practical purposes, and by which alone the end can be obtained. Ile will find nothing recondite or obscure in the system of procedure; it is perfectly simple and comprehensive; it is clastic, and reachly adaptable to circumstances, and, provided no condition is left unfulfilled, is proved to be sound beyond the possibility of doubt by the 
ordinary test. As he progresses in drawing inferences from facts, in reading aright the signs of local surroundings, and in deciphering the more obscure passages in the great book of Nature, he deserves well ; and when he gains an advantage over his comradc, that rouses the enthusiasm which warmed the Spring-time of his career, he fares as well as he deserves. He then sees the good of having based his principles on a safe foundation. He has, for instance, kept his sombre flies for dull, dark days, his bright ones for fine clear weather; and has reserved his special patterns for those particular occasions which have been enumerated in these pages and in my previnus publication.

In truth, the system is one which will force itself sooner or later upon the attention of one and all alike.

These observations would, however, be manifestly incomplete were not some notice taken of " the genuine old stager " ever ready to offer a helping hand to younger members of the vocation. He finds time, and no small amount of time either, to show them with frank sincerity and conspicuous ability, where to stand, what fly to use and how to use it, and his ideal is attained when, under his own personal supervision, thcy succeed where they have previously failed.

But, as a leading feature of their nature is a restless activity of mind which prompts them to get every scrap of information obtainable, they are occasionally tempted to hold friendly fellowship with the too learned enthusiast, who, with a sublime disregard of the consequences of his gratuitous instruction, and abortive struggic to help the world along, is too often in evidence. They can identify him directly he talks, just as they can grasp the extent of the knowledge of an angler who starts on the perilons adventure of rushing into print, and struggles to prove an universal negative. He 
Is on the rampage at once. If will tell them, for instance, not to put up a small rod and use a fine line in dead low water, but to continue with the tackle in use, and shorten the rod by catching hold higher up than usual. Or he may bring out a "Mary-anne" in stiff, pretentious costume, which, though absolutely useless in their steady flowing water, he bids them "put on and keep on till they've got him and his great-grandfather." They will also find that this "too learned enthusiast" does not merely ignore, but decry and calumniatc all ceremony and all system in fishing. But since the conclusion cannot be avoided that he possesses no clear idea upon any one branch of the subject, and prides himself in pursuing old nursery nostrums, they pass on full of sorrow, sceing that reason, instead of having served as a mental rudder to steer his mind into the right course, has suffered itself to be borne away hy the strong gales of a disorganised and vitiated fancy.

With the hope, then, that the present little work may be found acceptable to all in a measure not inferior to its more voluminous predecessor, "The Salmon Fly," I cast it forth upon the waters, hoping to meet with it (or rather an appreciation of it) "after many days." 


\section{PRESS OPINIONS OF "THE SALMON FLY."}

The art of catching salmon with a fly is often regarded, especially by beginners, as a very abstruse and complicated problem. There is no doubt that the want of success experienced by most tyros leads them to lay this flattering unction to their soul, that it's "the sort of thing no feller can understand," as I ord Dundreary used to say.

But how if they set about it by entirely the wrong method: How if they pursue "Rules of Thumb" which will never lead them anywhere !

I have set forth in The Salmon Fly, a regular and systematic plan based upon the practical observation of a lifetime, which if it be not a Royal Road to success, will yet lighten very materially the burden to be carried by these young beginners, and may even afford some valuable wrinkles to older hands.

To show that this is not merely an unsupported assertion of my own, I have ventured to print below a number of cuttings from the papers containing reviews of the book. I do so for the purpose of pointing out that salmon fishing with the fly, is susceptible, like many other pursuits, of a treatment based upon knowledge and experience, which will certainly yield results, in the hands of those who deign to try it, very different from any that can be expected from the haphazard treatment of the "chuck-and-chance-it" school. The whole subject has been expounded at great length, and is alluded to in the extracts given below.

\section{THE TIMES, March 7 th, I 896.}

"The Salmon Fly, by Geo. M. Kelson (published by the Author), is an elaborate and fully illustrated volume on a subject of profound interest to many sportsmen. Mr. Kelson writes with the authority of a skilled and enthusiastic angler." 
SCOTSMAN, Warch $9 t h, 1896$.

"There is much more in Mr. Kelson's book on The Sulmon Fly, than the title would indicate. It is a complete treatise on the science and art of salmon fishing, written by one who is an acknowledged authority on the art, as well as a noted exponent of it. Mr. Kelson is convinced that care and skill in fly dressing, will meet with their full reward at the waterside, and the directions that he gives for performing the various operations incidental to the making of a fly, are as complete as the veriest tyro could desire, while even the practised hand will find much to learn from his description. A list is given of some 300 standard patterns, in which the materials of the various parts, the rivers and circumstances to which they are appropriate, are carefully detailed. The more characteristic patterns are illustrated by a series of coloured plates. Having dealt with the flies themselves, Mr. Kelson has much to say with regard to their proper choice under various circumstances. The different casts in use are minutely described, and directions for their performance are given. which are as explicit as written directions illustrated by drawings can be. Due attention is also given to other articles of the fisherman's equipment."

\section{DAILY NEWS, March $12 t h, 1896$.}

"The typical salmon fly is a gaudy object ; it is so small that half a dozen may he stowed away in any compartment of a purse without inconvenience, yet in Mr. Geo. M. Kelson's recently published book, The Salmon Fly, it demands a matter of five hundred pages, with profuse illustrations, and type exceeding 200,000 words. The interested enthusiast, will perhaps, go into retreat to grapple with the contents of this gigantic work, and should he live to a green old age may possibly have learned its lessons if he has not climbed to the scientific elevation to which the author points. . . We have diagrams devoted to the complications of not merely the ordinary and Spey casts, etc. In some of these evolutions the course of the line fills the horizon with its curves and doubles, or ascends to the sky in graceful loops. . . Mr. Kelson gives a series of eight plates, upon which fifty-two patterns of flies are beutifully represented in colours, but this is only a tythe. In addition there are the full dressings of 300 salmon flies. No angler for the future can complain that he las not ample store from which to choose, and any successor to Mr. Kelson may be warned that he will find marvellously little gleaning in the field which he has shorn so close. . . . We should have liked to do full justice to this bulky volume, for, in truth, it is full of sound instruction and classified informaticn. Mr. Kelson has been known for many years as a highly successful salmon fisher, and one of the foremost living authorities upon the structure of the salmon fly. . . We may add that Mr. Kelson's style is clear, and, if his original theories do not 
prove acceptable to all experts, they are courageously laid down and insisted upon with real earnestness. . . . The salmon angler may be expected to treasure this work as the apple of his eye ; others have aforetime written upon salmon flies, and how to dress them, but neither in America nor in England has the task ever been done with such thoroughness as by Mr. Kelson."

\section{THE FIEL.D, March $14 t h, 1896$.}

"This is a magnum ofus, not only on the part of Mr. Kelson but anong the endire category of practical angling books. . . . It is the long expected, come at last, it being well known that $\mathrm{Mr}$. Kelson has been labouring for years at this monumental embodiment of his wide experiences and theories in salmon fishing, flies and general equipment ; and in all these matters he may be justly said to have achieved fame. . . The introduction is an essay in which much is said about the need of system, the science, the generalities of rods, flies, fish and fishing. The remark that certain flies bear unmistakably distinetive marks is abundantly illustrated upon the eight beautifully coloured plates of fifty-two salmon flies. . . The dressings of most of the flies mentioned by Mr. Kelson are given. . . . Of these 300 flies, 71 are represented as the author's own patterns. . . After the introductory chapter, the author comes to a classification of salmon flies, which the amateur or young angler may be recommended to master by aid of the diagrams, and explanations. . . . and in all these indispensables the reader is being instructed by a master of the craft, while the methods of silk tying, hackle manipulation, putting on wings, tinselling, and topping are illustrated by clear and commonsense diagrams. . . The rod and special equipments are the subject of a thoroughly practical chapter. The essential qualities stamping a good line, Mr. Kelson thinks, are compactness, suppleness, evenness, and durability. He looks with indifference upon the element of strength, from the fact that even the thin end of a tapered line, fit for use, stands a far heavier strain than the gut attached to it. . . In 'The Rod at the Riverside' we arrive at a variety of casts. . . . There are several diagrams as to shooting line . . . (The Governor Cast) is one of Mr. Kelson's ingenious inventions, and he knows of no other way of reaching fish lying fifty yards or more across the stream. After the casts the reader is instructed as to the places to fish and how to fish them, conclusions in weather study, the effect of rain, the state of the atmosphere, hooking foul, changing flies, artificial catches, striking, playing, gaffing and wading. The chapter entitled 'miscellaneous,' has an essay on silkworm gut, and the way of twisting and looping it. . . varieties of such impedimenta as receptacles for tackle, an antidote for midges and mosquitoes, with other matters herald the conclusion, to which is appended a table showing the limits of fishery districts, close seasons, rod licenses, and names and addresses of the chairmen and clerks of the several boards of conservators. If any reader has 
ever felt puzzled to know how a one armed angler maniges a salmon rod, he will be enlightened by studying the illustration entitled 'the necklace.' We heartily congratulate Mr. Kelson upon the publication of this most exhaustive, interesting and instructive work upon the salmon fly and its use."

\section{DAILY GRAPHIC, March $16 t h, 1896$.}

". . As it happens, this is not a case of the book making the reputation of the writcr, for in this instance the author's fame has gone long before. That by no means insignificant community which in proper season, in various portions of the world, pursues the sport of salmon fishing, with the zest of preoccupation, will recognise that no one could be more fitted by acknowledged ability than Mr. G. M. Kelson, for the task which he has taken upon himself. lioth as a tier of flies and a wielder of the rod he is so expert that it is scarcely possible to say at which he excels the more, and as he has done his best to place on record what he knows in these two departments, the reader may be allowed to make his choice. . . . The details dealing with the choice of feathers and hooks, and the hundred and one little expedients in fly-tying which only long experience could evolve, seem to us to leave nothing to be said. From the very beginning the art is taught as we do not remember to have seen it taught before. . . . In describing the various casts, Mr. Kelson is as much at home as in instructing in the tying of flies. . . . Besides these leading topics, all manner of useful hints are given in anticipation of the various troubles and difficulties which beset the angler, who will find it difficult to think of anything he wants to know and not find it alluded to in this volume."

\section{WESTERN MAIL, April $15^{t / h,} 1896$.}

"Mr. Kelson is well known as a mighty fisheuman, and he has indeed producel a miglity and tremendous book . . It a pity that this sumptuous volume, with its wealch of new ideas, theories and suggestions, should necessarily be reserved for the comparatively few."

\section{THE POST, March 23rd, 1896.}

". . We have seen many attempts to reproduce, by a process of coloured plates, the standard Hies of to-day. . . But it has not hicherto fallen to our lot to peruse a work on the various branches of the subject at all satisfactory or exhaustive. It is, tliercfore, doubly pleasurable to posscss a treatise containing sume 500 pages in quarto form, written by a gentleman whose name alone sufficiently guarantees that the information is reliable and authentic. Mr. Kelson has devoted a 
lifetime to the study and practice of angling. He is one of those untiring sportsmen who can boast of a well-filled past and look forward to a considerable historic future. He has edited weekly journals, treating of the subject of fishing, and his contributions to the Press are as familiar as bousehold words. His genius, it can be called nothing else - for fly invention, fly dressing and salmon angling, is of a very rare quality. It is by no means our intention, in this busy thoroughfare of ours, to attempt to criticise at great length, the up-to-date methods and principles clearly and cleverly set forth in The Salmon Fly, by so popular an expert as the author of this really beautiful book. . . Mr. Kelson has indeed attained an ideal reputation as an exponent of the art. He has fortunately published an account of his exploits, which seems destined to decorate the libraries of his colleagues, if not of all sportsmen, for many years to come. Mr. Kelson is the pioneer of a system of salmon fishing, and if there is a fault to be found with him it rests in the superficial fact of his concrete doctrines appearing somewhat in advarice of the times, though in reality they compose another step toward the ideal salmon fisherman of the future. To give the reader an idea of the estimation in which he is held by rich and poor alike, His Royal Highness the Prince of IVales, and the Duke of Saxe-Coburg, have honoured him by gratiously accepting a copy of his book, whilst our own gillie declines 'to retire to rest without diving into the mysteries of the gentle craft between the sheets.' The Salmon Fly is replete with original epigrams, and merits a place among the standard works of the day. . . . All those who want to know how best to tie a fly or catch a salmon cannot do better than read it. To appreciate the book one must read it carefully, and to read it carefully is to enjoy it."

\section{TRUTH, Warch igth, i 896 .}

“. . Mr. Kelson's monumental work on The Salmon Fly will specially appeal to your interest. For my own part, I am too humble a fisherman to venture to criticise one who writes with such experience and authority."

\section{LAND AND WATER, March 21 st, 1896.}

"Quite an edition de luxe is this, the latest work on angling, by Mr. G. M. Kelson. I'rinted in very legible type on good paper, containing a large number of capital illustrations, it is one of the most claborate books of the kind ever published. . . In dealing with practical matters, the author's long experience and careful study of the best means of capturing salmon, impart great value to his opinions and instructions. . . . The author's disquisitions on feathers and materials of various kinds used in fly-making, will be found simply invaluable by those who dress their own flies. . . . The descriptions of various methods of casting are excellent, and ably illustrated by illustrations. . . The subject never before has been so fully and thoroughly handled. . . . Mr. Kelson has much to tell us on the patterns of 
salmon flies to use in varying conditions of weather and water; when a change should be made, and of what nature and how the fly should be presented. . . . Mr. Kelson treats every branch of his subject from a superior standpoint."

\section{VANITY FAIR, March $25^{t h}, 1896$.}

"Written by a past master in the art of salmon-fishing, who not only knows everything that there is to be known in the art of tying flies and generally preparing fishing tackle of every kind, but who also knows when, where, and how to catch his fish, this book differs from almost every book of the century, in that the writer knows what he is writing about, and conveys his knowledge tersely, pithily and well to his reader. . . . Though ' as light in weight and reading as may be,' it is a big and heavy book, yet worth its weight in gold all the same. . . . As to the letterpress, from the first page to the last, from the directions how to tie a fly, to the directions how, when and where to use the fly when tied, the book is from cover to cover admirable. . . The whole book is full of information, is, obviously, honest and is a book which, not to-day.nor to morrow, but for long years to come, will be the premier book upon the subject. . . . some of his ideas, indeed, are quite admirable, and the whole work teems with suggestions which must be valuable to every fisherman. . . We have hardly touched upon the thousand and one merits of this book. It is not that it deals admirably with many things, but that it omits nothing."

\section{ST. JAMES'S GAZETTE, Warch 3 rst, 1896 .}

"It is to be doubted whether the revered father of fishermen (Izaak Walton) would not have moditied his opinion had he been privileged, as we have been, to peruse this latest classic on the science of fishing. No doubt, for the true fishing enthusiast, who sees the world through piscatorial spectacles, even in the close season, when most of us have dismissed our thoughts with our gillie and our gear, all this carefully worked-out information will be of great assistance; but it is probable that the less accomplished majority of fishermen will be more grateful for the practical hints on the actual catching of the wily salmon, liberally given by one whose experience, knowledge and authority on the matter are unimpeachable. There is much that is interesting in the author's observations and deductions on the muchdisputed habits and motives of the salmon. . . . 'The Complete Angler' informs us that 'angling is an art; the only question being for a beginner whether he is capable of learning it.' Mr. Kelson has shown us that fishing can be more than an art-it can be a science; and his book will undoubtedly do much towards rendering this science learnable by those who have not leisure or capacity to work it out for themselves." 


\section{THE WESTERN MORNING NEWS, June $26 t h, 1896$.}

"This volume is a comprehensive treatise on the subjects of its title, and contains in addition, most interesting matter in relation to salmon angling. It will be valued by all salmon fishers as a book of reference, and not alone in connection with the beautifully executed example of the various flits in use throughout the United Kingdom and the minutixe of their manufacture, but likewise for the thoughtful and thorough manner in which the exceptional experiences of a lifetime, affording opportunities on all the best known rivers, are placed before the reader. Mr. Kelson's name is already well-known to the sporting fraternity; and, as he says in his preface, his own experiences are fortified by those inherited by him by generations of salmon anglers. . . . The author tells us that 'my programme embraces so much that is technical and mechanical that 1 should rather endeavour to please by instructing than to instruct by pleasing,' and his endeavour is fairly carried out. . - Mr. Kelson's volume is, in fishing metaphor, admirably 'prescnted,' and we can most cordially recommend it to all who are interested in the noble sport with which it deals."

PALL MALL GAZETTE, Afril $29 t h, 1 \$ 96$.

"Mr. George Kelson, in his recent book on salmon fly-tying, has gone one better than the famous adage of Mrs. Glasse with regard to the cooking of hares. Our present author, a fine all-round sportsman and an accredited authority on the Ultim thule of piscatorial art-salmon fishing-harks back and practically says: first make your fly, then rast it ; look your fish, then land it. Sound advice. . . . On the tying of salmon flies, there are but few books, and none so complete as the one under review: . . . As he progresses, he warms to his work, becomes more discursive, and without losing anything in technique, is both instructive and interesting. . . . Mr. Kelson has written a fine work, which is a great acquisition to the angling library."

\section{EVENING STANDARD, July $6 t h, \mathbf{1} 896$.}

"Mr. George Kelson, we need scarcely say, is a recognised authority on all that relates to the salmon fly, and the most approved methods of dressing and using it. He is an enthusiast as well as an expert. . . . There are many finely coloured plates in the book. . . . This book is filled not so much with counsels of perfection as with pithy, business-like directions, and its value to the man who wishes to conquer the mysteries of the art of fly-fishing, so far, at least, as salmon are concerned, is not open to question." 


\section{c.
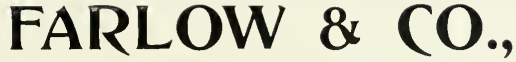 \\ $1.1 \mathrm{MITLD}$}

191, STRAND, LONDON, W.C.,

M.INTEATLRERS OF HICH.CL.ISS

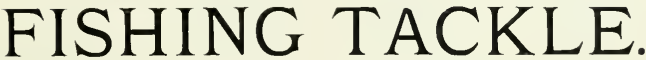

Special Patterns of Greenheart Salmon Rods,

of which we have the Exact MIodels in Stock, as suppliel and made by us for the following well-known Gentlemen:

(i. M. KELSON, Esq., "The Spey" Improved Rod. 16ft. Spliced, in 3 pieces, i7ft.

(i. M. KELSON, Esq., Celebrated “108," 3 pieces, i8ft. long.

It was with this particular Rod that Mr. Kelson won First Honours when competing for the six different methods of Salmon-Fly Casting, at the International Tournament, 1885 The Rod is specially recommended by the Author in this Book

Major TRAHERNE, 17 ft. 4 in., 3 pieces, Spliced or Ferrule Fittings. , " $\quad$ I6it., 3 pieces, Spliced or Ferrule Fittings. strongly Recommonded in the Volume on " Salmon and Tront," of the Badminton Library.

W. WELLS RIDLEY, Esq., I8ft., 3 pieces (much liked).

These Rods are made from the Choicest Logs and Best Seasoned Wood obtainable, none being used unless it has been in stock four years.

All Rods are balanced and constructed at our own Factory by the most Experienced and Retiable Workmen.

The "KELSON" Patent Silent Aluminium Salmon Winch. Highly liecommended,- Vide chapler vi., page 130.

\section{Sillmon \\ df lies: \\ a

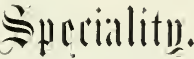

Matcrials of every description for Dressing Salmon IFlies kept in Stock

INTERNATIONAL. FISHERIES EXHIBITION, I883.

6 Prize Medals, 6 Diplomas of Honour, and

Special Money Prize for Best Collection of Rods.

Prize Medal, 1862.

Catalogue containing upwards of 200 Illustrations, Gratis

\section{Farlow \& Co., Ltd., 191, Strand, London, W.C.}




\section{THE LONDON SHOE CO.

WHOLESALE BOOT FACTORS. SINGLE PAIRS SOLD.

Makers to H.R.H. the Crown l'rince of Greece.

CATALOGUES POST FREE. TERMS CASH.

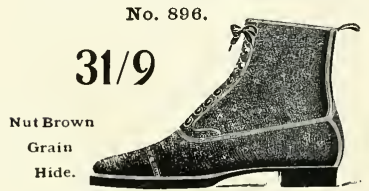

GOLF BOOT.

Best Hand-Sewn.

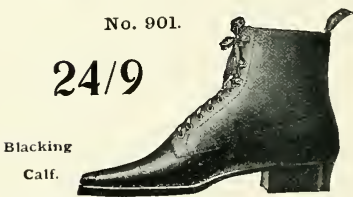

STOUT WALKING BOOT.

Leather Lined. Medium Toe.
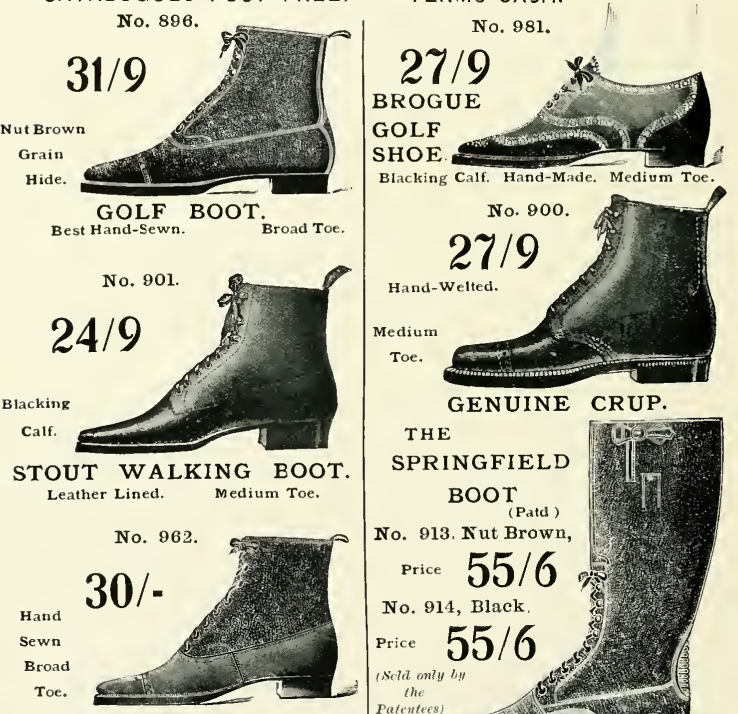

Blacking Calf, Hand-Made. Medium Toe.

No. 900

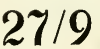

Hand-Welted.

\section{Medium \\ Toe. \\ THE \\ SPRINGFIELD BOOT (Patd)}

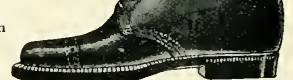

GENUINE CRUP.

No. 913, Nut Brown,

$$
\text { Price } 55 / 6
$$

No. 914, Black.

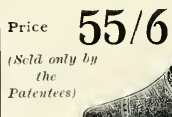

\section{GRAIN LEG, CALF GOLOSH.}

Goods sent on approbation "fon recipt of London Trade References.

Carriage Paid on Rritish Letter Orders only, but not on Aptrobatnon P'arcels.

THE LARGEST STOCKS OF HIGH-GRADE BOOTS AND SHOES IN EUROPE.

Head Office- $\quad$ West-End $(116 \& 117$, New Bond St., W. $123 \& 125$, QUEEN VICTORIA ST., E.C. Branches $\{21 \& 22$, Sloane St., S.W. 


\section{THE LONDON SHOE GO.}

WHOLESALE BOOT FACTORS. SINGLE PAIRS SOLD.

Jakers to 11.R.I1. the Crowon P'rince of Grece and the Principal Conrts of Europe. CATALOGUES POST FREE.

TERMS CASH.

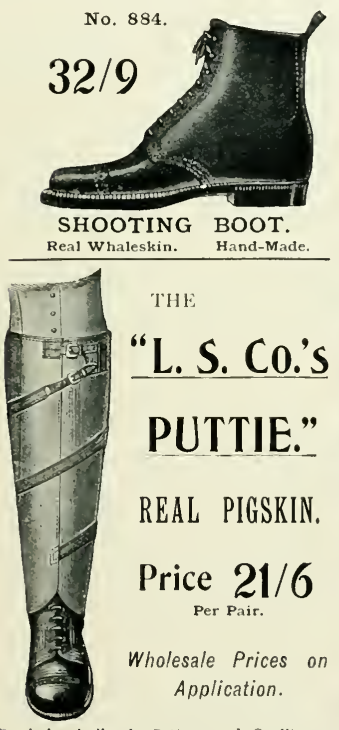

Precisely similar in Fattern and Quality as sold elsewhere at $42 \mathrm{~s}$.

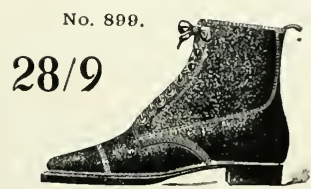

BROWN COWHIDE.

Hand Welted, Medium Toe.

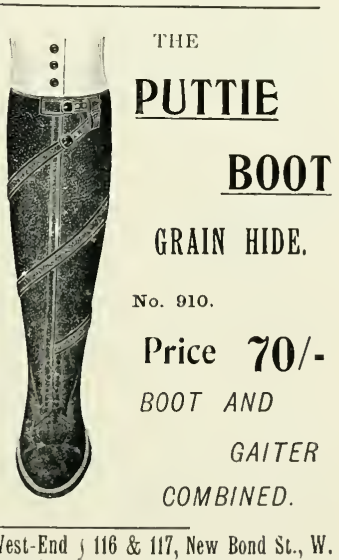

West-End $1116 \& 117$, New Bond St., W.

Head Office$123 \& 125$, QUEEN VICTORIA ST., E.C. Branches $121 \&$ \&2, Sloane St., S.W. ALL LETTERS TO CITY. 


\section{Messrs. REDPATH \& Go.,}

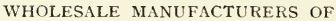

P.

\section{Jishing}

Flies, Baits, Gaff

AND

GENERAL FISHING TACKLE OF THE BEST QUALITY, For River, Loch and Sea Fishing,

\section{TWEEDSIDE WORKS, KELSO-0 N-TWEED, SCOTLAND.}

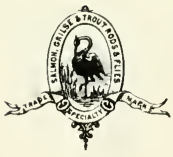

Artes est

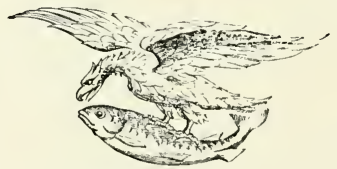

TRADE MARKS.

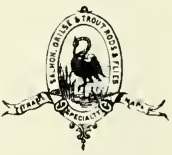

celare artem.

ESTABLISHED UPWARDS OF HALF A CENTURY.

I: rhibited for the first time at the International Fisherits Exhibition, Edinburgh, 1 S82.

$$
\text { - AWARDS - . }
$$

GOLD MEDAL and SIECIAL PRIZE for FISHING RODS, \&c.

SPLCIAL PRIZE for SALMON, GRILSE, and TROUT Flies

... Edinburgh, $188_{2}$

SI'ECIAL I'RIZE for Materials used in dressing SAI.MON and TROUT FLIES do. 1882 SILIER and BRONZE MEDALS (Highest Awards) for FISHING?

RODS and TACKLE

...

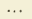
... GOLD MEDAL for Wholesale MaNufacturers' EXhibit
Tynemouth, $188_{2}$ ... London, $188_{3}$

Nessrs. Redpath \& Co. have NOT Exhibited at any Foreign or Colonial Exhibition. 


\title{
WILLIAM GARDEN, - Gulln, Fishing Rod, Reel and Tackle Maker . 122 $\frac{1}{2}$, UNION STREET, ABERDEEN,
} RESPECTFULLY invites the attention of Sportsmen to his Stock of

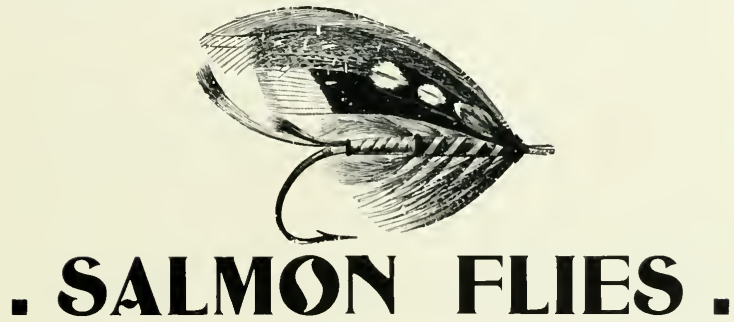

The quality of the material and the excellence of workmanship have gained them

A WORLD-WIDE REPUTATION. Stock includes all the standard Plain and Fancy Patterns.

ABERDEENSHIRE DEE LOCAL PATTERNS. (See p. I 42. ) woch and raiver Trout Flies

For Inverness, Ross and Sutherlandshire, Ireland, and Norway.

FLY DRESSING TO PATTERN A SPECIALITÉ. . SALMON AND TROUT FISFING RODS .

W. C. being a practical Workman as well as Angler of many years' experience, takes particular interest in this department. All Rods are hand made on the premises.

\section{AMMUNITION OF EVERY DESCRIPTION.}
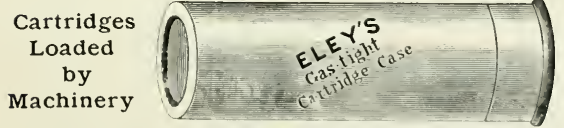

\author{
Of the \\ most \\ Modern \\ Description,
}

Insuring uniform charges und rugularity of compression, so very essentiat to satisfactory Shootmg.

Guns, Fishing Rods, and Reels Repaired. . . . ILLUSTRATED PRICE LIST POST FREE. 


\section{THE “ OLINEA" WATERPROOF LINE.}

T HE only perfect Waterproof Line in theory and in practice is the "OLINEA." This line is enamelled under the vacuum process, and is hand-finished on an entirely new principle. The strength of each line is tested and guaranteed by us. The line itself is plaited solid, which is an admitted improvement on the old style of core lines. The "OlineA" lines are so enamelled as to render them a perfectly solid mass of silk and composition, flexible and smooth, and free from any danger of knuckling, and as no varnish is used in the process, the enamel of the "OLINEA" line may be relied on not to crack or chip off.

The "OLINEA" lines are made from a special quality of silk of extraordinary strength, and we have no hesitation in $\mathrm{m}$ intaining that the thicker of the Trout sizes are quite strong enough for Salmon fishing. These are made in Olive Green, and Dark Brown colours.

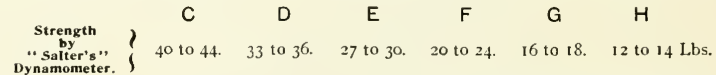

1

$\mathrm{H}$

G

$\mathbf{F}$

E

D

C

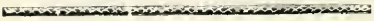

B

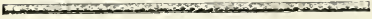

A

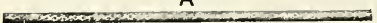

A few Extracts out of a great many Letters testifying to the Excellence of our Solid Plait "OLINEA" Level and Tapered Lines.

Extract of litter from Mr. WILLIA

GARDEN, Fishing Tackle Maker, Aberticn (one of the best known Anglers in the North of Scotland), Dated 14th . Warch, 1896.

"'The 'OlineA' Lines 1 have had from you are the strongest W.P. Silk Lines I have ever used. As a Spinning Line, in particular, they are superior to any other in the market. Customers who use them once will have no other. As a Salmon Line they are unequalled. They are so strong and free from kink or knuckle, the great trouble in most of other W.P. Silk Lines."

Extract of letter from Major TRAHERNE (a gentleman known to every Angler), Dated 23rd Fanuary, 1898.

"Please send me one 'OlineA' Line, size $C$, and as it is the best dressed Line 1 ever had 1 want you to send me another. I have used the one I bought from you for spinning, and it has had a great deal of wear, but it lasts longer than any Spinning Line 1 ever fished with."

Extract of letter from S. MALTBY, Sen. Montrial, Canada, Dated 4th April, 1899 .

"I see they are trying to imitate your Lines in the States, but they cannot do it, as you see every defect in their production. I can throw a fly with your 'OLINEA' Line ten yards further than with any other."

\section{MORRIS CARSWELL \& CO., LTD., SOLE MANUFACTURERS, 90, MITCHELL STREET, GLASGOW.} To be obtained Retail through any Fishing Tackle Dealer. 


\section{THE "KELSON" ENAMELLED SALMON LINE.}

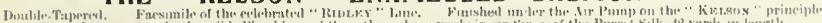

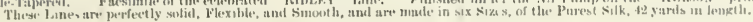

N.I.

No. 2.

N!3.

N.4.

N.5.

N.6.

Wr perfectly rememiner the " Romex" lıne, which was, however, never in such general nse as its sterling ytualities de'surved,

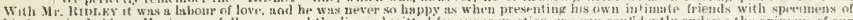

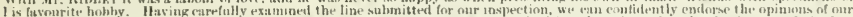
cormepondent. Mr. GRaNT. So such lane has ever been on the market hefore, and, alihough we know hew hard it is to reaseh finality

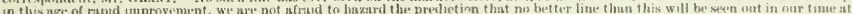

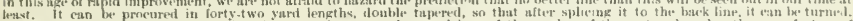
Anglers who have from time to time in onr columis mule complaints of the qualiry of the matertal useel in the munufacture of Casting lines, muy now rest assured that in future thev can become possessid of a salmon lime at once suited to their parjose, and also to lise hat it a moderate ligure.-ED. I-Land and Water.

Sole Manufacturers, MORRIS CARSWELL \& Co., Ltd., 90, MITCHELL STREET, GLASGOW.

The Trade only supplied.

\section{"The Salmon Fly,"}

HOW TO DRESS IT, AND

HOW TO USE IT,

\section{By GEO. M. KELSON.}

See Press Opinions, p. 162).

To be had at FARLOW'S, 191, STRAND, and direct from the Author, 25, Victoria StreEt, WeStMinSter.

ONLY A FEW COPIES LEFT. 


\section{Is your Rod too Whippy?}

Then ...

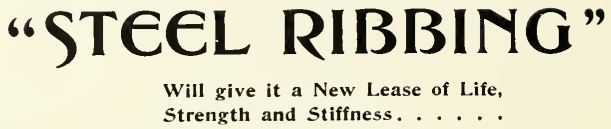

This Transformation can be effected at a merely nominal cost, viz :-

59 for a Trout Rod with One Top (Extra Tops, 1/9 each).

$9 / 3$ for a Salmon Rod $, \quad, \quad 19$,

The Additional Weight is less than a Quarter of an Ounce !

The Additional Strength after Steel Ribbing has been proved at the Sheffleld Testing Works to be nearly Doubled I I

Every habitual user of a Steel Ribbed Rod proves to be an efficient medium for advertising Steel Ribbing, for Old, Weak. Wet Fly Rods are transformed by Steel Kibbing (which is Rustless and Durable) into Strong Up-to-date Dry Fly Rods, and unduly Swoppy Back-boneless Salmon Rods are Stiffened and Strengthened by Steel Ribbing in a way that is declared by every post by numbers of our delighted Clients to be marvellous.

Send us your Rod and we will report on it (without charge).

Steel Ribbing has been recommended by

Mr. W. SENIOR, Editor of the "Field."

MR. MARSTON, Editor of the "Fishing Gazette."

Mr. G. M KELSON, the Well-known Writer on Angling.

Mr. GEDNEY, the Well-known Writer on Dry Fly Fishing.

Send for

\section{FOSTER'S CATALOGUE OF ANGLERS' REQUISITES.}

It is Posted Free to any Address on receipt of $3 \mathrm{~d}$, in Stamps to pay cost of parcel postage It contains 280 pages, and in it there are over 300 Illustrations of Tackle, together with One Coloured Plate and Collotype Frontispiece.

"Well Worth 1/-"-Vide "Fishing Gazktte."

\section{D. \& W. H. FOSTER,}

\section{FISHING TACKLE MANUFACTURERS,} ASHBOURNE, DERBYSHIRE.

ESTABL.ISHED 1833 .

TELEPHONI: No. 0198.
14 EXHIBITION AWARDS. Including Three Highest for Rods, Lines and Flies 


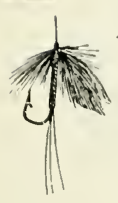

\section{Anglers ton't forket that Murton's Flies}

Xiver Fail to Kill, and that the l'p-tu-Date. Ingler muy horo ohtuin Reliable Modern Fishing Tackle.

Thu langest, Newest and Best Issorted stock in the North. sen 1 for Catalogue, und louk at the prices hefore buyiog clsewhere.

MURTON'S "SPECIAL" TYNESIDE ROD, 9 or ro-ft., 7/6. II -ft., 8/6. I2-ft., 9/6.

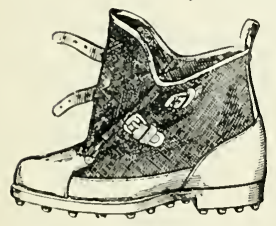

Mude from Sivected Cironbest, in Three Joint : Balaneed Handle, Ilandsomely Pinished. Wiacis Fittings and Fierrules, Button. lingel, Brazed and Tenoned.

Murton's 'Special' Salmon Rods, I6-ft., 176,256 and $40 /=$. I 8 -ft., $35 /$ - and $\mathbf{5 0} /=$.

Murton's 'Special' Sea Fishing Rods, I6-ft. Tops, $15 / 6$ complete.

BOTTOM ROD, 11-ft., Brazed and Winch Fittings, from $4 / 6$. MURTON'S "Perfection" Split Cane Trout and Salmon Rods.

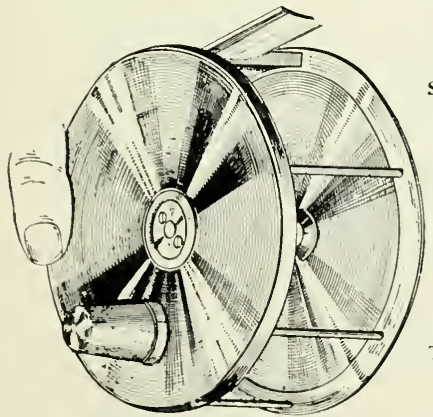
CELEBR
"Tyneside" Reels and lines.

Superior Bronzed Reels 2.ius. 46.

Our New Brass Reel, Iunortant to silnon Fishirts, ns sketels.

\section{Spanish}

Silk-Worm Gut, Best Vulue in the Trule.

Casts and Traces. Hooks to Gut.

Artistically Dressed Trout \& Grayling Flies. Hackled or Winged. I 6 per doz.

Mounted Casts, 1 - and 1/4-3 Hlies. Tapered Casts, 1- and 1/6. Lock Jilies, $2 /=$. Sea 'Trout Flies, $2 / 6$ per doz. Local and Standard Pattern Salmon Flies, Splendid Selection.

NOTED FOR WAIERS \& WATERPROOFS OF EVERY DESCRIPTION

\section{HENRY A. MURTON,}

Grey Street and Market Street, Newcastle=on=Tyne. And at SUNDERLAND. 


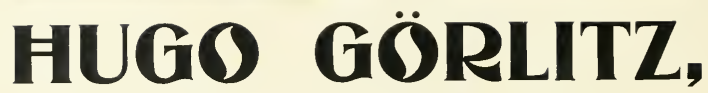

Musical \& Dramatic Agency,

\section{9 , New Bond Street, London, W.}

Nine Years Private Secretary to Paderewski.

Director of all...

\section{PADEREWSKI TOURS}

in America, Mexico, Canada, Russia, Holland, and liermany.

THE LEADING LONDON . .

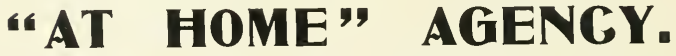
Sole Manager for PHIL MAY.

All the Best Artistes, Entertainers and Bands, can be procured through this Agency.

Complete Programmes prepared, and Private Concerts and At Homes, including all Preliminary Arrangements, carried out.

Every well-known and successful Artist can be engaged through...

HUGO GÖRLITZ,

119, New Bond Street, London, W.

Telephone: 4013 Gerrard.

Telegraphic Address: "Hugonotas, London." 


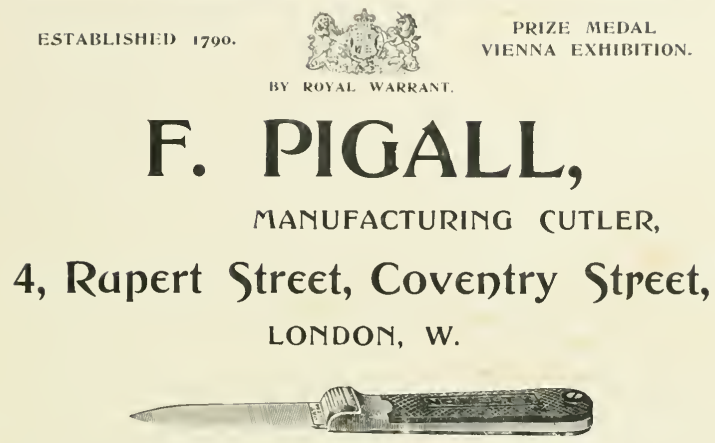

The Novelty Fishing Knife

Can be opened and closed with one hand. Sportsmen will find this Knife a most

POST FREE, 19. uiteful adjunct to their Fishing Kit.

\section{Best Sheffield HOLLOW (iROUND RAZORS $4 /=$ and $5 /=$ each . \\ (iuaranteed to shave well.}

\section{SPECIALITY!!}

REPAIRING and SHARPINING all kinds of Cutlery. A Competent Staff of Workmen kept on the Premises. 




$12 x^{2}$

(8) 